Portland State University

PDXScholar

1994

\title{
Oregon Primary Care Physicians' Support for Health Care Reform
}

Timothy Alan Baker

Portland State University

Follow this and additional works at: https://pdxscholar.library.pdx.edu/open_access_etds

Part of the Health Policy Commons, Public Administration Commons, and the Public Affairs Commons

Let us know how access to this document benefits you.

\section{Recommended Citation}

Baker, Timothy Alan, "Oregon Primary Care Physicians' Support for Health Care Reform" (1994).

Dissertations and Theses. Paper 4755.

https://doi.org/10.15760/etd.6635

This Dissertation is brought to you for free and open access. It has been accepted for inclusion in Dissertations and Theses by an authorized administrator of PDXScholar. Please contact us if we can make this document more accessible: pdxscholar@pdx.edu. 


\section{OREGON PRIMARY CARE \\ PHYSICIANS' SUPPORT FOR HEALTH CARE REFORM \\ By \\ TIMOTHY ALAN BAKER}

A dissertation submitted in partial fulfillment of the requirements for the degree of

DOCTOR OF PHILOSOPHY

in

PUBLIC ADMINISTRATION AND POLICY

Portland State University

School of Urban and Public Affairs

Portland, Oregon

${ }^{\circ} 1994$ 


\section{DISSERTATION APPROVAL}

The abstract and dissertation of Timothy Alan Baker for the Doctor of Philosophy in

Public Administration and Policy was presented April 15, 1994 and accepted by the dissertation committee.

APPROVALS:

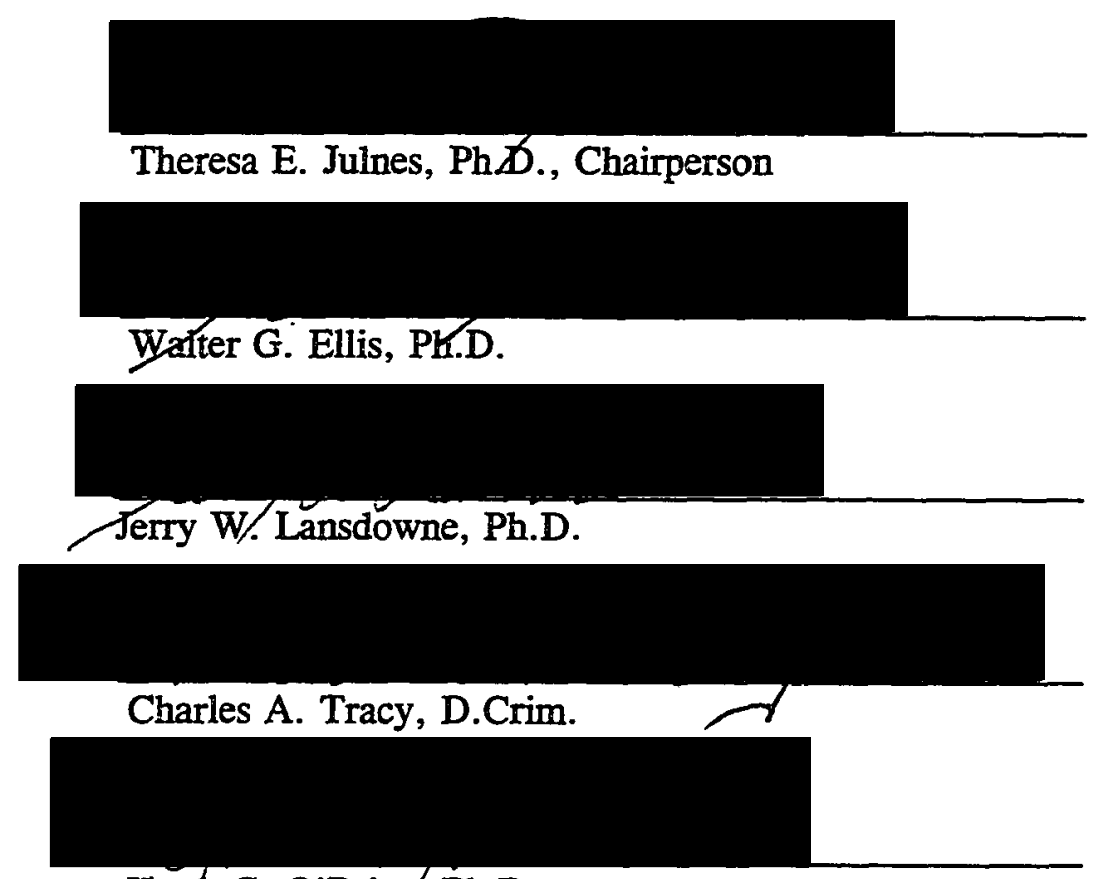

Kerth C. O'Brien, Ph.D.

Representative of the Office of Graduate Studies

Elizabeth A. Kutza, Coordifiator, Ph.D. Program in Public Administration and Policy

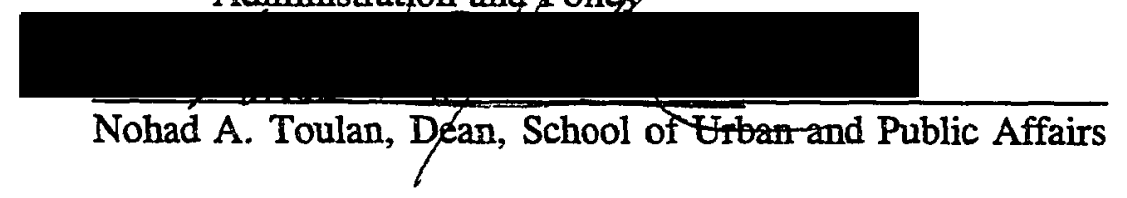

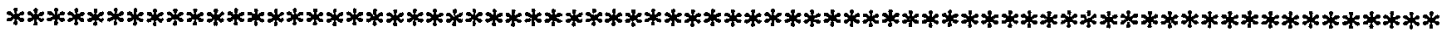

\section{ACCEPTED FOR PORTLAND STATE UNIVERSITY LIBRARY}

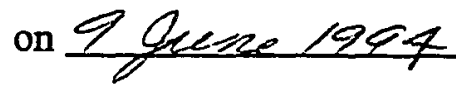




\begin{abstract}
An abstract of the dissertation of Timothy Alan Baker for the Doctor of Philosophy in Public Administration and Policy, presented April 15, 1994, School of Urban and Public Affairs, Portland State University.

Title: Oregon Primary Care Physicians' Support for Health Care Reform
\end{abstract}

This dissertation studies Oregon primary care physicians' attitudes toward health care reform. Two models of reform are examined: one, health care rationing such as that proposed by the Oregon Health Plan (OHP); and, two, support for national health insurance (NHI).

This works examines the necessity for changing the present health care system, traced from the early origins of the medical profession to the present day health care "crisis." The high cost of health care is examined and an overview of the OHP is provided, including citations from John Kitzhaber, M.D., author of the plan.

Overall, Oregon primary care physicians overwhelmingly supported health care rationing policies. Just under 75 percent of the physicians expressed support for health care rationing policies such as that proposed by the Oregon Health Plan. However, just under 48 percent of the same physicians expressed support for national health insurance (NHI). Internal medicine physicians were most supportive of health care rationing policies and $O B / G Y N$ physicians were least supportive. Conversely, pediatricians were most supportive of NHI and OB/GYN physicians were least supportive.

Regression analyses explained 11.5 percent of variation in support for health care rationing policies and 20.9 percent of their support for national health 
insurance (NHT).

While strong support measures were found for health reform such as that proposed by the Oregon Health Plan (HOP), no similar measures of support for NHI emerged. Almost universal support for health care reform such as the OHP was found among primary care physicians across the state, however similar patterns were not found for NHI. It appears from the research's findings that attempts to change the health care system that include the physician's ability to ration care would be more successful than a more systematic change such as would occur under a national health insurance program.

This dissertation points out that physicians represent strong supporting forces and/or opposing forces for health care reform. Their attitudes toward such reform must be considered if successful change is to occur in the U.S. health care system. 
TABLE OF CONTENTS

LIST OF TABLES $\ldots \ldots \ldots \ldots \ldots \ldots \ldots \ldots \ldots \ldots \ldots$

LIST OF FIGURES $\ldots \ldots \ldots \ldots \ldots \ldots \ldots \ldots \ldots \ldots \ldots \ldots \ldots$

ACKNOWLEDGEMENTS $\ldots \ldots \ldots \ldots \ldots \ldots \ldots \ldots \ldots \ldots$ xii

CHAPTER

I. INTRODUCTION $\ldots \ldots \ldots \ldots \ldots \ldots \ldots \ldots$

Changing the Health Care System .............. 4

The Oregon Health Plan $\ldots \ldots \ldots \ldots$

Research Problem \& Significance of the Problem ......... 9

Significance of Research Questions ... . . . . . . . . . 11

Theoretical Emphasis ................... 13

Research Outline ..................... . . 15

II. HISTORICAL DEVELOPMENT OF

U.S. HEALTH CARE SYSTEM $\ldots \ldots \ldots \ldots \ldots \ldots$

The History of Disease . . . . . . . . . . . 17

Problems Facing the Health Care System . . . . . . . 21

Periods of System Development and Change . . . . . . . 22

The Period of Rationing . . . . . . . . . . . . . 25

Present Healti Care System . . . . . . . . . . . 27

What is Health Care Rationing? . . . . . . . . . . . . 30

III. THE HIGH COST OF HEALTH CARE $\ldots \ldots \ldots \ldots \ldots 35$

A State of Crisis . . . . . . . . . . . . 38

Changing the U.S. Health Care System . . . . . . . . 39

The Oregon Health Plan . . . . . . . . . . . . . . 40

Physician Resistance to Health Care Change $\ldots . . \ldots \ldots$. . 44 
IV. NEED FOR THE OREGON HEALTH PLAN . . . . . . . . . 48

Health Care Access Barriers ................. . . 56

Need for the Oregon Health Plan ............. 58

V. CHANGE AND THE U.S. HEALTH CARE SYSTEM:

A CONCEPTUAL MODEL AND RELATED RESEARCH

LITERATURE ..................... 60

Lewin's Force Field Model: Analysis of Change . . . . . . . . . 62

Changing the Oregon Health Care System . . . . . . . . . 66

VI. HYPOTHESES AND MEASURES . . . . . . . . . . . . . . 69

Operational Measures: Dependent Variables . . . . . . . . . . 71

Hypothesis 1: Independent Variables . . . . . . . . . 72

Operational Measures: Hypothesis Two ... . . . . . . . 81

Hypothesis 2: Independent Variables . . . . . . . . . . . 82

Statistical Techniques . . . . . . . . . . . . . . . 84

VII. RESEARCH DESIGN .................. 88

Sources of Data . . . . . . . . . . . . . 88

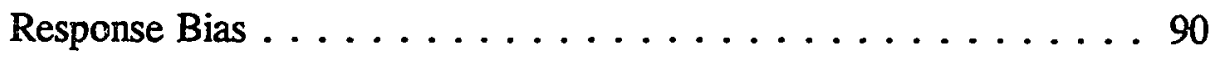

Questionnaire Design .................... 90

VIII. RESULTS OF DATA ANALYSIS . . . . . . . . . . . . . 92

Descriptive Statistics . . . . . . . . . . . . . . . . . 92

Support for Health Care Rationing Policies . . . . . . . . . . 103

Rationing Support: by Primary Care Specialty . . . . . . . . . . . 104

Rationing Support: by Geographic Location . . . . . . . . . . . . 105

Rationing Support: by City Size . . . . . . . . . . . . . . . . 107

Rationing Support: by Type of Practice . . . . . . . . . . . . 108

Rationing Support: by Managed Care Affiliation . . . . . . . . 110

Rationing Support: by Years Practicing ............ 111

Rationing Support: by M.D. and D.O. Physicians . . . . . . . 113

Rationing Support: by Patient Insurance Status . . . . . . . . . . 114

Rationing Support: by Physicians with Medicaid Patients . . . . . 115 
VIII. RESULTS OF DATA ANALYSIS, Continued

Mean Support Measures . . . . . . . . . . . . . . . . . . 116

Mean Levels of Support . . . . . . . . . . . . . . . . 117

Rationing Mean Support: by Rural Physicians . . . . . . . . . 119

Rationing Mean Support: by City Size . . . . . . . . . . . . 120

Rationing Mean Support: by Practice Type . . . . . . . . . . . 122

Rationing Mean Support: by M.D. and D.O. Physicians . . . . . 123

Rationing Mean Support: by Managed Care Affiliations . . . . . 124

Rationing Mean Support: by Patient Insurance Status . . . . . . 125

Rationing Mean Support: by Medicaid Status . . . . . . . . . . . 126

Rationing Mean Support: by New and Established Physicians . . . 127

Analysis of all Independent Variables: Regression . . . . . . . 130

Support for Health Care Rationing by Pediatricians . . . . . . . . 132

Support for Health Care Rationing by Internal Medicine Physicians 135

Step-wise Regression . . . . . . . . . . . . . . . . . 135

Support for Health Care Rationing by OB/GYN Physicians . . . . 137

Step-wise Regression . . . . . . . . . . . . . . . . . . . . 139

Support for Health Care Rationing by Family Practice Physicians 140

Support for Health Care Rationing by Other Primary Physicians . 143

Step-wise Regression . . . . . . . . . . . . . . . . . . . 143

Hypothesis Two: Support for National Health Insurance (NHI) . . 148

NHI Support: by Physicians' Primary Care Specialty . . . . . . . 150

NHI Support: by Physicians' Geographic Location . . . . . . . . 151

NHI Support: by Physicians' City Size of Practice . . . . . . . 152

NHI Support: by Physicians' Clinic Practice Type . . . . . . . . . . 155

NHI Support: by Physicians with Managed Care Affiliation (MCA) 156

NHI Support: by New and Established Physicians . . . . . . . . 157

NHI Support: by M.D. and D.O. Primary Care Physicians . . . . 159

NHI Support: by Physicians with Uninsured Patients . . . . . . 160

NHI Support: by Physicians who accept Medicaid Patients . . . . 162

Mean Levels of Support for National Health Insurance . . . . . . 166

Mean Levels of Support: Rural and Urban Physicians . . . . . . 167

Mean Support for NHI: Type of Practice . . . . . . . . . . . 168

Mean Support for NHI: M.D. and D.O. Physicians . . . . . . . 169

Mean Support for NHI: Managed Care Affiliations . . . . . . . 170

Mean Support for NHI: Physicians with Uninsured Patients . . . . 172

Mean Support for NHI: Physicians with Medicaid Patients . . . . 173

Mean Support for NHI: Newly Established Physicians . . . . . . 175

Analysis of all Independent Variables: Regression . . . . . . . . 178

Support for NHI by Pediatricians . . . . . . . . . . . . . . . 182

Support for NHI by Internal Medicine Physicians (IM) . . . . . 184 
VIII. RESULTS OF DATA ANALYSIS, Continued

Support for NHI by OB/GYN Physicians . . . . . . . . . . 187

Support for NHI by Family Practice Physicians . . . . . . . . . . 189

NHI Support by Other Types of Primary Care Physicians . . . . 192

IX. DISCUSSION AND CONCLUSIONS ... . . . . . . . . 196

Hypothesis One: Support for Health Care Rationing . . . . . . . . 198

Hypothesis One: Explaining Why? . . . . . . . . . . . . 201

Hypothesis Two: Support for National Health Insurance . . . . . 204

Hypothesis Two: Explaining Why? . . . . . . . . . . . . 209

Conclusions and Final Remarks . . . . . . . . . . . 210

Areas for Future Research and Limitations . . . . . . . . . . . 214

References Cited ..................... 216

Appendix A: Questionnaire Used ............... 225

Appendix B: Resume of Timothy A. Baker ........... 231 


\section{LIST OF TABLES}

\section{TABLE}

1. Death Rate for Leading Causes of Death in U.S., 1900 and 1990 . 19

2. Four Phases of Development of U.S. Health Care System . . . . . 23

3. Pearson Correlations of Health Insurance Status and States' Population with Health Insurance . . . . . . . . . 30

4. Methods of Health Care Rationing in the U.S. . . . . . . . . 33

5. Number of Americans Uninsured and U.S. Health Care Spending . 34

6. Health Care Expenditures as Percentage of GNP, U.S. and Other Countries, and Infant Mortality Rate ... . . . . 37

7. Regression Analysis of Infant Mortality Rate . . . . . . . . . 37

8. Oregon Survey of Respondents to Health Services

Commission Survey on Health Care Access Problems . . . . . . . . 49

9. Percentage of Households not seeing a Physician During the Past Twelve Months, when They Should have seen one . . . . 50

10. Percentage of Households not seeing a Physician During the Past Twelve Months, when They Should have seen one, by Gender ......................... 51

11. Percentage of Households not seeing a Physician During the Past Twelve Months, when They Should have seen one, by Medicaid Status . . . . . . . . . . . . . . . 52

12. Percentage of Households not seeing a Physician During the Past Twelve Months, when They Should have seen one, by Health Insurance Status . . . . . . . . . . . . . 53

13. Percentage of Households not seeing a Physician During the Past Twelve Months, when They Should have seen one, by Federal Poverty Level Status . . . . . . . . . . . . . . . 55 
TABLE

14. Primary Reasons Oregonians Did Not See Physician, when the should have seen one $\ldots \ldots \ldots \ldots . \ldots . \ldots 57$

15. Practice Characteristics of Oregon Primary Care Physicians

Responding to Dissertation Survey . . . . . . . . . . 98-102

16. Physicians' Support for Health Care Rationing . . . . . . . . . 103

17. Physicians' Support for Health Care Rationing by Practice Specialty . . . . . . . . . . . . . . . 105

18. Physicians' Support for Health Care Rationing by Practice Location . . . . . . . . . . . . . . . . . . 106

19. Physicians' Support for Health Care Rationing, by City Size of Practice . . . . . . . . . . . . . . . . . 108

20. Physicians' Support for Health Care Rationing by Practice Type . . . . . . . . . . . . . . . . . . . . 109

21. Physicians' Support for Health Care Rationing, by Managed Care Affiliation . . . . . . . . . . . . . . . 110

22. Physicians' Support for Health Care Rationing, by Newly Established \& Established Physicians . . . . . . . . . 112

23. Physicians' Support for Health Care Rationing, by Length of Years in Practice ... . . . . . . . . . . 113

24. Physicians' Support for Health Care Rationing, by Type of Medical Degree . . . . . . . . . . . . . . . . . 114

25. Physicians' Support for Health Care Rationing by Physicians with Uninsured Patients ............ 115

26. Physicians' Support for Health Care Rationing, by Physicians with Medicaid Patients . . . . . . . . . . 116

27. Mean Levels of Support for Health Care Rationing, by Primary Care Physicians . . . . . . . . . . . . . . . 118 


\section{TABLE}

28. Mean Levels of Support for Health Care Rationing, by Urban and Rural Physicians . . . . . . . . . . . . . 120

29. Mean Levels of Support for Health Care Rationing, by City Size . . . . . . . . . . . . . . . . . . . . . 121

30. Mean Levels of Support for Health Care Rationing, by Solo and Group Practice Physicians . . . . . . . . . . . . 122

31. Mean Levels of Support for Health Care Rationing, by M.D. and D.O. Physicians . . . . . . . . . . . . . 123

32. Mean Levels of Support for Health Care Rationing, by Physicians with Managed Care Affiliations . . . . . . . . 125

33. Mean Levels of Support for Health Care Rationing, by Physicians with Uninsured Patients . . . . . . . . . . . 126

34. Mean Levels of Support for Health Care Rationing, by Physicians with Medicaid Patients . . . . . . . . . . . . . 127

35. Mean Levels of Support for Health Care Rationing, by New and Established Physicians . . . . . . . . . . 128

36. Mean Levels of Support for Health Care Rationing, by Length of Years in Practice

37. Regression of Primary Care Physicians Support for Health Care Rationing . . . . . . . . . . . . . . . . . 131

38. Regression of Pediatrician Primary Care Physicians Support for Health Care Rationing . . . . . . . . . . . . . . . . . . . . . 134

39. Regression of Internal Medicine Primary Care Physicians Support for Health Care Rationing . . . . . . . . 136

40. Step-wise Regression of Internal Medicine Regression . . . . . 137

41. Regression of OB/GYN Primary Care Physicians Support for Health Care Rationing . . . . . . . . . . . . . . 138

42. Step-wise Regression of OB/GYN Regression . . . . . . . . 140 
TABLE

43. Regression of Family Practice Primary Care

Physicians' Support for Health Care Rationing . . . . . . . . . 142

44. Regression of Other Primary Care Physicians' Support for

Health Care Rationing . . . . . . . . . . . . . . . . . . . . . 144

45. Step-wise Regression of Other Physicians' Regression $\ldots \ldots .146$

46. Physicians' Support for National Health Insurance (NHI) . . . . 148

47. Physicians' Support for National Health Insurance (NHI)

by Practice Specialty . . . . . . . . . . . . 151

48. Physicians' Support for National Health Insurance (NHI)

Urban and Rural Physicians . . . . . . . . . . . . 151

49. Physicians' Support for National Health Insurance (NHI),

by City Size . . . . . . . . . . . . . . . 152

50. Physicians' Support for National Health Insurance (NHI)

by Clinic Type . . . . . . . . . . . . . . . . . 150

51. Physicians' Support for National Health Insurance (NHI), by Managed Care Affiliation . . . . . . . . . . . . . 156

52. Physicians' Support for National Health Insurance (NHI), by New and Established Physicians . . . . . . . . . . . 157

53. Physicians' Support for National Health Insurance (NHI), by Years in Practice . . . . . . . . . . . . . . . 158

54. Physicians' Support for National Health Insurance (NHI), by M.D. and D.O. Physicians . . . . . . . . . . . . . . 159

55. Physicians' Support for National Health Insurance (NHI), by Physicians with Uninsured and Insured Patients . . . . . . 160

56. Simple Regression Analysis of Physician Support for National Health Insurance (NHI), by Percentage of Patients without Health Insurance 
TABLE

57. Physicians' Support for National Heaith Insurance (NHI)

by Physicians with Various Percentage of Uninsured Patients . . . 162

58. Physicians' Support for National Health Insurance (NHI)

by Physicians with Medicaid and no Medicaid Patients . . . . . 163

59. Simple Regression Analysis of Physician Support for

National Health Insurance (NHI), by Percentage of

Patients on Medicaid . . . . . . . . . . . . . 164

60. Physicians' Support for National Health Insurance (NHI)

by Physicians with Various Percentages of Patients

on Medicaid . . . . . . . . . . . . . . . 165

61. Mean Level of Support for National Health Insurance (NHI) by

Physicians' Primary Care Specialty . . . . . . . . . . . 166

62. Mean Level of Support for National Health Insurance (NHI)

by Physicians' Geographic Location of Practice . . . . . . . 167

63. Mean Level of Support for National Health Insurance (NHI)

by Solo/Partnership and Group Practice Physicians . . . . . . 169

64. Mean Levels of Support for National Health Insurance (NHI),

M.D. and D.O. Physicians . . . . . . . . . . . . 170

65. Mean Levels of Support for National Health Insurance (NHI), by Physicians with Managed Care Affiiiations . . . . . . 171

66. Mean Levels of Support for National Health Insurance (NHI), By Physicians with Uninsured and All Insured Patients . . . . . 173

67. Mean Levels of Support for National Health Insurance (NHI), by Physicians with Medicaid Patients . . . . . . . . . . 174

68. Mean Levels of Support for National Health Insurance (NHI), by Newly Established Physicians . . . . . . . . . . 176

69. Mean Levels of Support for National Health Insurance (NHI), by Physicians by Length of Years in Practice . . . . . . . . 177 
TABLE

70. Regression of Primary Care Physicians' Support for National Health Insurance (NHI) $\ldots \ldots \ldots \ldots 18 \ldots$

71. Regression of Pediatrician Primary Care Physicians' Support for National Health Insurance $(\mathrm{NHI}) \ldots \ldots . \ldots 183$

72. Regression of Internal Medicine Primary Care Physicians' Support for National Health Insurance $(\mathrm{NHI}) \ldots \ldots \ldots \ldots$

73. Regression of OB/GYN Primary Care Physicians' Support for National Health Insurance $(\mathrm{NHI}) \ldots \ldots \ldots \ldots$

74. Regression of Family Practice Primary Care Physicians' Support for National Health Insurance (NHI) . . . . . . . . . . . . . . . 191

75. Regression of Other Primary Care Physicians' Support for National Health Insurance (NHI) . . . . . . . . . . . . . . . . 194

76. Lewin's Force Field Analysis Applied to Categories of Oregon Primary Care Physicians' Support for Health Care Rationing Policies . . . . . . . . . . . . . . . 202

77. Lewin's Force Field Analysis Applied to Categories of Oregon Primary Care Physicians' Support for National Health Insurance 


\section{LIST OF FIGURES}

\section{FIGURE}

1. U.S. Health Care Expenditures as Percentage

of Gross National Product (GNP), 1950-1990. . . . . . . . . . . . . 26

2. Lewin's Force Field Analysis Conceptual Model . . . . . . . . . . 64

3. Lewin's Force Field Analysis applied to Oregon Primary Care

Physicians ........................ 68

4. Matrix for Hypothesis 1: Health Care Rationing $\ldots \ldots \ldots$. . . 80

5. Matrix for Hypothesis 2: National Health Insurance . . . . . . . 83

6. Likert Scale used to measure Physicians' Support

for Health Care Reform . . . . . . . . . . . . . . . . . . . 117

7. Matrix of Regression Probabilities for Hypothesis

1: Health Care Rationing $\ldots \ldots \ldots . \ldots . \ldots 147$

8. Oregon Primary Care Physicians' Attitudes

Toward National Health Insurance . . . . . . . . . . . . . . 149

9. Percentage of Oregon Primary Care Physicians

Expressing Support for NHI, by Practice Location . . . . . . . . . 154

10. Matrix of Regression Probabilities for Hypothesis

2: National Health Insurance . . . . . . . . . . . . . . . 195

11. Percentage of Oregon Primary Care Physicians Supporting

Health Care Rationing and National Health Insurance . . . . . . . 197

12. Lewin's Force Field Analysis Model

applied to Hypothesis One: Health Care Rationing . . . . . . 199

13. Lewins' Force Field Analysis Model

applied to Hypothesis Two: National Health Insurance . . . . . . 205 


\section{ACKNOWLEDGEMENTS}

This dissertation represents three and a half years of my life and three and a half years of other's lives, as well. There were times when I thought it would never be finished. However, I must acknowledge my sincere gratitude to Dr. Theresa Julnes, the chairperson of my dissertation committee, for her knowledge, expertise, patience, guidance, and unwavering support while I conducted my research. Without a chair such as her, I would never have been able to complete this work. Her kicks in the pants, endless energy, and persistent encouragement at the ariopriate moments are gratefully acknowledged. Thank you.

I would also like to acknowledge those in my life who have influenced me in ways they can not imagine and acknowledge the personal sacrifices they made while I worked on this research. First, to my loving daughter, Amanda, who is just finishing high school (we're both the class of 94) as I complete this work, thank you for being so wonderful, so smart, so beautiful, and so understanding for all those times when you wanted to be with me or tried to reach me by telephone, but I was with my work. The world is a much better place because of you. Thank you, too, to Cricket, my significant other during much of this dissertation. Your smiling face was appreciated more than you will ever know. I hope your dreams come true.

Thank you, too, to all of my professors at Portland State University, School of Urban and Public Affairs. You taught me how to think. A very special acknowledgement is made to my supportive dissertation committee: Drs. Walter Ellis, 
Jerry Lansdowne, Charles Tracy, and Kerth O'Brien from the department of psychology, for their guidance and for reading this dissertation and providing feedback for improvements. You were all wonderful to work with. Thank you, too, to Dr. Brian Stipak, Portland State University for really making me understand statistics, and to Dr. Theresa Julnes for compelling me understand their usefulness and application. Also, thank you to Kelly Charles, one of my students at Linfield College, for proof-reading the final draft. Job well done.

Last, but certainly not least, I would like to thank two special individuals, both excellent mentors, who may have not known it, but who have had a profound influence on my life and my leadership style. First, thank you to Clifford "Kelly" Keliikoa who taught me while working in Saudi Arabia that "people are lead; animals are herded." Thank you for your knowledge, friendship, and support. And thank you to John Kitzhaber, M.D., for believing in me while working on the Oregon Health Plan at Oregon Health Sciences University, and for your belief that it is more important to do the right thing than it is to do things right. Thank you, too, for not being too upset that I've used the " $\mathrm{R}$ " word so often in this dissertation. Both of these individuals are true leaders in every sense of the academic model.

I dedicate this dissertation to four very special individuals. The first two are my loving father and mother, Dean and Billie Baker; the third, my grandmother, Ila Hammond. Without them, this research effort would never have been conducted. I would like to thank them for all of their love and support throughout the years and for their understanding when I didn't call, come visit for months on end, send a birthday 
card on time, or come to dinner when I was invited. It wasn't because I didn't want to, it was because I always seemed to have one more revision that had to be made, and never enough time. Also, thank you for your support even when you didn't really understand what it was I was doing (no, Granny, they still won't let me work on humans!). Also, thank you for just being you. You're wonderful parents and grandparents.

Finally, I would like to dedicate this work to the memory of Dr. W. Edwards Deming, not a health policy expert, but an incredible genius in organizational system design and quality. I was most fortunate to spend four of Dr. Deming's last days with him in Los Angeles in December 1993 (he passed away two week later at the age of 93) learning about systems design and quality. His theories and publications have taught me more about quality and systems design than any other author to which I've been exposed. Physicians, nurses, politicians, insurance executives, and health administrators who speak of losing quality health care if the U.S. reforms its health care system need to discover the work of Dr. Deming. I hope to continue to blend my work in health policy with Dr. Deming's work in quality systems design.

Financial assistance for this dissertation by the Osteopathic Physicians and Surgeons of Oregon is acknowledged. While this research was not directly funded by the Osteopathic Physicians and Surgeons, their funding of another research project allowed me to collect the data used in this dissertation. Also, Dr. Julnes and Portland State University are gratefully acknowledged for providing me a two year graduate assistantship that certainly helped pay my tuition and keep me in computer disks, 
printer paper, and popcorn; all essential components of a completed dissertation.

Thank you, all, very much. 


\section{CHAPTER I}

\section{INTRODUCTION}

Former Vice President Hubert H. Humphrey, terminally ill with cancer, once said that the moral test of a government is how it treats its citizens who are in the dawn of life, the twilight of life, and the shadow of life -- a nation's children, elderly, and sick, needy, and disabled (Litman and Robins 1984). He observed that a government that can neither educate its children, care for its elderly, nor meet the needs of its sick, poor, and disabled, is a nation without compassion. Litman and Robins (1984) argue that such a country is a nation without a soul.

The United States' ability to care for its sick and disabled has changed significantly since the professionalization of the health care system in the early 1900 s (Starr 1982; Williams and Torrens 1988; Coile 1990; Williams and Torrens 1993). Before the turn of the century, the U.S. health care system was a blend of mid-wives, charity hospitals, unlicensed medical men, apothecaries, and private practice general practitioners. Most of the actual health care was delivered by women in the family (Raffel and Raffel 1994). However, Anderson (1984) writes that in the late 1870s, personal health care services became a growth enterprise in a relatively unsophisticated delivery system. Despite the limited technology with which to affect medical cures, individuals were able to find some form of medical treatments from 
private physicians, charity hospitals, or the myriad of individuals who practiced the medical arts (Raffel and Raffel 1994).

Today, the U:S. health care system has evolved into a highly sophisticated industry. The 1994 system is no longer comprised of charity hospitals and general practitioners. Instead, it consists of comprehensive medical centers, group practice clinics, medical malls, health maintenance organizations, managed care relationships, outpatient surgical centers, free-standing diagnostic laboratories, long-term care facilities, pharmaceutical companies, hospices, and myriad of special medical organizations and practitioners, mostly funded by private and public health insurance plans.

As a result of this rapid explosion of medical technology and health care delivery, the current U.S. health system is being forced to address major changes in such areas as teaching, education, technology, financing, politics, research, and the very structure of the delivery system itself (Williams and Torrens 1988; Zaldivar 1994). However, corollary to these changes, Derzon (1988) writes that Americans pride themselves on the wealth, intellectual and technological capacities, organizational skill, and determination to provide health care to every citizen in need. He does not believe that we are doing so, however. Derzon (1988) underscores a grave social concern that in the 1990 s it is questionable whether the U.S. health care delivery system actually does provide health care to each and every American.

Published health care statistics underscore Derzon's concern. Despite a record $\$ 750$ billion spent on health care in 1992 (O'Neil 1992; Wright 1992), \$990 billion 
spent in 1993 (Zaldivar 1994), and a projected \$1 trillion to be spent in 1994 (Zaldivar 1994), between 31 million and 38.9 million Americans are without health insurance (Raffel and Raffel 1994; Zaldivar 1994), another 55 million are underinsured, and 1 million Americans are denied access to health care each year because of an inability to pay for it (American College of Physicians 1990).

Health policy observers and critics of the U.S. health care system seem to agree that the 1990s are tumultuous times for the direct deliverers of health care (Derzon 1988; Califano 1989; Coile 1990), and the decade will witness major changes in the way the U.S. health care system delivers health care. Pressures to contain and reduce health care expenditures have emanated from almost all major health policy actors -- federal and state governments, employers and their insurers, retirees, health and welfare trusts, and an increasing number of uninsured citizens (Derzon 1988; Raffel and Raffel 1994). And while the supply of health care personnel (with the possible exception of registered nurses) have more than met the demand for services that are now being financed (Derzon 1988), the health care paradox of the 1990s is that of increased spending without an associated increase in health care status or increased numbers of people receiving health care. It appears that we, as a nation, are spending more and more resources, but receiving less and less care. 
Changing The Health Care System

Health futurist Russell Coile (1990) and others (Califano 1989, 1991; Eddy 1991; Kitzhaber 1991, 1991b; Zaldivar 1994; Clinton 1994) argue that change in the present health care system is inevitable. Coile (1990) believes that the future of medicine is evident in the observation of current events. To support this supposition, Coile (1990) cites several change signals that predict to a newly emerging health care system:

- The Harvard Relative Value Scale (RVS) study establishing national physician rates.

- National health insurance back on the policy agenda.

- National expenditures for physician services rising at a 10 percent annual rate.

- Medicare spending on physician services rising at an 18 percent annual rate.

- A potential federal "cap" on physician payments.

- $\quad$ Outcomes of medical care published in newspapers and the popular press.

- $\quad$ Rationing of medical care becoming state law in Oregon.

It is Coile's (1990) last health care change signal -- the rationing of medical care in Oregon -- that this research effort addresses. Oregon is emerging as a leader in national health care reform with its Oregon Health Plan (OHP). The OHP is a health care policy that seeks to address, simultaneously, health care for the uninsured and rising health care costs. The plan expands Medicaid and private insurance to large numbers of Oregonians who presently have no health insurance, but, as Strosberg $(1992,3)$ writes, "... at the price of explicitly deciding not to cover some procedures widely accepted as beneficial." In short, the OHP rations health care to 
some segments of society while expanding access to others.

The plan has been watched closely by state, national, and world policy experts (Morgan 1990; Strosberg, Wiener, Baker, and Fein 1992; Fox and Leichter 1993), as well as physicians, hospitals, and health care providers throughout the U.S. (Haglund and Peck 1990; Kitzhaber 1991a; Clements 1993). As gate-keepers to the Oregon health care system, primary care physicians in the state provide an ideal referent group from which to study physician's attitude toward health care reform. They, of any physician in the U.S., should be the most familiar with the publicity surrounding the development of the Oregon Health Plan (OHP).

Focusing on Coile's rationing change signal, this research effort seeks to measure the attitudes of Oregon's primary care physician toward health care reform such as that proposed by the OHP. Secondarily, this dissertation seeks to measure support among Oregon primary care physicians for alternative forms of health care reform, namely national health insurance (NHI), a health care access scheme presently being proposed by the Clinton Administration in one form (Clinton 1994), and several other federal policy makers in various other forms (Zaldivar 1994; The Oregonian, 1994).

\section{The Oregon Health Plan}

The State of Oregon has undertaken a new approach toward providing universal health insurance to all of its citizens. Part of the plan seeks to prioritize or 
ration health care to some Oregon citizens so that the money saved can be redistributed to other citizens in the form of expanded health insurance coverage. This prioritization process or "rationing" strategy is what Coile (1990) believes to be a major change in the way the U.S. health care system is evolving. Some authors and social policy observers have even suggested that the Oregon Health Plan represents a potential international model of health care reform (Morgan 1990; Baker 1992; Julnes and Baker 1991).

Oregon's health care rationing plan arose from the 1989 Oregon Basic Health Services Act, now more commonly known as the Oregon Health Plan (OHP) (Kitzhaber 1991b). The Act is comprised of five Senate Bills that, in part, legalize health care rationing ${ }^{1}$ in the State of Oregon. Senate Bill 27 (SB 27), the center-piece of the OHP, created a Health Services Commission and mandated that the State provide a basic level of health care to all citizens with incomes at or below the federal poverty level (FPL) through a reformed Medicaid program. Senate Bill 935 (SB 935) created incentives for small businesses to make health insurance available to their employees. It also mandated, by 1995, universal employer health care coverage of employees and dependents with a benefit package equal to or greater than the package provided to the Medicaid recipients.

Senate Bill 534 (SB 534) established a high-risk pool to make health insurance

1 John Kitzhaber, MD, former Oregon Senate President, and author of the original OBHSA, refers to the outcome of the policy as health care "prioritization" (Kitzhaber 1991b). He doesn't believe that rationing non-effective medical services really constitutes rationing. For this research effort, the terms "rationing" and "prioritization" are synonymous. 
available for persons who were unable to obtain private market insurance. Together, these three statutes, passed into law in 1989, constitute the Oregon Basic Health Services Act, the derivation of the Oregon Health Plan (OHP). Two additional bills were added in $1992 .^{2}$

The key to the OHP is in the provision of "basic" health care to all Oregon citizens. The term basic refers to the development of a minimum level of health care provided to all Oregon citizens. To determine this minimum level of care, the OHP systematically pairs all known diagnoses with their respective treatments. These diagnoses-treatment pairs (DTPs) are ranked according to their medical effectiveness. The provision of medical treatments for DTPs shown to be most efficacious are provided to all citizens in the state as a minimum level of care guaranteed to all (Kitzhaber 1990). Under the OHP, high-cost, low-efficacy treatments are not be paid for and the savings associated with the elimination of such treatments are redistributed to pay for more effective care for more Oregon residents. By redistributing the cost of medical treatment, the Oregon Health Plan seeks to provide a minimum level of

2 In 1992, the Oregon Senate introduced, in the words of John Kitzhaber's executive assistant Mark Gibson (1992), two "housekeeping bills" designed to improve the Oregon Health Plan. Senate Bill 1076 (SB 1076) requires all insurance companies in the state to offer an insurance plan equal to the basic package developed under Senate Biil 27. Senate Bill 44 (SB 44) expands the Oregon Health Plan to include the blind, disabled, aged, and foster children. Individuals in these categories were originally exempt from coverage under the Oregon Health Plan that began in February 1, 1994. This bill also requires the Oregon Health Services Commission (HSC) to create a priority list of mental health and chemical dependency services, such as they did for medical treatments. As of March 14, 1994, the HSC has not completed this process. Before SB 44 can be fully implemented, another federal waiver of Federal Medicaid regulations is required (Julnes 1994). 
effective health care to a greater number of individuals.

The OHP represents a significant change in the way health care is financed in this state and, for that matter, this country. Never before has a governmental body in the U.S. institutionalized the concept of health care rationing, in the form of an explicit definition of a "basic" level of care, into the health care delivery system Higgins 1989; Coile 1990; Kitzhaber 1991a). By doing so, explicit health care rationing has moved from the realm of academic possibility to programmatic reality.

Oregon appears to be the first state in the Union to address this topic of explicit rationing in an open and prescribed manner (Kitzhaber 1991a; Fox and Leichter 1993). A review of the literature reveals no other successful attempts by any local or state government. A few unsuccessful attempts have been reported, however.

Colorado attempted to emulate the Oregon plan in 1991, but it failed to pass both houses of its state legislature (Kitzhaber 1991a). Alameda County, California attempted to pass a similar rationing program for its uninsured population, but it, too, failed to be implemented (Higgins 1989). In 1993, the Clinton Administration refused to adopt the Oregon model as part of any national health care reform (Zaldivar 1994), citing the concept of rationing as unacceptable, endorsing, instead, a national health insurance plan using the theory of managed competition to help drive down health care costs (Zaldivar 1994). As such, the Oregon Health Plan (OHP) stands as a single health policy specifically designed to ration health care to some segments of society while expanding health care services to another segment. This concept serves 
as a potential model for the remainder of the country (Strosberg, Wiener, Baker, and Fein 1992) and may be a model with which to expand health care to these individuals without significantly increasing costs (Kitzhaber 1991a; 1991b).

\section{Research Problem \& Significance of the Problem}

As Oregon experiments with its new model of health care reform, a rare opportunity exists to research the attitudes of a state's physicians toward their acceptance of health care reform. As such, this dissertation represents an attitudinal study of Oregon primary care physicians' support for changing the state's health care system to include explicit health care rationing. It also represents an analysis of these same physicians' attitudes towards the more accepted method of health care reform, national health insurance (NHI).

As Oregon stands alone as a model of health care reform built upon a systematic attempt to prioritize health care procedures, Oregon primary care physicians will be the first medical doctors to practice within such health care guidelines. This situation provides a unique opportunity to research these physicians to determine if they accept this concept of health care rationing, or if they will accept more conventional forms of health care reform, such as national health insurance (NHI). It also provides an opportunity to determine if they will support any type of health care reform.

The primary research questions examined by this dissertation are two fold. 
Since others have already published reports in the literature about the Oregon Health Plan (OHP) and the process by which it was developed, this work combines their research with the author's own research to provide insight into the support for health care reform from the state's medical community. This is the first published work to undertake such a study. It will also be the first published research of physicians' attitudes toward national health insurance from doctors who practice in a state considered a pioneer in health care reform (Strosberg, Wiener, Baker, Fein 1992).

The design of this research represents a support analysis for the OHP and/or alternative models of health care reform such as national health insurance (NHI). As earlier research (Baker 1992) has found a significant number of Oregonians reporting trouble accessing the health care system (Oregon Health Services Commission 1991; Baker 1992), the need to expand health care access is well documented. However, this work seeks to determine if support for expanding that access, by changing the Oregon health care system, is present among Oregon primary care physicians, the theoretical gatekeepers to the state health care system. Support for change is measured by the strength of support by primary care physicians for health care rationing policies such as the OHP and for alternative models of NHI using Lewin's Force Field Analysis.

In examining the support for change, this research effort examines if broad or localized support for health care rationing and/or NHI is evident (that is, if it is found, is the support for rationing and NHI ubiquitous or clustered; does it exist statewide or is it found only in urban or suburban areas, for example). This work 
also examines the difference in strength of support for health care rationing and NHI between primary care specialty groups (family practice, internal medicine, obstetrics/gynecology [OB/GYN], and pediatrics).

The determination of need for the Oregon Health Plan (OHP) or other such health care access policies has been shown by earlier studies (Baker 1992). However, an examination of physicians' aptitudes toward health care rationing (HCR) policies such as the OHP will determine if support for the OHP is present. A Aiternately, an examination of physicians' attitudes toward national health insurance (NHI) will provide evidence that Oregon health policy makers may approach health care reform from another perspective -- national health insurance (NHI).

\section{Significance of Research Questions}

This research effort contributes unique knowledge in three important ways. First, the research contributes to the body of health policy literature by providing attitudinal research on Oregon physicians' acceptance of health care reform, in general. Second it seeks to measure these physician's attitudes toward public policies that seek to explicitly ration health care. Third, it provides measures of support for national health insurance from the same Oregon primary care physicians.

Although economic texts, journal articles, and popular press reports are evident that predict the ultimate necessity to ration health care (Lamm 1989; Lindberg 1991; Fredman 1991; Eddy 1991; Strosberg, Wiener, Baker, and Fein 1992), as of 
this writing no Oregon specific study, national study, nor body of literature exists that measures physician's support for the concept of health care rationing. This research effort will provide quantitative measures of primary care physician support for such health care reform.

Literature does exist that documents long-term opposition to national health insurance (NHI) (Williams and Torrens 1988; Califano 1989; The Health Poll 1989) by organized medicine. For example, a 1989 study showed that 50 percent of U.S. physicians felt that national health insurance (NHI) would have a negative impact on the quality of medicine (The Health Poll 1989). This research reports that 72 percent of the physicians felt that NHI would expand access to basic health care, but 60 percent felt NHI was a bad idea (another 7 percent were unsure). The study did not ask, however, if they would support the concept of NHI. It did report that 74 percent of the physicians felt that it was likely that NHI would be enacted in the 1990s (The Health Poll 1989), however. As of 1994, no Oregon study has yet been published.

This research effort will be of interest to policy makers, physician groups, academicians, and other interested parties for several reasons. First, it determines if support exists from primary care physicians in Oregon for rationing policies (if it is not, the implementation of the OHP is in question). Second, it determines if alternative forms of access expansion programs such as national health insurance (NHI) are supported by Oregon's primary care physicians. If significant physician opposition to both rationing and NHI is found to exist, the implementation of either approach to changing the Oregon health care system, and expanding access to health 
care in Oregon, is in question. If support for NHI is found but not for rationing policies, Oregon may be taking the wrong path toward health care reform. Although the State recently communicated that "several hundred physicians" have expressed a desire to participate in the Oregon Health Plan (OHP), no quantitative analysis has been performed by state officials to measure the strength or geographic dispersion of that support (Sipes-Metzler 1992).

\section{Theoretical Emphasis}

As primary suppliers of health care (and indirect demanders of high-cost secondary care), physicians serve as either supporting forces or restraining forces to any attempt to change the health care system (Beckhard and Harris 1987). While the primary theoretical emphasis of this research effort is grounded in heaith policy, an ancillary emphasis is provided by organization theory. While the health policy literature has shown that physicians, as an organized group, are generally opposed to universal health insurance programs (Brown 1987; Williams and Torrens 1988, 1993), this dissertation will test the strength of physician supporting forces for policies that seek to ration health care or try to develop national health insurance (NHI).

Health care economic theory (Feldstein 1988) suggests that physicians act as both suppliers and indirect demanders for health care, as such they can pose considerable resistance to any major change in the health care delivery system. Likewise, organization theory suggests that resisting forces will typically oppose 
major changes in the prevailing structure of any formal organization or system (Kanter 1983). Beckhard and Harris (1987) feel that a desired change will not eventuate unless the commitment of the essential "critical mass" is in effect, or unless the successful elimination of significant restraining forces is accomplished. Both elements serve to impede or accelerate the implementation of change.

Change in the health care system is more likely to be supported by physicians if the change is incremental in nature (Beckhard and Harris 1987). Change such as that proposed by the Oregon Health Plan (which seeks to ration health care), while somewhat drastic in concept, actually represents incremental change. That is, it does not impose major change onto physicians nor does it dramatically change the health care system. It allows physicians to keep control of their practice while eliminating some medical services. Organization theory would predict that such change would be more likely supported by physicians than would major change proposed by restructuring the entire health care system around a national health insurance program.

The support for change research reported in this study is designed to measure the strength of the theoretical forces necessary to support or resist the Oregon Health Plan (OHP) and/or national health insurance. Both health policy initiatives represent a significant change in the predominant structure of the health care finance and delivery system in Oregon. 
Research Outline

The format of this dissertation is straight forward. It provides both a historical perspective of health care access problems, an overview of the Oregon Health Plan, and reports the measure from Oregon primary care physician support for health care policies that clearly will change the way health care is practiced and financed in Oregon. In Chapter 2, the evolution of the so called U.S. health care crisis, and its resulting health care access problems, is outlined. This chapter also outlines the development of the U.S. health care system from the crude, turn of the century public health model to present, acute care model of health care delivery. A review of the literature documenting opposition to earlier attempts at health care reform is also addressed in Chapter 2.

Chapter 3 outlines the present health care crisis; a crisis that was exacerbated by the passage of the federal Medicare and Medicaid programs in the mid-1960s. Chapter 3 also discusses the Oregon Health Plan in detail (OHP).

Chapter 4 discusses the need for policies such as the Oregon Health Plan. It examines earlier work done by the author of this dissertation, and overviews health care access problems reported by Oregon citizens.

Chapter 5 provides a conceptual force-field model within which the OHP framework can be examined. Lewin's Force Field Analysis is discussed as an analytical tool with which to measure physician support for both the OHP and NHI. The last four chapters provide the methodology and findings of the research 
undertaken for this dissertation. Chapter 6 outlines the hypotheses tested by this research effort, it discusses the dissertation's research design, and provides the measures used in the data analysis. Chapter 7 overviews the research design used to operationalize this study. Chapter 8 reports the results of the data analyses. Chapter 9 discusses significant findings and provides conclusions from the data analysis. It also provides future areas for research and discusses the limitations of this work.

While reading this dissertation, one should keep in mind that health policy is open ended, indefinite in duration, universal in nature, controversial and political, and a dynamic process (Litman and Robins 1984). Wilber Cohen (Litman and Robins 1984 , xii) writes, " ... it is a real challenge to those who chose to study and work in this important field. It warrants continued attention" (Litman and Robins 1984, xii). This dissertation attempts to shine a bit of academic light on the primary question of how to expand health care access to every citizen in the State of Oregon; an area that, too, is both a real challenge and in need of continued attention. 


\section{CHAPTER II}

\section{HISTORICAL DEVELOPMENT OF THE U.S. HEALTH CARE SYSTEM}

William Shakespeare once wrote "what is past is prologue" (Williams and Torrens 1988). George Santayana warned that those who cannot remember the past are doomed to repeat it (Williams and Torrens 1988). Both often quoted passages are particularly applicable to the U.S. health care system. Many of the historical issues and political forces that have helped shape and form the system, continue to influence it today. If one is to understand the future of the health care system, one must first look to its past.

\section{The History of Disease}

For centuries, human beings have suffered from the effects of epidemics and pandemics of infectious disease. For thousands of years, plague, cholera, typhoid, smallpox, influenza, yellow fever, and myriad other diseases have raged at will, unaffected by available methods with which to stop them (Williams and Torrens 1993).

During the mid-1800s, these acute epidemics were the most critical health care problem of a majority of Americans. Diseases caused by inadequate food processing, 
contaminated water supplies, insufficient sewage disposal, and generally poor economic conditions particularly effected those citizens living during the period of 1850 to 1900 . For example, a cholera epidemic occurred in the United States during this time that killed 5071 people in New York City, alone, with an unofficial toll several times higher (Williams and Torrens 1993). Yellow Fever killed 9000 people in New Orleans in 1853, 2500 in 1854 and 1855, and another 5000 in 1858 (Williams and Torrens 1993).

By 1900 , the epidemics of acute infectious disease were contained in this country, primarily because of major public health efforts. Improved environmental conditions were most responsible for this disease containment. During the later part of the nineteenth century, cities began improving their sanitation systems and water supplies. Milk and food processing were improved, as well. Agencies were formed to monitor urban living conditions. Public health departments began to grow in size and power, and by 1900 those epidemics that had plagued the country, and the world, for centuries were eliminated as major causes of death in this country (Starr 1982; Williams and Torrens 1988; Raffel and Raffel 1994). Table 1 shows the death rates for leading causes of death in this country for 1900 and ninety years later.

During the 1800 s, the power of the physician was greatly limited. Science had not yet been introduced into the art of medicine. The pharmaceutical industry was still years from developing antibiotics and other drugs which could be used to fight disease. However, after the turn of the century, the emphasis of medical care began to change. The health care system started to treat diseases that were either infectious 
TABLE 1

DEATH RATE FOR LEADING CAUSES OF DEATH

IN U.S., 1900 AND 1990

\begin{tabular}{lrlr}
\multicolumn{2}{c}{1900} & \multicolumn{2}{c}{1990} \\
\hline Causes of death & rate $^{1}$ & Causes of death & rate $^{l}$ \\
\hline \multicolumn{1}{c}{ All causes } & 1719.0 & All causes & 874.8 \\
Pneumonia & 202.2 & Heart Disease & 325.0 \\
Tuberculosis & 194.4 & Malignant neoplasms & 191.7 \\
Diarrhea, enteritis, \& & & Strokes & 64.0 \\
$\quad$ other intestinal & 142.7 & Accidents & 38.6 \\
Heart Disease & 137.4 & Chronic obstructive & \\
Senility & 117.5 & diseases & 31.2 \\
Intracranial lesions & 106.9 & Pneumonia \& influenza & 27.9 \\
Nephritis & 88.6 & Diabetes mellitus & 16.2 \\
All accidents & 72.3 & Suicide & 12.0 \\
Cancer \& tumors & 64.0 & Chronic liver disease & \\
Diphtheria & 40.3 & and cirrhosis & 11.2 \\
& & Atherosclerosis & 9.9
\end{tabular}

Source: Williams and Torrens 1993 from data in Vital Statistics of the United States, 1972 and 1991

1 - Crude death rate per 100,000 population per year

or traumatic (Starr 1982; Williams and Torrens 1988); diseases that infected individual patients. The significance of medical concern changed from epidemics that affected large numbers of people to conditions of a more personal nature. As Table I shows, individual infectious diseases such as pneumonia and tuberculosis were the primary causes of death in 1900, with heart disease, nephritis (kidney disease), and accidents not far behind (Williams and Torrens 1988; Williams and Torrens 1993). 
As medical practice became less preoccupied with large scale epidemics, medical science began developing better surgical techniques, new treatments for pneumonia and syphilis, and more accurate diagnostic tests. Hospitals experienced rapid growth, primarily as places to house the new medical technology (Califano 1989) and medical schools prospered (Starr 1982; Williams and Torrens 1988; Califano 1989).

Significant advances were made in the field of medical treatment in the early 1900s. Surgeons began operating on patients whose disease had previously been beyond the help of such treatment. Advances in obstetrics make it safer for women to have children. Insulin was discovered in 1922. And research on the causes of pernicious anemia led to a rush to find new treatments for other serious medical conditions (Williams and Torrens 1988).

By the late 1920s, new discoveries were being made in all areas of medicine. In 1928, for example, a Scottish researcher, Alexander Fleming produced the first mold culture that would eventually lead to the development of antibiotics. This discovery served to significantly alter the course of medical care and treatment. Within a few years, by the mid-1940s, antibiotics became available with which to treat patients suffering from acute infectious disease. Illnesses that had before been fatal now could be cured.

With the resulting conquest of disease with antibiotics, the predominant medical problems of Americans became chronic illnesses. With the effects of many acute illnesses diminished, Americans were living longer and beginning to manifest 
long-term chronic diseases (Williams and Torrens 1988). As shown in Table 1, page 19, shows, chronic diseases now comprise almost two-thirds of all deaths in the United States.

However, by the early 1980 s, the disease trends began to reverse. While treatable diseases such as bacterial pneumonia and cerebral meningitis could be successfully treated, the appearance of acquired immune deficiency syndrome (AIDS), viral hepatitis, and drug resistant tuberculosis surfaced in the U.S. in potentially epidemic proportions (Williams and Torrens 1988). AIDS, a viral caused immune system disease, is most likely predictive of the types of diseases that the American people will face in the future (Williams and Torrens 1988). However, while potentially fatal viral diseases will come to be a predominant health problem in the U.S., chronic conditions related to genetic makeup, personal lifestyle, and environmental hazards will continue to dominate the health care policy arena.

\section{Problems Facing the Health Care System}

Optimal care for long-term chronic illnesses poses a particular problem for the organization of the U.S. health care system. Health services in this country continues to be modeled on the disease patterns that were predominant in the period of 1900 1945. This health model concentrated on individual episodes of illness as if they were short-term in duration and non-continuous. The predominant medical model treats chronic illnesses as a series of separate acute episodes (Robins 1982; Starr 
1982; Williams and Torrens 1988; Raffel and Raffel 1994). This trend is reinforced by the present method of financing health care. With the exception of managed care, insurance reimburses with the emphasis on paying for individual medical services provided, rather than on long-term, continuous preventative care designed to affect the underlying disease process (Williams and Torrens 1988; Califano 1989; Williams and Torrens 1993).

However, the present reversal of disease processes -- from chronic, long-term to acute, potentially fatal diseases -- may serve to create a set of conditions that will require a different array of health services and treatments. Torrens (Williams and Torrens 1988) writes:

It will be important for future generations of health professionals to watch for changes in predominant disease patterns to ensure a health care system that is genuinely pertinent and responsive to the problems of the day.

\section{Periods of System Development and Change}

The U.S. health care delivery system has had four important periods of development and change. Torrens (Williams and Torrens 1988) outlines these periods as: 1) growth of hospitals as nexus of the health care system; 2), scientific methods are incorporated into the practice of medicine; 3 ) the growth of the health insurance industry; and 4) an era of limited resources and restrained growth. The U.S. health care system may now be entering a fifth period of development and change, a period 
of health care rationing. Table 2 displays these development periods.

The first developmental period began in the mid-nineteenth century, around 1885, when the first large hospitals began to flourish. Both Bellevue Hospital in New York City and Massachusetts General in Boston symbolized the institutionalization of health care for the first time in this country (Starr 1982; Williams and Torrens 1988).

TABLE 2

FOUR PHASES OF THE DEVELOPMENT OF THE U.S. HEALTH CARE SYSTEM

\begin{tabular}{lll}
\hline Phase & Date & \multicolumn{1}{c}{ Significance } \\
First & 1850 & Hospital nexus of health care system \\
Second & 1900 & Scientific method introduced to medicine \\
Third & 1945 & Major health insurance plans begins \\
Fourth & 1983 & Limited resources, restricted growth \\
\hline
\end{tabular}

Source: constructed from data in Starr (1982); Williams and Torrens (1988)

Before that time, health care was a loose collection of services functioning independently, without significant relationship to each other (Williams and Torrens 1988). By 1992's standards, these hospitals were not remarkable, however, they did provide the first distinct institution around which health care services could be organized (Starr 1982; Williams and Torrens 1988).

The second important historical period in the development of the U.S. health 
care system began around the turn of the century. Around 1900, the scientific method was introduced into the practice of medicine (Starr 1982). Before that time, medicine was not considered a science (Williams and Torrens 1988). After 1900, encouraged by the opening of a new medical school at the John Hopkins University in Baltimore, medicine acquired a more solid scientific foundation that eventually changed it from a dutiful but poorly equipped art into a detailed and more clearly defined science (Starr 1982; Williams and Torrens 1988).

The health care system entered the third stage of its transformation with the ending of World War II. In the early- to mid-1940s the United States was involved in a major social, political, and technological reformation. The effect of which would be to bring to a close the second period of development in the health care system, signaling the beginning of the third period of health care change (Williams and Torrens 1988).

By 1945 , the third period of the evolution of the health care system was beginning to develop. Paralleled by a growing attention to scientific advances, interest in the social and organizational structure of health care became grounded in policy. During this time, health care financing schemes and insurance plans were beginning to appear. The result was the Blue Cross and Blue Shield insurance plans (Starr 1982).

The 1940s, 1950s, and 1960s were also a time of increasing concentration of power in the federal government. As a result, the Hill-Burton Act (Hospital Survey and Construction Act) was implemented, huge research budgets of the National 
Institutes of Health (NIH) were approved, and, more recently, and probably most significantly, Medicaid and Medicare were passed in the mid-1960s. It was with the passage of these two government insurance programs that the principle of health care as a right, not as a privilege, was widely discussed and, in Torrens' view (1988), customarily accepted by the general population.

The 1980s marked the beginning of the fourth period of development of the U.S. health care system (Williams and Torrens 1988). The year 1983 marked the beginning of the era of limited resources, restricted growth, and reorganization of the methods of financing health care and its delivery (Eastaugh 1987; Williams and Torrens 1988; Williams and Torrens 1993). Before this period, the health care system had been encouraged to grow and expand (Eastaugh 1987), both in size and complexity. It had been felt that there would always be sufficient resources to support such growth. However, with the introduction of the Prospective Payment System (PPS) in 1983 -- the Federal government's Medicare capitated payment system - the period of unlimited growth was replaced with a period of limited resources. By the mid-1980s, the U.S. health care system was being forced to consider options or alternatives to unrestricted growth and expansion (Williams and Torrens 1993).

\section{The Period of Rationing}

Aggregate expenditures on health care continued to grow after the mid-1980s, despite the federal government's efforts to curtail them. In dollar volume, the U.S. 
health care industry is second only to the U.S. manufacturing sector (Williams and Torrens 1993). From 1980 to 1990, the percentage of gross national product (GNP) devoted to health care rose from 9.2 percent to $\mathbf{1 2 . 2}$ percent (Williams and Torrens 1993). Just four years later, the U.S. is projected to spend more than $\$ 1$ trillion (Zaldivar 1994) or roughly 15 percent of its GNP on health care (see Figure 1). Possibly these increases in health care spending may be forcing the health care system into a fifth phase of evolution, a period marked by explicit health care rationing.

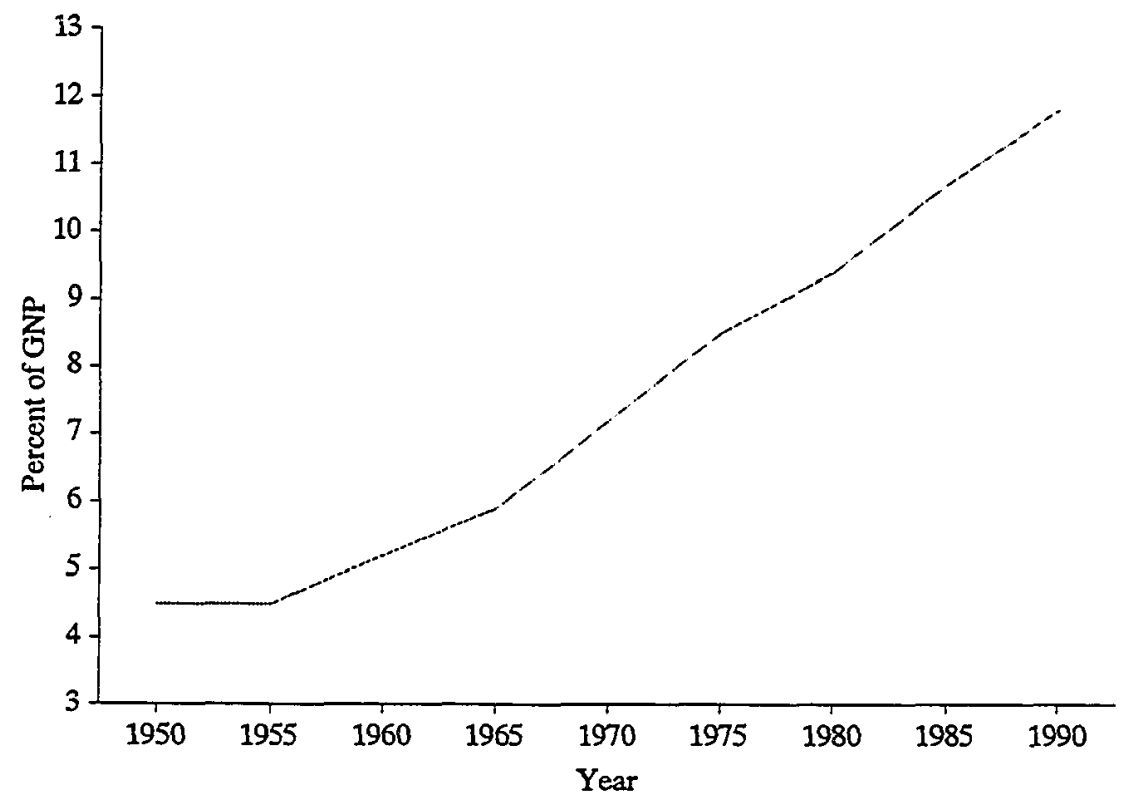

Figure 1. U.S. Health Care Expenditures as Percentage of Gross National Product (GNP), 1950 - 1990. Source: Zaldivar 1994. The Year 1990 is estimated.

Ironically, the fourth phase of health care system development has evolved amidst a projected excess capacity of hospital beds and a reported surplus of physicians. The effect of this development is an increase in the number of Americans 
without health insurance. As such, pressures for smaller sized health care facilities, less consumption of health care resources, and a reduction in health care expenditures are beginning to be felt in the structure of the U.S. health care system (Eastaugh 1987; Feldstein 1988; Williams and Torrens 1988; Califano 1989; Kitzhaber 1991a).

However, as the U.S. health care system moves out of its fourth period into a possible fifth phase of historical development -- one marked by health care rationing or universal health insurance-- it is witnessing the appearance of new types of health care organizational models. Most of these models are designed to inject some form of efficiency into the delivery of health care. The concept of the multi-hospital system approach to health care delivery, for example, has spread rapidly with a resulting myriad of hospital mergers (Eastaugh 1987; Williams and Torrens 1988). The health maintenance organization (HMO) model is now in all 50 states (InterStudy 1990). The term "joint venture" has become part of the health care vernacular, now used to describe new forms of partnership activities between hospitals and physicians (Williams and Torrens 1988). Torrens (1988) feels that almost no health care organizational model has been left untouched by the recent trends and changes in the health care system.

\section{Present Health Care System}

Despite major restructuring of the U.S. health care system, the federal government reports some alarming statistics. Despite record expenditures on health 
care, in 1994 between 31 and 38.9 million Americans are estimated not to have health insurance (Zaldivar 1994). This represents a 24 percent increase in the last decade in the total number of uninsured people in the United States, the biggest increase in five years (Zaldivar 1994). Among this figure lies a 40 percent increase in the number of uninsured children (Walden, Wilensky, and Kasper 1985; Short 1990; Cunningham and Monheit 1990).

Recent studies suggest that despite uncompensated care provided by hospitals and physicians, Americans without health insurance face barriers to the receipt of needed health services (Blendon and Edwards 1986; Hayward 1991). Blendon and Edwards (1991) show that the uninsured suffer from higher rates of illness than do the insured population, however, they report fewer hospitalizations and fewer visits to a physician, shorter hospital stays, and fewer discretionary inpatient hospital treatments and tests, at a higher cost. The uninsured also experience higher mortality rates when hospitalized than persons with health insurance coverage who have similar medical diagnoses (Freeman, Blendon, et. al 1983; Blendon, Freeman, et. al, 1986; Hadley, Steinberg, and Feder 1991; Blendon and Edwards 1991), and a 1993 study found that people without medical coverage had a 25 percent higher risk of shortened life spans (Zaldivar 1993a).

The problem may be worse than it appears. Lindberg (1991) suggests that access to even basic medical care for all U.S. citizens is not a reality. He suggests that the most significant reasons for this inability to access health care is long- 
standing, systematic, institutionalized racial discrimination (Lindberg 1991). Trevifio, Moyer, Valdez, and Stroup-Benham (1991) support Lindberg's (1991) contention that health care is mal-distributed, especially with regard to Blacks and Hispanics. Baker (1991) has shown a strong, positive correlation $(r=.89)$ between the percentage of a state's residents who are White, and the percentage of the state's residents who have health insurance. Not surprisingly, an almost inverse relationship exists between the percentage of a state's residents who are Black and the percentage of residents who do not have health insurance $(r=-0.72)$. These correlations, and others, are shown in Table 3, next page. Lindberg $(1991,2566)$ writes:

It is not a coincidence that the United States ... and the Republic of South Africa - the only two developed, industrialized countries that do not have a national health policy ensuring that all citizens have access to basic health care -- also are the only two such countries that have within their borders substantial numbers of under-served people who re different ethnically from the controlling group.

However, health care access is also made difficult for reasons other than racial or political discrimination. Hayward (1991) has shown that 17 percent of the U.S. population does not have a regular source of ambulatory health care. Bivariate comparisons of Hayward's sampling frame showed that those aged 13 to 44 were more likely than other age groups to lack a regular source of ambulatory care. Besides ethnicity, this study also found that not having a regular source of care was more common among the uninsured and those in excellent or good health (Hayward et al., 1991). As noted earlier, the American College of Physicians (1990) reports that an estimated one million Americans are refused access to health care each year 
because of an inability to pay. Clearly, health care is being rationed to some

TABLE 3

PEARSON PRODUCT MOMENT

CORRELATIONS WITH THE VARIABLE

HEALTH "HEALTH INSURANCE STATUS" -- PERCENT

OF A STATE'S POPULATION WITH HEALTH INSURANCE $(\mathrm{N}=50)$

1991

Variable

Percent of state population White

Percent of state population Black

Percent of state population completing high-school

Percent of state population Asian

Percent of state population Hispanic

Total state population

Percent of state population poor

Percent of state population unemployed
Correlation

0.89

$-0.72$

0.59

$-0.39$

$-0.36$

$-0.27$

$-0.25$

$-0.23$

Source: Baker 1991a, from 1989 data

segments of the U.S. society. To better understand this phenomenon, an overview of the concept of health care rationing is in order.

What is Health Care Rationing?

The condition of health and the state of being healthy are elusive concepts.

The World Health Organization (WHO) defines health as a state of "complete 
physical, mental, and social well-being and not merely the absence of disease" (Longest 1984,3$)$. Lindberg (1991) feels that no one is completely healthy on any day. As such, to attempt to cure one's mental, physical, and social health provides the potential for using medical resources essentially without limits. Since health care resources are limited by available supply, in Lindberg's $(1991,12)$ view, health care is "rationed every day." He calls this de facto rationing (Lindberg 1991).

Robert Baker (1992) believes that health care rationing is an emotionally charged term. He also believes that most scholars, especially those who believe in market force economics, define it in such a way that market allocations never ration anything, let alone health care (Baker 1992). He points out that there is an etymological rationale for this form of usage. The term ration is derived from the Latin, ration, which means to reason or to calculate. The literal English meaning of the noun ration is a share of something. He believes the term ration means, then, a calculated share. The verb form, however, is often more broadly defined as any process by which resources are allocated. The economic term rationing occurs when demand (or need) is not completely satisfied, that is, in the words of economics, any mechanism of allocation under conditions of scarcity (Baker 1992).

While health care is not scarce (if you have the money to pay for it), Lindberg (1990) delineates several methods by which the U.S. health care system does ration care. These methods are summarized in Table 4, page 33. Although these causes are all considered implicit rationing mechanisms, rarely in the U.S. is health care explicitly rationed in the form of a public policy process (Kitzhaber 1991a; Strosberg, 
Weiner, Baker, and Fein 1992). That is what makes the Oregon Health Plan (OHP) unique among other attempts at U.S. health care reform (Fox and Leichter 1993). Health care rationing exists because of the way health care is financed in the U.S. Friedman (1991) and others (Eastaugh 1987; Feldstein 1988) suggest that health care underwriting, experience rating of insurance policies, refusal to cover those deemed non-insurable, cancellation of policies on short notice, and high health care premiums are common barriers -- or rationing mechanisms - for those seeking access to health insurance, and health care. These practices serve to eliminate many of those citizens who are most likely to need coverage; those who are poor, sick, and/or unable to acquire insurance from their employer.

Robert Baker (1992) writes that health care rationing tends to be invisible to the patient. Neither uninsured patients who are unable to find a private physician, nor similar patients who are discharged earlier from a hospital, are in a position to perceive the mechanism that denies them access. Most uninsured or underinsured patients, he argues, may not even realize they have been denied access to care (Baker 1992).

Amid a system of substantial excess capacity to provide health care, what contributes to this concept of health care rationing? A major element is the reality that health care costs are rising and the attempt by health care organizations and government to do something about these costs. The Bureau of Labor Statistics reported that in 1993, for example, that national health care spending increased 11.1 
TABLE 4

METHODS OF HEALTH CARE RATIONING IN THE U.S.

Method

Economically

Sexually

Pricing

Insufficient

Resources

Situational

Supply

Practice Variations

Payment Policies

Social Class

Ignorance

Dialectly \&

Culturally

Training

Structurally

Administratively

\section{Definition}

By denying access to care, or to expensive treatments and technology, for those citizens without insurance, adequate insurance, or other means to pay for the care provided. By providing more care to male patients than is provided to female patients, and visa versa.

Control through pricing that does not discriminate between needed and effective medical care and unneeded or ineffective care.

Not providing sufficient resources for disease prevention, which results in unwanted teenage pregnancies, wide-spread initiation of tobacco addiction, and rampant sexually transmitted disease.

Insufficient transportation to appropriate facilities that affects rural and inner-city residents.

By absolute and relative shortages of technologies such as organs for transplantation, or lack of health care facilities in certain areas.

By major variations in practice patterns between geographic areas without outcome differences. Differing payment approval policies that function under widely varied rules and institutionalize such variations. By accepting social class membership as a determinant of whether patients can or cannot pay. Through ignorance about the availability and desirability of effective preventive and treatment services. By language and cultural barriers that exclude people of color or other cultures from appropriate access. By not training sufficient numbers of health professionals from minority backgrounds.

By training insufficient numbers of primary care physicians and excessive numbers of specialists.

Denial for services for administrative reasons.

Source: adapted from Lindberg 1991, 2566-2567 
percent to $\$ 940$ billion, or approximately 13 percent of the country's gross national product (GNP) (Davis 1991; Zaldivar 1993b; Zaldivar 1994), representing a 128 percent increase in spending over the past 10 years. Insurance premiums reflect those costs, leading to average increases in premiums of 18 percent in 1991, over the prior year of 1990 (Cerne 1990). The paradox of the 1990s is that as more and more money is being spent on health care, more and more people are finding themselves uninsured (See Table 5, below). It is to the reasons behind the high cost of health care that this dissertation now turns.

TABLE 5

NUMBERS OF AMERICANS UNINSURED AND U.S. HEALTH CARE SPENDING, 1989 to 1993

\begin{tabular}{ccc}
\hline Year & $\begin{array}{c}\text { Millions } \\
\text { of Americans } \\
\text { Uninsured }\end{array}$ & $\begin{array}{c}\text { Billions of } \\
\text { Dollars Spent } \\
\text { on Health Care }\end{array}$ \\
1993 & 39.9 & $\$ 940$ \\
1992 & 38.9 & 750 \\
1991 & 36.6 & 720 \\
1990 & 36.0 & 660 \\
1989 & 34.7 & 600 \\
\hline
\end{tabular}

Source: Anthony 1993; Zaldivar 1993b; Zaldivar 1994 (1992 dollar figures estimated); (1993 numbers of uninsured projected by author). 


\section{CHAPTER III}

\section{THE HIGH COST OF HEALTH CARE}

Since 1965 , health care costs have been increasing faster than the general rate of inflation (Feldstein 1988, 1992; Wright 1991). During the 1980s, the health care component of the Consumer Price Index (CPI) increased at an annual rate of 8.3 percent, compared to 5.5 percent for the overall CPI of all goods and services (Wright 1991). Medical inflation in 1993 was 5.4 percent, representing a 20 year low, but still twice as high as overall inflation (Zaldivar 1994). In Portland, Oregon, for example, the prices of some of the most commonly performed medical procedures have risen twice as fast as the general rate of inflation (O'Neill 1992). Health care costs are projected to rise throughout the 1990s, consuming 37 percent of the gross national product (GNP) by the year 2030 (Darman 1991) if the health system continues to function as it has for the past 20 years.

These annual increases reflect higher prices for medical services, plus an increased utilization of services (Feldstein 1988). Factors that contribute to these cost increases are: 1) increased elderly population; 2) more sophisticated medical technology; 3) specialization and labor intensiveness of health care delivery; 4) an absence of appropriate and less expensive alternatives to hospital care; 5) costly treatments for illnesses such as cancer and AIDS; 6) abuses of Medicare and 
Medicaid programs; 7) pharmaceutical cost increases; 8) health care needs by victims of crime, drugs, and accidents (Feldstein 1988; Wright 1991); and 9) health care fraud (Witkin et al., 1992).

Health care expenditures have continued to increase every year since such statistics were first complied. Health care expenditures averaged $\$ 3,160$ per capita in 1992 , of which 88 percent of that was for personal care, the remainder went to research, construction, program administration, the net cost of health insurance, and public health activities (Wright 1991; Clements 1993). The per capita expenditure for personal health care represents an increase of 10.6 percent over the prior year and was due, primarily, to economy-wide and industry-specific price inflation (Wright 1991).

The Organization for Economic Cooperation and Development (Wright 1991) reports that the U.S. spends more than any other developed nation on health care relative to its economy and boosts the worst health care performance statistics of any developed country in the World (Wright 1991). Our infant mortality, for example, is the worst of all other industrial countries.

This finding is not surprising. Health expenditures and health care effectiveness appear not to be synonymous. For example, there is a low statistical correlation $(r=0.13)$ between a country's gross national product (GNP) expended on health care and its infant mortality rate, one accepted measure of quality of a country's health care system. Only 1.7 percent of a nation's infant mortality rate can be explained by its total GNP expenditures on health care. See Table 6 and 7, next page. 
TABLE 6

\section{HEALTH CARE EXPENDITURES AS A PERCENTAGE OF GNP FOR SELECTED COUNTRIES, AND INFANT MORTALITY RATE ${ }^{1}$ 1989 DATA}

\begin{tabular}{lcc}
\hline Country & Pct. GNP & $\begin{array}{c}\text { Infant } \\
\text { Mortality }\end{array}$ \\
United States & $11.8 \%$ & $10.1 \%$ \\
Sweden & 8.8 & 5.7 \\
Canada & 8.7 & 7.3 \\
France & 8.3 & 7.8 \\
Germany & 7.8 & 8.2 \\
Australia & 7.0 & 8.7 \\
Japan & 6.7 & 5.0 \\
United Kingdom & 5.8 & 9.2 \\
\hline
\end{tabular}

1 - number of babies who died before one year of age per 1,000 live births.

Source: Cited in Wright 1991, from data reported by U.S. Department of Health and Human Services 1990/91; Organization for Economic Cooperation and Development 1991.

TABLE 7

SIMPLE REGRESSION ANALYSIS EXPLAINING VARIATION IN DEPENDENT VARIABLE: INFANT MORTALITY RATE, $(\mathrm{N}=8)$ 1989 DATA

Dependent Variable: Country's Infant Mortality Rate/100,000 population

Variable

Constant

Percent of GNP

spent on health care

$r^{2}=0.017$
Coefficient

6.84

0.128

ANOVA F-Ratio 0.154
Std. Coef.

$P(2$ Tail $)$

0.000

0.031

0.130

0.704 


\section{A State of Crisis}

At present, the American health care system appears to be in a state of crisis (Starr 1982; Califano 1989; Fein 1989; Kitzhaber 1991a; Karaim 1992). However, the crisis has been emerging since the late 1960s (Clements 1993). Although considered one of the best in the world, ${ }^{3}$ the way the U.S. provides and pays for medical care is an example of neither equity nor of efficiency (Feldstein 1988; Fein 1989). In response to this perceived crisis, inequity and inefficiency, social observers, political participants, and health care professionals (Fein 1989; Califano 1989; Kitzhaber 1991a; Karaim 1992; Associated Press 1992) believe that the U.S. health care system is failing and that it is in need of major change (Califano 1989; Sharp, Register, Leftwich 1990; Kitzhaber 1991a).

Major change, however, in segmented, mature institutions, such as those found in American medicine, does not typically occur without significant justification and overt resistance (Starr 1982; Kanter 1983). However, as annual health care costs rise (Wright 1991), the fundamental faults in the U.S. health care system become more evident (Fein 1989); the need for change more important. For example, while those citizens in the middle and upper socio-economic classes continue to receive, or

3 Sharp et al., $(1990,350)$ feel that the American health care system would probably be judged the " ... best in the world" if the sole criterion for judging a system is the amount of money spent to provide health care. However, if the system is judged with respect to efficient supply of services and in an equitable distribution of these services, the U.S. system would probably be rated last when compared with all other industrial countries, except South Africa (Kitzhaber 1991). 
can afford to purchase, health care benefits (thus, access to the health care system), those citizens in the lower socio-economic classes and below are seeing their health care benefits eliminated (Employee Benefit Research Institute 1989; Karaim 1992) and, plausibly; their access to the health care system made more difficult or denied. Further, a significant number of people with preexisting medical conditions, regardless of their socio-economic stature, are being denied health care insurance altogether (Borderline Medicine 1991; Associated Press 1992).

\section{Changing the U.S. Health Care System}

The major assumption for changing the U.S. health care system is that the present system fails to provide equity of services to all citizens in the U.S. A minor justification is that the system is efficient in its delivery (Kitzhaber 1991a). The problems associated with this inequity and inefficiency have not gone unnoticed by the major political actors. In 1992, an election year, all major presidential candidates proposed methods to deliver some form of national health insurance or health care expansion program (Associated Press 1992; Karaim 1992). All five Democratic primary candidates supported programs to guarantee health care access for every American and, as well, former President Bush proposed an expansion program consisting of insurance reform and tax incentives (Karaim 1992).

Some political candidates favored a major system change to a Canadian-like health care model; others preferred a "play or pay" system whereby employers either 
purchase private insurance programs for their employees or they are required to participate in a government run scheme (Karaim 1992). Presidential candidate Bill Clinton proposed a universal health insurance system that drove down costs, got tough with insurance and drug companies, and put greater emphasis on prevention and research (Clements 1993).

In 1993, First Lady Hillary Clinton chaired a health care task force as part of the Clinton Administration's health care reform proposal. That proposal, called the Health Security Plan, was announced in September 1993 (Ota 1993; Clinton 1994). However, critics of the Clinton Administration's proposed health care plan, as well as other plans recently accounted, feel that implementation would turn the American system into a "giant version" of the Veterans Administration, "... underfunded, undersupplied, and understaffed" (Karaim 1992, A11). The National Committee for Quality Health Care (an industry group), however, believes that the time has come to ration health care so that costs can be contained (Karaim 1992) and health care access expanded. The State of Oregon appears to have set the stage for such a move.

\section{The Oregon Health Plan}

Public policy development is typically a corrective reaction to a perceived public problem (Stokey and Zeckhauser 1978; Brown 1987). Stokey and Zeckhauser (1978) argue that the purpose of public decisions is to promote the welfare of society. They believe that which affects individual welfare affects the welfare of society 
(Stokey and Zeckhauser 1978). The State of Oregon perceives such a public problem in the form of medically uninsured residents (Kitzhaber 1991a).

Former Oregon Senate President John Kitzhaber, ${ }^{4}$ a physician and author of the Oregon Health Plan (1991a), believes that uninsured Oregonians are being denied access to health care. However, while Kitzhaber believes that access to health care must be expanded to all Oregonians, he, like other health policy observers (Callahan 1987; Lamm 1989; Califano 1991), recognizes that health care limits must be realized (Kitzhaber 1991a). Kitzhaber cites the Massachusetts example of legislating a form of universal health insurance to its citizens. After one year of operation, the Massachusetts health insurance was running a $\$ 1$ billion deficit. Rhetorically, Kitzhaber asks what would happen if the U.S. developed a $\$ 1$ million dollar pill that cured cancer, could we, or would we, make that pill available to every citizen in the U.S. at an estimated cost of $\$ 49.4$ trillion, roughly 8 times the present U.S. health care budget. He feels that the cancer pill would be rationed to a small number of U.S. citizens who would benefit most from its effects or made available to those citizens who could afford to purchase it.

Former Senator Kitzhaber (1991a) and others (Lamm 1989; Califano 1989;

4 John Kitzhaber, an emergency physician, did not seek another senate term in 1993. Instead, he announced his candidacy for governor and began actively campaigning for the position in 1994. During his election campaign he continues to be active in the health policy arena, appearing before an Oregon Legislative subcommittee in July 1993 to testify on behalf of The Oregon Health Plan. On July 29,1993 , he published an editorial commentary on the future of the Oregon Health Plan (see Kitzhaber, John A., "Oregon's future now in hands of committee," The Oregonian, July 29, 1993, p.F7). 
Sipes-Metzler 1992; Califano 1991) believe that citizens should be provided a right to a basic level of health care, however they do not have a right to, in Kitzhaber's words, a premier level of "cadillac" health care coverage (Kitzhaber 1991a) as is now afforded to many citizens with health insurance or other means to pay.

The latter type of care is typically determined by the physicians, hospitals, and other suppliers of health care, in concert with the patient's demands, without regard to cost or effectiveness. Basic health care, on the other hand, is defined by Kitzhaber (1991a) as medical care that is known to "work," care that is cost effective (citing prenatal care and antibiotic treatments for bacterial infections as examples), and care that provides the greatest good for the greatest number of citizens (Kitzhaber 1991a). Kitzhaber (1991a) feels that it is unthinkable for society to condone transplants for one, while denying prenatal care for one-thousand, as is now done in State Medicaid programs and insurance schemes throughout the U.S.

Kitzhaber (1991a) believes that our health care system can eliminate highcost/high-tech medicine, such as expensive chemotherapy or organ transplants, when their use provides little or no benefit to the patient. Savings associated with this type of rationing can be redistributed to other patients for basic health care shown to be effective. In essence, Kitzhaber has proposed that Oregon begin rationing health care to one segment of the citizenry, redistribute funds associated with that rationing, and provide basic health care to all citizens who do not now have health insurance (Kitzhaber 1991b; Kitzhaber, Baker, Hanville 1991).

Kitzhaber's solution to the health care crisis, at least in Oregon, is the Oregon 
Basic Health Services Act (OBHSA), also called the Oregon Health Plan (OHP) (Kitzhaber 1991b). The OHP is a program of five Senate Bills that, in essence, legalizes explicit health care rationing in the state Medicaid program. Senate Bill 27 (SB 27), the center-piece of the Act, mandates that the State provide a basic level of health care to all citizens with incomes at or below the federal poverty level (FPL) (State of Oregon 1989a). Conversely, Senate Bill 935 mandates that employers provide the same basic level of health care to their employees (State of Oregon 1989b). Senate Bill 534 creates state subsidized risk pools designed to provide the same basic level of care to residents who are unable to obtain health insurance due to preexisting illness (State of Oregon 1989c).

Kitzhaber feels the key to the Oregon Health Plan (OHP) is in the provision of "basic" health care. The OHP represents a significant change in the way health care is financed in this state and, for that matter, in this country. Never before has a U.S. governmental body institutionalized the concept of explicit health care rationing, in the form of an explicit definition of a "basic" level of care, into the health care delivery process by way of public policy (Higgins 1989; Coile 1990; Kitzhaber 1991a).

While other countries have informally adopted the concept of rationing into their health care systems, this form of rationing is considered implicit or silent rationing, rather than explicit or specific rationing (Hughes 1991). Implicit rationing is typically expressed by the government's planned limitation of medical technology, or by the forced placement of patients in paper queues, waiting lists that require 
patients to wait for medical services (Brown 1987). These forms of rationing are considered implicit because they are not openly discussed or debated, nor are they written into public policy. These implicit rationing attempts are used to provide equity in the delivery of health care or to attempt to control costs of health care by controlling high cost/high tech medicine (Califano 1989; Coile 1990; Hughes 1991). Until Oregon passed its OBHSA in 1989, no political entity in the U.S. had sought to explicitly ration health care to any portion of its citizenry (Kitzhaber 1991a; Coile 1990). A review of the literature shows that Oregon was the first state in the Union to address the topic of explicit rationing in an open and prescribed manner (Kitzhaber 1991a), and the first to make it a part of public policy. Oregon may provide a model with which to expand health care to these individuals without significantly increasing health care costs (Kitzhaber 1991a; 1991b).

\section{Physician Resistance to Health Care Change}

Providing a conceptual model for health care reform and providing a working model of health care reform are not necessarily the same thing. New models of reform of any kind are often met with resistance. Physicians have long resisted major changes in the U.S. health care system (Starr 1982). That resistance continues today.

A growing body of literature supports the theory that physicians will not support major changes in the U.S. health care system. In Connecticut, for example, physicians, along with lobbyists from the hospital industry, forced Connecticut policy 
makers to repeal the State's 3-year old prospective payment system (Health Poll 1989). That system, which placed ceilings on fees charged to the state's Medicaid program, was replaced with a system that allows physicians and hospitals to set their own rates, within predetermined ranges (Page 1989). In Michigan, physicians sued Blue Cross/Blue Shield because they contended a proposed managed care pilot program (designed to compete against the 10 physicians) that would unlawfully interfere with the physician-patient relationship (Kertesz 1988). And in California, in 1989 , just after Oregon enacted its health plan, physician groups and health care advocates succeeded in blocking an Alamedia County program designed to ration health care to Alamedia County's uninsured population (Higgins 1989).

Besides documented long-term opposition to national health insurance (Starr 1982; Williams and Torrens 1988), there is other evidence of resistance to change for even basic health care expansion programs. For example, New York's physicians are resisting the $U N Y^{*}$ Care program which seeks to guarantee a basic package of health care to all New York citizens (Page 1989). The Medical Society of the State of New York and some legislators have raised concerns about the radical nature of the proposed changes to the health care system (Page 1989). The American Medical Association objected to the New York plan on cost and mandatory assignment issues (Page 1989).

Despite this long standing opposition to health care reform, there is some evidence that physicians may now accept some change in the U.S. health care system. Probably the greatest evidence of that was a recent editorial in The New England 
Journal of Medicine (January 12, 1989) which called for the federal government to enact a program of national health insurance to close the gaps that leave 35 million Americans with no health insurance. The Journal also published two proposals, one from the Harvard based Physicians for a National Health Program and one from Stanford University economist Alvin Enthoven. The Editor of the Journal, Arnold S. Relman, stated that " $\ldots$ it is time for our profession to make common cause with government and with the major private payers in seeking solutions to a pressing social problem that is not going to solve itself" (Relman 1989, vi). Relman said that this is the first time he, or any major medical journal, has called for national health insurance.

However, despite recent evidence that physicians may be ready to support change in the health care system (and the health care financial system), before any successful attempts at health care reform can be ensured, support from physician groups must be secured. Physicians control an estimated 80 percent of hospital resource utilization and direct the majority of health care expenditures in this country (Coile 1990). They function as the nexus between the health care system and the patient. Coile (1990) believes that hospitals and other health care organizations are retreating from marketing health services on the retail model because physicians still control patients and drive the health care delivery system. As such, all reforms to be made in the health care industry will involve changing physician behavior. As Coile 
(1990, p.xiii) forewarns:

Physicians occupy the high ground at the mouth of the channel, and any alternations of the U.S. health system must take this into account.

Without developing a critical mass of support from physicians, the implementation of any public health policy program, whether health care rationing or national health insurance, cannot be guaranteed or predicted. It is that measure of support this dissertation now addresses. 


\section{CHAPTER IV \\ NEED FOR THE OREGON HEALTH PLAN}

There is little disagreement that a large number of Oregon residents have no health insurance (Strosberg, Weiner, Baker, and Fein 1992; Baker 1994). According to the State of Oregon (Summry of the Oregon Basic Health Services Act 1989 1991), 400,000 Oregonians are not insured. The Employee Benefit Research Institute (1989) estimates that as many as 478,000 Oregonians may actually be without health insurance. Of those 400,000-plus residents who are uninsured, 70 percent are working full- or part-time (or are dependents of someone who is working), a third are under the age of 17 , and a majority, roughly 60 percent, are women and children (Summary of the Oregon Basic Health Services Act 1989 1991; Employee Benefit Research Institute 1989).

Baker (1994) reported in a study of 1,001 Oregonians responding to an Oregon Health Services Commission (HSC) survey that just under 13 percent of the state's households are uninsured. He found that 12.8 percent of the respondents surveyed revealed that no one in their household had health insurance. Of the 88 percent of the households reporting that they or someone in their household had health insurance, another $\mathbf{1 1 . 6}$ percent reported that some household members were, in fact, uninsured. This finding suggests that closer to 20 percent of the state's population may actually 
have no health insurance, intimating a greater problem with uninsured residents than the State realizes. The actual number of Oregon uninsured may be closer to 600,000 residents (Baker 1994). Table 8 shows his (Baker 1994) findings.

However, Baker (1994) and Taylor (1986) argue that the lack of insurance does not necessarily mean a person is having trouble accessing (or being denied access to) the health care system. Policy makers and social psychologists (Taylor 1986; Califano 1989; Kitzhaber 1991a) have pointed out that often the uninsured seek care in hospital emergency departments or public clinics. While care is sometimes delayed, it is still received. Yet, research by Baker (1994), the Oregon Health

\section{TABLE 8}

\section{OREGON SURVEY RESPONDENTS TO HEALTH SERVICES COMMISSION STRATIFIED RANDOM SAMPLE SURVEY OF 1,001 OREGONIANS 1990}

\section{Respondents}

With Health Insurance

No Health Insurance

Of All Households Insured:

All Members Insured

Some Not Insured

Of those Households With

Some Members Not Insured:

One Member Not Insured

Two Members Not Insured

More Than Two Not Insured

\section{Percent}

$87.0 \%$

12.8

$88.4 \%$

11.6

67.3

14.8

17.8
Number

868

128

767

101

Source: Baker 1994, from 1990 Oregon Health Services Commission data 
Services Commission (HSC) (1990), and others (Taylor 1986; Clements 1993;

Williams and Torrens 1993) have shown that the uninsured often fail to see a physician (or delay seeing one) when they should because of barriers to health care access. In 1972, Herman first reported that the lower social classes use medical services less than do the upper classes (Taylor 1986). And while several reasons are given for this under use, the primary reason, Herman and others (Clements 1993; Baker 1994) feel, is related to finances. Baker (1994) has found this to be true in Oregon. According to his work, many residents are not seeking care when they should because of an inability to pay for it (Baker 1994).

Baker's (1994) analysis of the Oregon Health Services Commission data suggests that almost a quarter of Oregonians are not seeking care from a physician when they believe they should be seeking care. In response to the HSC survey question, "During the past 12 months, was there anytime when you or someone in

\section{TABLE 9}

RESPONSES TO THE QUESTION "DURING THE PAST 12 MONTHS, WAS THERE ANY TIME WHEN YOU OR SOMEONE IN YOUR HOUSEHOLD SHOULD HAVE SEEN A PHYSICIAN BUT FOR SOME REASON DID NOT?" ( $=993)$ 1992

\begin{tabular}{lcr}
\hline & $P c t$. & $N$ \\
No & $75.1 \%$ & 753 \\
Yes & 24.1 & 241 \\
Didn't Answer & 0.8 & 8 \\
Total & $100.0 \%$ & 1001 \\
\hline
\end{tabular}

Source: Baker 1994, from 1990 Oregon Health Services Commission data 
your family should have seen a physician but for some reason did not, " just over 24 percent of the survey respondents answered Yes to this question. Seventy-five percent answered No, and 0.8 percent did not answer the question at all. This finding is reported in Table 9, previous page.

Baker (1994) found that females were significantly more likely to report that during the past 12 months they or someone in their household did not see a physician when they should have seen one. While 21.4 percent of the male respondents reported they or someone in their family did not see a physician when they should have, 26.1 percent of the females reported that they or someone in their family did not see a physician when they should have seen one. Table 10 shows this finding.

\section{TABLE 10}

PERCENTAGE OF RESPONDENTS, BY GENDER, ANSWERING THE QUESTION "DURING THE PAST 12 MONTHS, WAS THERE ANY TIME WHEN YOU OR SOMEONE IN YOUR HOUSEHOLD SHOULD HAVE SEEN A PHYSICIAN BUT FOR SOME REASON DID NOT" $(\mathrm{N}=993)$ 1992

\begin{tabular}{lll}
\hline & \multicolumn{1}{c}{ Male } & Female \\
No & $78.6 \%$ & $73.9 \%$ \\
Yes & 21.4 & 26.1 \\
Total Pct. & 100.00 & 100.00 \\
$\mathrm{~N}$ & 388 & 605 \\
$\mathrm{X}^{2}=2.870$ & $\mathrm{P}=0.090$ & Df $=1$ \\
\hline Source: Baker 1994, from 1990 Oregon Health Services Commission data
\end{tabular}


Baker's (1994) analysis of the HSC data also showed that Medicaid recipients were significantly more likely to report that during the past 12 months they or someone in their family did not see a physician when they should have see one. He found that while 32.9 percent of Medicaid respondents reported not seeing a physician, only 23.4 percent of non-Medicaid respondents reported not seeing one. This finding is displayed in Table 11 .

TABLE 11

PERCENTAGE OF RESPONDENTS, BY MEDICAID STATUS, ANSWERING THE

QUESTION "DURING THE PAST 12 MONTHS, WAS THERE ANY TIME WHEN YOU OR SOMEONE IN YOUR HOUSEHOLD SHOULD HAVE SEEN A PHYSICIAN BUT FOR SOME REASON DID NOT" $(\mathrm{N}=993)$ 1992

\begin{tabular}{lcc}
\hline & Non-Medicaid & \\
& & \\
No & $76.6 \%$ & $67.1 \%$ \\
Yes & 23.4 & 32.9 \\
Total Pct. & 100.00 & 100.00 \\
$\mathrm{~N}$ & 911 & 79 \\
$\mathrm{X}^{2}=3.606$ & $\mathrm{P}=0.05$ & \\
& & \\
Source: Baker 1994, from 1990 Oregon Health Services Commission data
\end{tabular}


The HSC data also showed that even among families with health insurance, almost a quarter (22.4 percent) of them reported not seeing a physician when they should have. However, almost twice the percentage of respondents from households where none of the members had health insurance reported they or someone in their household did not see a physician during the past 12 months when they should have seen one. His analysis of Oregon Health Services Commission data showed that just over 38 percent of the non-insured respondents reported that they or someone in their family did not see a physician when they should have, while 22.4 percent of the insured did not see a physician when they should have seen one. Table 12 shows these findings.

\section{TABLE 12}

PERCENTAGE OF RESPONDENTS, BY HEALTH INSURANCE STATUS, ANSWERING THE QUESTION "DURING THE PAST 12 MONTHS, WAS THERE ANY TIME WHEN YOU OR SOMEONE IN YOUR HOUSEHOLD SHOULD HAVE SEEN A PHYSICIAN BUT FOR SOME REASON DID NOT" $\quad(\mathrm{N}=993)$ 1992

\begin{tabular}{lcc}
\hline & \multicolumn{2}{c}{ Families with: } \\
\cline { 2 - 3 } & No Hlth. Ins. & Health Ins. \\
No & $61.9 \%$ & $77.6 \%$ \\
Yes & 38.1 & 22.4 \\
Total Pct. & 100.00 & 100.00 \\
$\mathrm{~N}$ & 126 & 862 \\
$\mathrm{X}^{2}=14.703$ & $\mathrm{P}<0.001$ & Df $=1$ \\
\hline Source: Baker 1994, from 1990 Oregon Health Services Commission data
\end{tabular}

Source: Baker 1994, from 1990 Oregon Health Services Commission data 
The HSC data (Baker 1994) shows an almost equal proportion of Caucasian and non-Caucasian respondents reporting that they did not see a physician when they should have..$^{5}$ Race appears not to be a significant factor in explaining why individuals do not seek care when they should. Baker (1994) showed that 24.2 percent of Caucasians responding to the HSC survey did not see a physician when they should have, while 26.7 percent of the non-Caucasian respondents reported not seeing a physician.

Part of the Oregon Health Plan (OHP) (specifically, Senate Bill 27) was enacted to respond to the needs of low income individuals without insurance (Summary of the Oregon Basic Health Services Act 1989, 1989). Before the OHP, Medicaid was not available to Oregon residents who were single individuals, two parent families, or single parents with incomes over 58 percent of the federal poverty level (FPL) (Summary of the Oregon Basic Health Services Act 1989, 1989). Baker (1994) has found individual respondents in households with incomes below the FPL (the official poverty level figure in effect when this survey was taken was the 1989 FPL) were significantly more likely to report that they or someone in their household did not see a physician when they should have seen one. The proportional differences were quite large between these two groups. While 21.5 percent of those respondents with household incomes above the FPL reported they did not see a physician when

5 Baker (1994) was not able to test for significant differences between the minority categories because of the limited number of minority respondents. Thus, he grouped all of the respondents into the two categories of Caucasian and non-Caucasian discussed above. 
they should have, more than twice as many of the officially poor households reported not seeing a physician.

Baker (1994) showed that 49.5 percent of those respondents with household incomes below the FPL reported that they did not see a physician when they should have. This compared to 21.5 percent of those respondents with household incomes above the FPL reporting not seeing a physician. These findings probably illustrate most greatly the need for health care reform. Clearly the state's poor are experiencing the most difficulty accessing the health care system. Table 13 shows Baker's (1994) analysis.

TABLE 13

PERCENTAGE OF RESPONDENTS, BY FEDERAL POVERTY LEVEL STATUS, ANSWERING THE QUESTION "DURING THE PAST 12 MONTHS, WAS THERE ANY TIME WHEN YOU OR SOMEONE IN YOUR HOUSEHOLD SHOULD HAVE SEEN A PHYSICIAN BUT FOR SOME REASON DID NOT" ${ }^{\prime \prime}(\mathrm{N}=993)$ 1992

\begin{tabular}{lcc}
\hline & \multicolumn{2}{c}{ Family Incomes } \\
\cline { 2 - 3 } & At or Below FPL & Above FPL \\
No & $50.6 \%$ & $78.1 \%$ \\
Yes & 49.4 & 21.5 \\
Total Pct. & 100.00 & 100.00 \\
$\mathrm{~N}$ & 91 & 873 \\
$\mathrm{X}^{2}=33.886$ & $\mathrm{P}<0.001$ & Df $=1$ \\
\hline Source: Balter 1994, from 1990 Oregon Heaith Services Commission data
\end{tabular}

Source: Baler 1994, from 1990 Oregon Health Services Commission data 


\section{Health Care Access Barriers}

Clearly, the available data suggest a need for health care reform in Oregon. Baker's 1994 analysis of Oregon Health Services Commission (HSC) data suggests that despite only 13 percent of the state's population with no health insurance, almost 25 percent of the population did not see a physician during the past 12 months when they should have seen one. This finding suggests that real or perceived barriers to health care access may be present.

In an analysis of the HSC data (Baker 1994), it was found that the primary health care access barrier was related to finances. This supports Kitzhaber's (1991a) view that Oregon residents are not seeking care because of an inability to pay for it. Baker (1994) showed that of the Oregon residents responding to the HSC survey, 39.3 percent of the respondents reporting that they did not see a physician because they had no money, couldn't afford treatment, or they were in too much debt.

Motivational factors were the second reason most often given, with 27.2 percent of the respondents not seeing a physician because they had no time, couldn't get time off from work, were lazy, or they had no transportation. Just over 20 percent of the respondents did not see a physician because of attitudinal factors such as being stubborn, didn't like the doctor, they feared the worst, thought the problem would get better, or that the doctor couldn't help. Interestingly, a factor related to health insurance was the last reason given for not seeing a physician, with 13 percent of the respondents reporting this as the primary reason. See Table 11, next page. 
While a lack of health insurance was not given as the primary reason for not seeing a physician, Baker (1994) did find it to be a significant secondary reason among those respondents who reported a primary reason related to finances. Just under 40 percent of the respondents who indicated a primary reason for not seeing a physician, also indicated a secondary reason. Over half of the respondents, 56.8 percent, indicated finances or no health insurance coverage as the secondary reason for not seeing a physician when they should have. See Table 14 , below.

TABLE 14

PRIMARY REASONS OREGON
RESPONDENTS REPORTING WHY THEY DID
NOT SEE A PHYSICIAN DURING THE PAST TWELVE
MONTHS WHEN THEY SHOULD HAVE $(\mathbf{N}=239)$
1992

Reasons Given $N$ Pct.

Financial 94 Motivational 65 $39.3 \%$

Attitudinal

Health Insurance

31

Total 239 $100.0 \%$

Attitudinal Reasons: Stubborn; didn't like the doctor; feared the worst; thought problem would get better; felt the doctor couldn't help.

Health Insurance:: The respondent didn't have health insurance; or health insurance wouldn't cover the office visit.

Financial Reasons: no money; couldn't afford treatment; too much debt. Motivational Reasons: Lazy; didn't get around to it; no transportation; out of time; and couldn't get an appointment. 
Baker (1994) also showed that among those respondents indicating financial factors as the primary reason for not seeing a physician, 80.0 percent indicated a health insurance related reason as the secondary barrier to health care access. Likewise, among those respondents who reported no health insurance coverage as their primary reason for not seeing a physician, 65.9 percent indicated financial reasons as a secondary barrier for not seeking care. Baker (1994) found these differences to be highly significant.

Need for The Oregon Health Plan

Clearly, a significant problem of health care access exists within the State of Oregon. Research has shown that a large number of Oregon residents have no health insurance and more are not seeing a physician when they should because of financial reasons (Baker 1994). However, a primary question remains: while the Oregon Health Plan is designed to increase access to the health care system for individuals presently without health insurance, will Oregon primary care physicians accept this innovative, yet experimental method of health care reform?

While studies show perhaps 20 percent of the state's population are uninsured (Baker 1994), the State appears to be moving ahead with its plan to expand health care access to these residents by way of the Oregon Health Plan (OHP). However, no corollary study has been undertaken to see if support for such health care rationing policies exists within Oregon's medical community. In order to fully enact the 
Oregon Health Plan, support from Oregon primary care physicians will have to be garnered. Failure to gain this support could cause the OHP to be partially implemented, at best.

Alternately, while the need for health care reform is evident within the state, national figures are discussing the creation of a national health insurance (NHI) plan as a way to expand health care access to all citizens. If it works, NHI appears to eliminate the need to explicitly ration health care. If support for NHI is found among Oregon's primary care physicians, perhaps the State is taking the wrong road toward health care reform.

The review of the literature and prior work by the author of this dissertation leaves two primary care questions unanswered: one, will Oregon primary care physicians support programs that ration health care (such as the Oregon Health Plan); and two, will Oregon primary care physicians support a national model of health care reform, national health insurance. The next chapter sets up a conceptual frame work from which these two important questions can be analyzed. 


\section{CHAPTER V}

\section{CHANGE AND THE U.S. HEALTH CARE SYSTEM: A CONCEPTUAL MODEL AND RELATED RESEARCH LITERATURE}

The presence of change is recognized today as one of the true constants in any system or organization (Kotter 1978; Knudson et al. 1979; Deming 1986). Few, if any, systems in our society have remained stable over the last 30 years (Deming 1986). For most of society, technological changes, social changes, and changes in governmental regulations have affected most organizations bringing about the need for rapid and sometimes unwelcome change (Knudson et al. 1979; Deming 1986). The health care system is no exception.

While the U.S. health care system is considered one of the best in the world (Sharp et al. 1990), the system came under great pressure to change in the mid-1980s. The advent of prospective payment systems such as that implemented by the federal Medicare program (which set fix rates for medical diagnoses) forced health care organizations to change the way they treated their patients. Financial pressures on state budgets forced Medicaid programs to eliminate individuals from receiving care under these programs. Health maintenance organizations forced fee-for-service hospitals to begin developing managed care affiliations. However, despite this rapid change that began to occur in the mid- to late-1980s, many social observers (Fein 
1989; Califano 1989; Kitzhaber 1991; Karaim 1992; Clements 1993; Clinton 1994; Iglehart and Reinhardt 1994) now believe the U.S. health care system is on the verge of failure and that it is in need of other major change (Califano 1989; Sharp, Register, Leftwich 1990; Kitzhaber 1991a).

Major change, however, in segmented, mature institutions such as those found in American medicine -- the gatekeepers to the U.S. health care system - typically does not occur without significant justification and overt resistance (Knudson, Woodworth, and Bell 1979; Deming 1986; Starr 1982; Kanter 1983). If change in the health care system is to occur, it must be supported by the primary suppliers of health care, the system's physicians and, to a lesser degree, the other health care providers, administrators, and financing organizations who support the medical component of the system.

Medical care, which is the output of the overall medical care market, is in reality the outcome of several interrelated components: supply for registered nurses, hospital services, and physician services. However, three types of general markets have been identified in the medical care sector:

1. Patient's demand for institutional settings

2. Patient's demand for types of manpower and factor markets

3. Patient's demand for educational markets

Regardless of direct patient demand, the indirect or latent demand for medical services is moderated, or brokered, by the physicians acting as a decision maker (Feldstein 1988). It's the beliefs of the physician that effects all three of these 
markets, and thus must be assured for the successful attempt at system change.

The patient's demand for medical treatment is expressed by going to a physician whose determination of how to treat the patient is based on both economic and non-economic factors. The physician's selection of one or more of these institutional settings -- hospitals, outpatient facilities, nursing homes, physician's offices, and such - is based on the relative prices of each of these settings, the relative cost of each to the physician, and the efficacy of each treatment. The demand for institutional care will depend on the patient's demand, physician consideration, and the relative price and efficacy of treatment in the different institutional settings (Feldstein 1988).

From this scenario it could be argued that the physician represents the primary driving force behind the annual increases in health care costs. Thus, to change the U.S. health care system means to change physician behavior. As primary suppliers of health care, and indirect demanders of high-cost secondary care, physicians serve as either supporting forces or restraining forces to any attempt to change the health care system (Davis and Newstrom 1985; Beckhart and Harris 1987).

Lewin's Force Field Model: An Analysis of Change

This research effort seeks to measure support from the state's primary care physicians for health care reform. As discussed in earlier chapters, reform is defined as either the Oregon Health Plan (OHP) or one of the federal universal health 
insurance plans presently being proposed in Washington, D.C. (Clinton 1994; Iglehart and Reinhardt 1994) (referred to in this work as "national health insurance").

Theoretically, the hypotheses advanced by this study (see Chapter 6 for a discussion of the hypotheses) are grounded in health policy. However, the impetus for the measurement of any supporting forces for changing the state's health care system is taken from the framework of organizational change theory.

In 1947, Kurt Lewin (Knudson et al. 1979), a social psychologist, developed a change model that allows public policies and structural change proposals to be examined, conceptually. That model is appropriate for an analysis of health care policies at both the state and the national level. Lewin (Knudson, Woodworth, Bell 1979) sees change not as an event, but as a dynamic balance of forces. His Force Field Analysis model considers this balance of forces working in opposite directions in a given context.

Lewin's model, shown in Figure 2, suggests that any situation can be considered in a state of equilibrium resulting from a balance of forces constantly pushing against each other. Lewin (Knudson et al. 1979) argues that certain forces in a situation tend to keep the situation static. These forces are called restraining or opposing forces. Acting opposite these forces, pushing for change, are certain driving or supporting forces. Lewin (1947) believes the combined effect of these two sets of forces results in the current situation and the model allows for an analysis of the degree of support or non-support for a given change situation.

Knudson, et al. (1979) have shown that supporting and opposing 


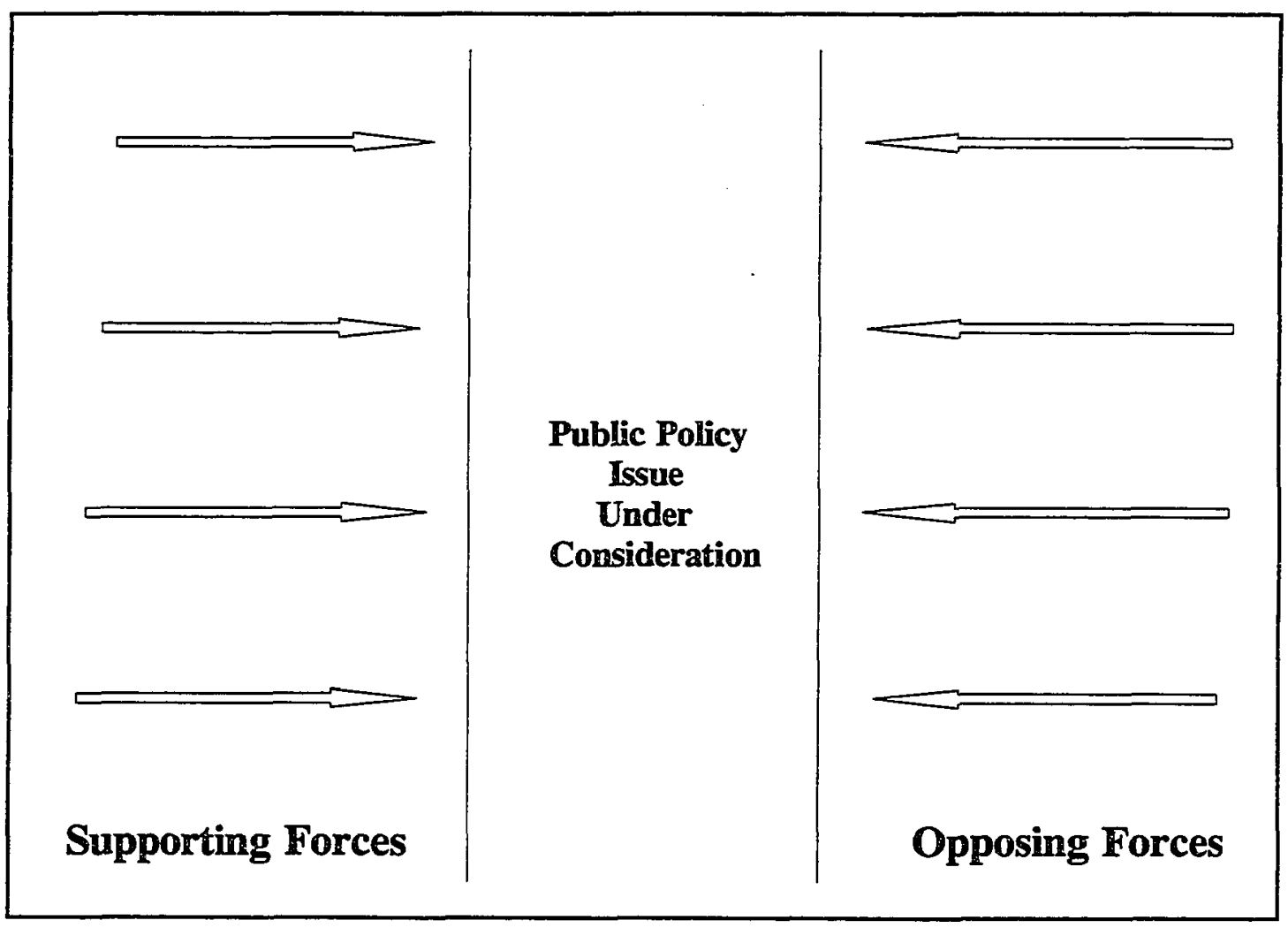

Figure 2. Lewin's Force Field Conceptual Model of Supporting and Opposing Forces for Change in a Public Policy. Source: Knudson, Woodworth, and Bell 1979, 214.

forces originate from several sources. These forces can generally be placed in the following categories:
1) Technological forces
2) Organizational forces
3) External forces
4) Individual forces

These four forces are found as both supporting and restraining forces, depending on 
the situation within which they are found. For instance, the advent of new technology may be resisted by some members of an organization, it may be supported by other members. The personal computer is an excellent example. In the health care system, health policies that attempt to restrict the use of revenue generating technology would most probably be resisted by physicians wanting to use (or are presently using) that technology. A magnetic resonance imager (MIR) is an example of such a technology. Technological forces arise because of the impact of technology on the system as a whole. The technological nature of the U.S. health care system, for example, has changed significantly since the mid-1940s and more rapidly since tise mid-1970s, with the introduction of more advanced technological procedures and diagnostic techniques (Fein 1989). According to Lewin, limitations of technology, which may occur with an significant change in the health care system, would be predicted to generate opposing forces.

Organizational forces are generated because of policies, procedures, regulations, customs, or rules that the organization itself has established over time. The U.S. health care system is absorbed with rules, regulations, and policies; those generated by the U.S. government, the health insurance industry, associations, state medical societies, educational institutions, and those created by the physicians, themselves. As discussed above, both supporting and/or opposing forces can emanate from any of these sources (Knudson et al. 1979).

External forces are typically found outside the system. Examples of this kind of force could be existing or probable laws or regulations, attitudes of society 
regarding particular patterns of behavior, or demands placed on the system by customers, patients, suppliers, competitors, or other such groups. The Oregon Health Plan and national health insurance represent significant sources of external change forces to the health care system (Knudson et al. 1979).

Supporting forces for system change often arise because of feelings, beliefs, values, or attitudes that are held by individuals in the system. Examples of forces from this category would be physicians' feelings that they are doing the right thing in the given circumstance, policy makers who recognize a public need, or citizens themselves (Clements 1993). Physicians who support change in the present health care system, despite the potential for financial and organizational loss, fit within this former category (Knudson et al. 1979).

\section{Changing the Oregon Health Care System}

The concept of health care rationing allows for the status quo in the basic structure of the Oregon health care delivery system. Such a change would, theoretically, allow an expansion of health benefits to those presently without health insurance or to individuals having trouble accessing the health care system. This change, however, would allow the basic structure of the Oregon health care system to remain as it is, presently. As such, the Oregon Health Plan, while somewhat drastic in concept, from a physician's perspective (Kitzhaber 1991a) represents incremental change of the health care system in the state. 
The adoption of national health insurance (NHI), on the other hand, requires a major change in the present health care system, particularly the financing component. Control of the health care financing system provides significant power to change the fundamental structure of the delivery system itself. Pfeffer (1980) has shown that a social actor or actors who control the resources of an organization or group, possesses enormous power over the group. A national health insurance (NHI) program places enormous power of $70-80$ percent of the health care financial resources in the hands of the federal government, a situation deemed unacceptable by the American Medical Association (Starr 1982; Brown 1987; Williams and Torrens 1988; Williams and Torrens 1993), and, quite possibly, by a significant number of medical practitioners and the general public (Matthews 1994).

Organization change theory would predict that unless change is in the best interest of the dominant organizational forces (Lewin 1947; Kotter 1989), incremental change would be more likely to be supported by those within the organization, while major change would be more likely to be resisted (Kantor 1983; Beckhard and Harris 1987; Kotter 1989). Scholtes (1991) argues that people don't mind change, they just dislike being changed.

As primary care physicians represent the theoretical gatekeepers to the U.S. health care delivery system -- therefore bearing the brunt of any significant change in the present system -- they are the units of analysis studied to validate this change support. Using the Lewin Force Field Analysis as a model with which to measure support for health care change, or in the vernacular of the 1994 policy makers, health 
care reform, the primary research hypotheses and operational definitions are advanced in the next chapter of this study. The Lewin model, with quantitative support measures shown for primary care physicians, will be applied to the findings of this research in Chapter 8. This-model is shown in Figure 3, below.

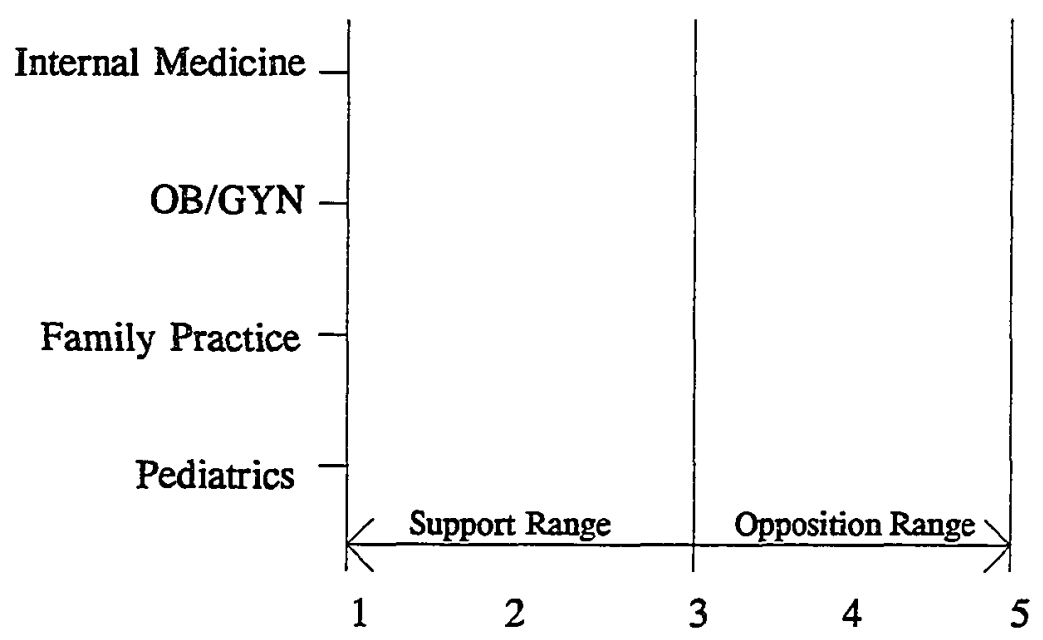

Figure 3. Lewin's Force Field Analysis Applied to Oregon Primary Care Physicians.

The same model can easily be used to analyze support from other physician groups, simply by changing the $\mathrm{Y}$ variables. For instance, the model can be changed to urban and rural, M.D. and D.O. or newly established or established physician. In Chapter 6, two hypotheses are developed that will generate data to be applied to this Force Field model. These measures form the basis for determining if Oregon primary care physicians will support health care reform. 


\section{CHAPTER VI}

\section{HYPOTHESES AND MEASURES}

To test for the existence of supporting forces for health care reform, support hypotheses were formulated and measurement scales were developed to be applied to the Force Field model. These hypotheses, structured in the form of questions on a general attitudinal survey, were sent to all primary care physicians licensed to practice in the state (the survey and subsequent database will be discussed in the next chapter). One question was designed to measure the physicians' support for health care rationing policies such as the Oregon Health Plan. The second question was designed to measure their support for national health insurance (NHI).

The two hypotheses tested by this research effort are stated in their null form. Both hypotheses deal with Oregon primary care physicians' attitudes toward health care reform. However, since no literature exists that determines the direction of support of the first hypothesis dealing with health care rationing, such reform is assumed to be supported (as discussed in the prior chapter) by organization change theory. Organizational change theory would predict that Oregon physicians would be supportive of health care rationing policies. Thus, as with null hypothesis testing 
methodology (Triola 1993) the first hypothesis is expressed in the negative form as:

\section{Hypothesis One $-\mathrm{H}_{0}: \quad$ Oregon primary care physicians will not support health care rationing policies such as the Oregon Health Plan.}

The alternative hypothesis is:

\section{Hypothesis One $-\mathrm{H}_{\mathrm{a}}: \quad$ Oregon primary care physicians will support health care rationing policies such as the Oregon Health Plan.}

Health policy literature does provide national statistics that suggest physicians are not generally supportive of the concept of national health insurance (NHI). Organization change theory would predict, too, that physicians would be resistant to policies that would substantially alter their control over the health care system. As such, the second hypothesis, again as with null hypothesis testing methodology (Triola 1993), is expressed in the negative form as:

\footnotetext{
Hypothesis Two $-\mathrm{H}_{\mathrm{o}}$ Oregon primary care physicians will not support national health insurance (NHI).
}

The alternative hypothesis is:

Hypothesis Two $-\mathrm{H}_{\mathbf{3}}: \quad$ Oregon primary care physicians will support national health insurance (NHI). 
These two hypotheses were used to test for supporting forces for health care reform among Oregon primary care physicians. The first hypothesis seeks to measure the level of support for rationing policies such as those proposed by the Oregon Health Plan (OHP). If support for health care rationing policies is found to be weak, the successful implementation of the Oregon Health Plan would be suspect. Such a finding would also provide evidence of substantial restraining forces for health system change among the state's primary care physicians.

The second hypothesis was used to measure support for other health care reform programs such as the Clinton Administration's proposal for national health insurance (NHI) ("Officials aim to defeat other plan," The Oregonian, 1994). If support is found to be strong enough for NHI, the need for rationing programs such as the OHP might be questioned. Perhaps Oregon policy makers should be looking toward the federal model for health care reform.

\section{Operational Measures: Dependent Variable}

Oregon primary care physicians' support for health care rationing policies such as the Oregon Health Plan (OHP) was measured by their responses to one of the questions on the survey. This question was How supportive are you of health care rationing such as that proposed by the Oregon Health Plan. Support was 
measured on a Likert scale of 1 to 5 . The scale was constructed as:

$$
\begin{aligned}
& 1=\text { Very Supportive of Rationing Policies such as the OHP } \\
& 2=\text { Supporive of Rationing Policies such as the OHP } \\
& 3=\text { Neutral toward Rationing Policies such as the OHP } \\
& 4=\text { Not Supportive of Rationing Policies such as the OHP } \\
& 5=\text { Unalterably Opposed to Rationing Policies such as the OHP }
\end{aligned}
$$

The dependent variable $(\mathrm{Y})$ is support for health care rationing policies such as the Oregon Health Plan.

\section{Hypothesis 1: Independent Variables}

Variation in support for health care rationing policies was examined using several independent variables, all related to physician practice characteristics. These variables are: 1) type of practice (solo/partnership or group); 2) location of practice (urban or rural); 3) city size of practice location; 4) years in medical practice; 5) type of primary care physician (pediatrics, obstetrics and gynecology (OB/GYN), internal medicine, family practice, and other general primary care physicians); 6) type of medical training (D.O. or M.D.); 7) percentage of patients on Medicaid; 8) percentage of patients on Medicare; 9) percentage of patients paying fee-for-service; 10) percentage of patients uninsured; 11) percentage of patients seen for chronic carepotentially fatal problems; 12) percentage of patients seen for chronic care-nonfatal problems; 13) percentage of patients seen for acute care-potentially fatal problems; 14) percentage of patients seen for acute care-nonfatal problems; 15) percentage of 
patients seen for maternity care; 16) percentage of patients seen for preventative care; 17) percentage of patients seen in the office each month (compared to in the hospital); 18) percentage of practice devoted to specialty medicine (as opposed to general practice); 19) managed care affiliation; and 20) physicians' attitudes toward national health insurance.

These independent variables and their measures are defined as:

1. Type of Practice

This variable explains the type of clinical arrangement of practice that a primary care physician reports.

1 = Solo/partnership

$0=$ Group practice

2. Location of Practice

This represents the physician's geographic place of practice.

$1=$ Urban

$0=$ Rural

3. City size of practice location

This variable represents the size of the city in which the physician practices.

$1=$ Urban, large city

$2=$ Urban, medium city

3 = Suburban

$4=$ Smaller city

$5=$ Rural town

4. Years in medical practice

$1=$ Less than five years

$2=$ Five years but less than 10 years

$3=10$ years to 20 years

$4=$ More than 20 years 
5. Type of primary care physician

$1=$ Pediatrics

2 = Internal Medicine (IM)

3 = Obstetrics/Gynecology (OB/GYN)

$4=$ Family Practice (FP)

$\mathbf{5}=$ Other types of primary care (emergency physicians, general practice, urgent care, public health, and other unspecified).

6. Type of medical training

1 = Allopathic physician (M.D.)

$0=$ Osteopathic physician (D.O.)

\section{Percentage of patients on Medicaid}

This is a measure of the percentage of a physicians patients on Medicaid insurance.

8. Percentage of patients on Medicare

This is a measure of the percentage of a physicians patients on Medicare insurance.

9. Percentage of patients paying fee-for-service

This is a measure of the percentage of a physicians patients paying feefor-service, typically with private health insurance (i.e., Blue Cross/Blue Shield, Etna, etc.).

10. Percentage of patients uninsured

This is a measure of the percentage of a physicians patients without health insurance.

11. Percentage of patients: chronic care - potentially fatal conditions.

This measure is the percentage of a physicians patients seen for potentially fatal, chronic conditions (i.e., high blood pressure), that if left untreated, could lead to death. 
12. Percentage of patients: chronic care - nonfatal conditions.

This measure is the percentage of a physicians patients seen for potentially nonfatal, chronic conditions, that if left untreated, could do not typically lead to death.

13. Percentage of patients: acute care - potentially fatal conditions.

This measure is the percentage of a physicians patients seen for potentially fatal, acute conditions (i.e., appendicitis), that if left untreated, could lead to death.

14. Percentage of patients: acute care - nonfatal conditions.

This measure is the percentage of a physicians patients seen for potentially nonfatal, acute care conditions (i.e., infections, sprains, flu, etc.), that if left untreated, do not typically lead to death.

15. Percentage of patients: maternity care

This measure is the percentage of a physicians patients seen for maternity care.

16. Percentage of patients: preventative care.

This measure is the percentage of a physicians patients seen for preventative care (i.e., well baby, checkups, pap smears, etc.)

17. Percentage of Practice: Office

Out of 100 percent, this is that percentage of a physicians' practice conducted in the office, compared to that practiced in the hospital.

18. Percentage of Practice: Specialty

Out of 100 percent, this is that percentage of a physicians' practice devoted to specialty medicine, compared to that devoted to general practice. 
19. Managed Care Affiliation

A measure of whether the physician is affiliated with a managed care organization and accepts patients with such insurance.

$$
\begin{aligned}
& 1=\text { Yes } \\
& 0=\text { No }
\end{aligned}
$$

20. Attitudes Toward Health Care Reform: national health insurance (NHI).

$$
\begin{aligned}
& 1=\text { Very Supportive of NHI } \\
& 2=\text { Supportive of NHI } \\
& 3=\text { Neutral toward NHI } \\
& 4=\text { Not Supportive of NHI } \\
& 5=\text { Unalterably Opposed to NHI }
\end{aligned}
$$

These independent variables were chosen because they provide important dimensions to the primary care physician's practice. For instance, small autonomous practices, such as solo or partnership clinics, were examined because they represent the preponderance of rural or small town medical practices (Oregon Office of Health Policy 1991). As support for health care rationing from these medical practitioners is critical to the successful implementation of the Oregon Health Plan (OHP), this was an important dimension to explore.

Geographic location is another important variable to include as an independent variable because the OHP is designed to be a state-wide program. If support is found to be isolated in urban areas, for example, the implementation of such a program is suspect. Oregon research (Baker 1992) has shown that there are a greater percentage of uninsured residents in the rural areas. If support for the Oregon Health Plan is not found to exist in these rural areas, the program will fail to reach its target market. Length of medical practice was included as an independent variable in this 
research effort. Fredrick (1985) has shown that physicians who have been in practice for some length of time are more opposed to health care change than their younger counterparts. He cites a North Carolina example where physicians were asked to voluntary restrict hospital stays and inpatient utilization to compete with HMOs. The older surgeons and obstetricians refused to participate because they regarded the program as "... unnecessary and professionally degrading" (Fredrick 1985, 11). This resistance to change will be measured among Oregon primary care physicians to determine if length of years in practice predicts to support for (or resistance to) health care rationing policies and/or national health insurance (NHI).

The various patient mix independent variables 7 through 16 used in the study were first delineated by the Oregon Health Services Commission (HSC) to categorize the specific types of medical treatments a physician performs in his or her practice (Health Services Commission 1990). They appear to have been generally accepted by the Oregon physicians studied for this dissertation. Few physicians were unable to answer this question and many indicated total percentages for all of these categories that equaled more than 100 percent. Their justification was that patients typically come to them with more than one medical condition. By allowing the total to equal more than 100 percent, co-morbidity was factored into the analysis.

Of significant importance to this study is the measure of differences between groups of primary care specialties in support for rationing policies and NHI. Family practice physicians are thought to be the gate-keepers to the health care system and their support will be most desired for the OHP to succeed. Additionally, pediatric 
and $\mathrm{OB} / \mathrm{GYN}$ support is important for the delivery of health care to uninsured children and mothers.

Health insurance status is included in the model because (Hayward 1991) has shown that persons without health insurance have a more difficult time accessing the health care system. It could be inferred that physicians who have a high percentage of their patients without health insurance would welcome a health care policy that provides reimbursement for at least some of the health care they deliver to their patients. This model will test to see if support differences exist between physician groups with no uninsured patients and physicians groups with greater than 10 percent of their patients without health insurance.

Finally, case mix is an important variable to include in this model. Since the OHP is considered a "basic" health care plan, physicians with high percentages of their patients who are seen for critical care: fatal or acute care: fatal medical conditions may be less likely to support health care rationing. As these patients typically consume higher medical resources (typically, expensive medical care), physicians with higher case mixes of these types of patients may not support rationing of this type of care. Again, differences for support between these groups will be tested.

Physicians' attitudes toward national health insurance are generally known from the literature. The model included this measure as a independent variable in the regression model because it was felt that if physicians do not support any form of health care reform, a strong correlation between their attitudes toward health care 
rationing and NHI would be found. Alternately, if the organization theory is correct, if physicians had strong attitudes towards NHI, they may not have such strong attitudes toward health care rationing. This variable was included in the model to test for such inverse relationships in attitudes toward health care reform.

This research effort does not include differences in support between male and female physicians. Gender of the respondent was not asked on the original survey; thus, this dimension cannot be explored.

Analysis was considered from both directions, across the row of dependent variables and down the column of independent variables. This matrix is show in Figure 4. 


\begin{tabular}{|c|c|c|c|c|c|c|c|c|}
\hline \multirow{2}{*}{$\begin{array}{l}\text { SUPPORT FOR } \\
\text { HEALTH CARE } \\
\text { RATIONING, by: }\end{array}$} & \multicolumn{8}{|c|}{ Independent Variables } \\
\hline & $\begin{array}{l}\text { Support For } \\
\text { NHI }\end{array}$ & $\begin{array}{l}\text { Percent Pts } \\
\text { Uninsured. }\end{array}$ & $\begin{array}{l}\text { Percent Pts } \\
\text { Medicare }\end{array}$ & $\begin{array}{l}\text { Percent Pts } \\
\text { Fee For Sve. }\end{array}$ & $\begin{array}{l}\text { Geographic } \\
\text { Location }\end{array}$ & $\begin{array}{l}\text { Type of } \\
\text { Practice }\end{array}$ & $\begin{array}{l}\text { Pct. Practice } \\
\text { Maternity }\end{array}$ & $\begin{array}{c}\text { Pct.Practice } \\
\text { Acute, Nonfatal }\end{array}$ \\
\hline All Physicians & $\mathrm{X}_{1}$ & $\mathbf{X}_{2}$ & $\mathrm{X}_{3}$ & $\mathrm{X}_{4}$ & $x_{5}$ & $x_{6}$ & $\mathrm{X}_{7}$ & $\mathbf{X}_{8}$ \\
\hline $\begin{array}{l}\text { Pediatricians } \\
\text { Internal Medicine } \\
\text { OB/GYN } \\
\text { Family Practice } \\
\text { Other }\end{array}$ & $\begin{array}{l}\mathbf{X}_{18} \\
\mathbf{X}_{35} \\
\mathbf{X}_{52} \\
\mathbf{X}_{69} \\
\mathbf{X}_{86}\end{array}$ & $\begin{array}{l}X_{19} \\
X_{36} \\
X_{53} \\
X_{70} \\
X_{87}\end{array}$ & $\begin{array}{l}X_{20} \\
X_{37} \\
X_{54} \\
X_{71} \\
X_{88}\end{array}$ & $\begin{array}{l}X_{21} \\
X_{38} \\
X_{55} \\
X_{72} \\
X_{89}\end{array}$ & $\begin{array}{l}X_{22} \\
X_{39} \\
X_{56} \\
X_{73} \\
X_{90}\end{array}$ & $\begin{array}{l}X_{23} \\
X_{40} \\
X_{57} \\
X_{74} \\
X_{91}\end{array}$ & $\begin{array}{l}X_{24} \\
X_{41} \\
X_{58} \\
X_{75} \\
X_{92}\end{array}$ & $\begin{array}{l}X_{25} \\
X_{42} \\
X_{59} \\
X_{76} \\
X_{93}\end{array}$ \\
\hline
\end{tabular}

\begin{tabular}{|c|c|c|c|c|c|c|c|c|}
\hline & & & & & endent Variable & & & \\
\hline $\begin{array}{l}\text { Pct. Patients } \\
\text { Medicaid }\end{array}$ & $\begin{array}{r}\text { Years in } \\
\text { Practice }\end{array}$ & $\begin{array}{l}\text { Pct. Practice } \\
\text { in Office }\end{array}$ & $\begin{array}{l}\text { Pct. Practice } \\
\text { Prev. Care }\end{array}$ & $\begin{array}{r}\text { Pct. Practice } \\
\text { Chronic, fatal }\end{array}$ & $\begin{array}{l}\text { Pct. Practice } \\
\text { Acute, fatal }\end{array}$ & $\begin{array}{c}\text { Pct. Practice } \\
\text { Chronic, nonfatal }\end{array}$ & $\begin{array}{l}\text { Pct. Practice } \\
\text { Specialty }\end{array}$ & $\begin{array}{l}\text { Managed Care } \\
\text { Affiliation }\end{array}$ \\
\hline $\begin{array}{l}\mathbf{X}_{9} \\
\mathbf{X}_{26} \\
\mathbf{X}_{43} \\
\mathbf{X}_{60} \\
\mathbf{X}_{7} \\
\mathbf{X}_{94}\end{array}$ & $\begin{array}{l}\mathbf{X}_{10} \\
\mathbf{X}_{27} \\
\mathbf{X}_{44} \\
\mathbf{X}_{61} \\
\mathbf{X}_{78} \\
\mathbf{X}_{95}\end{array}$ & $\begin{array}{l}\mathbf{X}_{11} \\
\mathbf{X}_{28} \\
\mathbf{X}_{45} \\
\mathbf{X}_{62} \\
\mathbf{X}_{79} \\
\mathbf{X}_{96}\end{array}$ & $\begin{array}{l}X_{12} \\
X_{29} \\
X_{46} \\
X_{63} \\
X_{80} \\
X_{97}\end{array}$ & $\begin{array}{l}X_{13} \\
X_{30} \\
X_{47} \\
X_{64} \\
X_{81} \\
X_{98}\end{array}$ & $\begin{array}{l}\mathrm{X}_{14} \\
\mathrm{X}_{31} \\
\mathrm{X}_{48} \\
\mathrm{X}_{65} \\
\mathrm{X}_{82} \\
\mathrm{X}_{99}\end{array}$ & $\begin{array}{l}\mathbf{X}_{15} \\
\mathbf{X}_{32} \\
\mathbf{X}_{49} \\
\mathbf{X}_{66} \\
\mathbf{X}_{83} \\
\mathbf{X}_{100}\end{array}$ & $\begin{array}{l}\mathbf{X}_{16} \\
\mathbf{X}_{33} \\
\mathbf{X}_{50} \\
\mathbf{X}_{67} \\
\mathbf{X}_{84} \\
\mathbf{X}_{101}\end{array}$ & $\begin{array}{l}\mathbf{X}_{17} \\
\mathbf{X}_{34} \\
\mathbf{X}_{51} \\
\mathbf{X}_{68} \\
\mathbf{X}_{85} \\
\mathbf{X}_{102}\end{array}$ \\
\hline
\end{tabular}

Figure 4. Matrix for Hypothesis 1, Oregon Primary Care Physician Support for Health Care Rationing Policies 
Operational Measures: Hypothesis 2

Oregon primary care physicians' support for national health insurance was measured by their response to the question: How supportive are you of national health insurance (NHI). The measure of this support question represents the dependent variable used to test this second hypothesis.

The second hypothesis is, too, represented by the same 20 independent variables designed to measure the dependent variable: support for national health insurance (NHI) with one exception. In the regression used to test this hypothesis, physicians attitudes toward health care rationing was substituted as a independent variable in the model. Again, a relationship between attitudes toward any form of heath care reform was being explored by incorporating this variable in the regression.

Strength of support for national health insurance (NHI) was determined in the same manner as support for health care rationing policies was determined. The same five point Likert scale is discussed above was used. This scale is:

$$
\begin{aligned}
& 1=\text { Very Supportive of NHI } \\
& 2=\text { Supportive of NHI } \\
& 3=\text { Neutral toward NHI } \\
& 4=\text { Not Supportive of NHI } \\
& 5=\text { Unalterably Opposed to NHI }
\end{aligned}
$$

The dependent variable (Y) in this case is support for national health insurance. 


\section{Hypothesis 2: Independent Variables}

Again, variation in support, mean support scores, and proportions of physicians expressing support for national health insurance policies were examined using several independent variables; the same variables used to test support for health care rationing policies. Again, these variables are: 1) type of practice (solo/partnership or group); 2) location of practice (urban or rural); 3) city size of practice location; 4) years in medical practice; 5) type of primary care physician (pediatrics, obstetrics and gynecology (OB/GYN), internal medicine, family practice, and other general primary care physicians); 6) type of medical training (D.O. or M.D.); 7) percentage of patients on Medicaid; 8) percentage of patients on Medicare; 9) percentage of patients paying fee-for-service; 10) percentage of patients uninsured; 11) percentage of patients seen for chronic care-potentially fatal problems; 12) percentage of patients seen for chronic care-nonfatal problems; 13) percentage of patients seen for acute care-potentially fatal problems; 14) percentage of patients seen for acute care-nonfatal problems; 15) percentage of patients seen for maternity care; 16) percentage of patients seen for preventative care; 17) percentage of patients seen in the office each month (compared to in the hospital); 18) percentage of practice devoted to specialty medicine (as opposed to general practice); 19) managed care affiliation; and 20) physicians' attitudes toward health care rationing policies such as the Oregon Health Plan. See Figure 5, next page. 


\begin{tabular}{|c|c|c|c|c|c|c|c|c|}
\hline SUPPORT FOR & & & & & dent Variable & & & \\
\hline $\begin{array}{l}\text { NATIONAL HEALTH } \\
\text { INSURANCE, by: }\end{array}$ & $\begin{array}{l}\text { Support For } \\
\text { HC Rationing }\end{array}$ & $\begin{array}{l}\text { Percent Pts } \\
\text { Uninsured. }\end{array}$ & $\begin{array}{l}\text { Percent Pts } \\
\text { Medicare }\end{array}$ & $\begin{array}{l}\text { Percent Pts } \\
\text { Fee For Svc. }\end{array}$ & $\begin{array}{l}\text { Geographic } \\
\text { Location }\end{array}$ & $\begin{array}{l}\text { Type of } \\
\text { Practice }\end{array}$ & $\begin{array}{l}\text { Pct. Practice } \\
\text { Maternity }\end{array}$ & $\begin{array}{c}\text { Pct.Practice } \\
\text { Acute, Nonfatal }\end{array}$ \\
\hline All Physicians & $X_{1}$ & $X_{2}$ & $\mathbf{X}_{3}$ & $X_{4}$ & $X_{s}$ & $\mathrm{X}_{6}$ & $X_{7}$ & $\mathbf{X}_{8}$ \\
\hline $\begin{array}{l}\text { Pediatricians } \\
\text { Internal Medicine } \\
\text { OB/GYN } \\
\text { Family Practice } \\
\text { Other }\end{array}$ & $\begin{array}{l}X_{18} \\
X_{33} \\
X_{52} \\
X_{69} \\
X_{86}\end{array}$ & $\begin{array}{l}X_{19} \\
X_{36} \\
X_{53} \\
X_{70} \\
X_{87}\end{array}$ & $\begin{array}{l}X_{20} \\
X_{37} \\
X_{54} \\
X_{71} \\
X_{88}\end{array}$ & $\begin{array}{l}X_{21} \\
X_{38} \\
X_{55} \\
X_{72} \\
X_{89}\end{array}$ & $\begin{array}{l}X_{22} \\
X_{39} \\
X_{56} \\
X_{73} \\
X_{90}\end{array}$ & $\begin{array}{l}X_{23} \\
X_{40} \\
X_{57} \\
X_{74} \\
X_{91}\end{array}$ & $\begin{array}{l}X_{24} \\
X_{41} \\
X_{58} \\
X_{75} \\
X_{92}\end{array}$ & $\begin{array}{l}X_{25} \\
X_{42} \\
X_{59} \\
X_{76} \\
X_{93}\end{array}$ \\
\hline
\end{tabular}

\begin{tabular}{|c|c|c|c|c|c|c|c|c|}
\hline & & & & & ndent Variable & & & \\
\hline $\begin{array}{l}\text { Pct. Patients } \\
\text { Medicaid }\end{array}$ & $\begin{array}{l}\text { Years in } \\
\text { Practice }\end{array}$ & $\begin{array}{l}\text { Pct. Practice } \\
\text { in Office }\end{array}$ & $\begin{array}{l}\text { Pct. Practice } \\
\text { Prev. Care }\end{array}$ & $\begin{array}{l}\text { Pct. Practice } \\
\text { Chronic, fatal }\end{array}$ & $\begin{array}{l}\text { Pct. Practice } \\
\text { Acute, fatal }\end{array}$ & $\begin{array}{c}\text { Pct. Practice } \\
\text { Chronic, nonfatal }\end{array}$ & $\begin{array}{l}\text { Pct. Practice } \\
\text { Specialty }\end{array}$ & $\begin{array}{l}\text { Managed Care } \\
\text { Affiliation }\end{array}$ \\
\hline $\begin{array}{l}\mathbf{X}_{9} \\
\mathbf{X}_{26} \\
\mathbf{X}_{43} \\
\mathbf{X}_{60} \\
\mathbf{X}_{7} \\
\mathbf{X}_{94}\end{array}$ & $\begin{array}{l}X_{10} \\
X_{27} \\
X_{44} \\
X_{81} \\
X_{78} \\
X_{95}\end{array}$ & $\begin{array}{l}X_{11} \\
X_{28} \\
X_{45} \\
X_{62} \\
X_{79} \\
X_{96}\end{array}$ & $\begin{array}{l}X_{12} \\
X_{29} \\
X_{46} \\
X_{63} \\
X_{80} \\
X_{97}\end{array}$ & $\begin{array}{l}X_{13} \\
X_{30} \\
X_{47} \\
X_{64} \\
X_{81} \\
X_{98}\end{array}$ & $\begin{array}{l}\mathbf{X}_{14} \\
\mathbf{X}_{31} \\
\mathbf{X}_{48} \\
\mathbf{X}_{65} \\
\mathbf{X}_{82} \\
\mathbf{X}_{99}\end{array}$ & $\begin{array}{l}\mathbf{X}_{15} \\
\mathbf{X}_{32} \\
\mathbf{X}_{49} \\
\mathbf{X}_{66} \\
\mathbf{X}_{83} \\
\mathbf{X}_{100}\end{array}$ & $\begin{array}{l}\mathbf{X}_{16} \\
\mathbf{X}_{33} \\
\mathbf{X}_{50} \\
\mathbf{X}_{6} \\
\mathbf{X}_{84} \\
\mathbf{X}_{101}\end{array}$ & $\begin{array}{l}X_{17} \\
X_{34} \\
X_{51} \\
X_{68} \\
X_{85} \\
X_{102}\end{array}$ \\
\hline
\end{tabular}

Figure 5. Matrix for Hypothesis 2, Oregon Primary Care Physician Support for National Health Insurance (NHI). 


\section{Statistical Techniques}

Several statistical techniques were used for this research. Chi-square was used to test for significant differences between groups of physicians. This is the appropriate test to use when testing nominal level data (Triola 1993).

Mean support scores were determined using simple regression analyses. Regressions were run on each subcategory identified above. The simple regression (same as an ANOVA test) is the appropriate test to use when mean scores are to be generated with only one independent variable (Triola 1993). The bi-variate regression means form the basis for support measures discussed in Chapter 8, and applied to the conceptual Force Field model discussed in Chapter 9. Scores that are equal to or greater than a mean of 3 are considered non-supportive or opposing forces to health care reform; mean scores that fall below three are considered supporting forces.

Variation in the dependent variables support for health care rationing (hypothesis 1) and support for national health insurance (hypothesis 2) were tested using multivariate regression analyses. The regression was used to attempt determine which physicians practice variables significantly explained variation in the dependent variables. 
The multi-variate regression model is expressed as:

Support for Rationing $(Y)=$ Constant $+\mathrm{B}_{1} \mathrm{X}_{1}+\mathrm{B}_{2} \mathrm{X}_{2}+\ldots \mathrm{B}_{20} \mathrm{X}_{20}$

Where:

Support for Rationing $=$ Support dimension on Likert scale $(1=$ high level of support to $5=$ unalterable opposition)

Independent Variables (X)

$\mathrm{B}_{1} \mathrm{X}_{1} \quad=\quad$ Dummy variable for type of practice

1 = Solo/partnership

$0=$ Group practice

$\mathrm{B}_{2} \mathrm{X}_{2}=$ Dummy variable for geographic location of practice

$1=$ Urban/suburban

$0=$ Rural/small town

$\mathrm{B}_{3} \mathrm{X}_{3} \quad=\quad$ City Size:

1 = urban-large

2 = urban, medium

3 = suburban

$4=$ small town

$5=$ rural)

$\mathrm{B}_{4} \mathrm{X}_{4} \quad=\quad$ Years in practice

$\mathrm{B}_{s} \mathrm{X}_{s} \quad=\quad$ Type of primary care physician

$1=$ Pediatrics

2 = Internal Medicine (IM)

3 = Obstetrics/Gynecology (OB/GYN)

$4=$ Family Practice (FP)

$5=$ General other

$\mathrm{B}_{6} \mathrm{X}_{6} \quad=\quad$ Type of medical training

$1=$ M.D.

$0=$ D.O.

$\mathrm{B}_{7} \mathrm{X}_{7}=\quad$ Percent of patients on Medicaid

$\mathrm{B}_{8} \mathrm{X}_{8} \quad=\quad$ Percent of patients on Medicare 


$$
\begin{aligned}
& \mathrm{B}_{9} \mathrm{X}_{9} \quad=\quad \text { Percent of patients with fee-for-service insurance } \\
& \mathrm{B}_{10} \mathrm{X}_{10}=\text { Percent of patients without health insurance } \\
& \mathrm{B}_{11} \mathrm{X}_{11}=\text { Percent of patients seen for chronic care, potentially fatal } \\
& \text { conditions. } \\
& \mathrm{B}_{12} \mathrm{X}_{12}=\text { Percent of patients seen for chronic care, } \\
& \text { non-fatal conditions. } \\
& \mathrm{B}_{13} \mathrm{X}_{13} \quad=\quad \text { Percent of patients seen for acute care, potentially } \\
& \text { fatal conditions. } \\
& \mathrm{B}_{14} \mathrm{X}_{14}=\text { Percent of patients seen for acute care, non-fatal } \\
& \text { conditions. } \\
& \mathrm{B}_{15} \mathrm{X}_{15} \quad=\quad \text { Percent of patients seen for maternity care. } \\
& \mathrm{B}_{16} \mathrm{X}_{16} \quad=\quad \text { Percent of patients seen for preventative care. } \\
& B_{17} X_{17}=\quad \text { Of } 100 \text { percent, what percent of practice } \\
& \text { conducted in office. } \\
& \mathrm{B}_{18} \mathrm{X}_{18}=\text { Of } 100 \text { percent, what percent of practice devoted } \\
& \text { to specialty type medicine } \\
& \mathrm{B}_{19} \mathrm{X}_{19}=\text { Managed Care Affiliation (MCA) } \\
& 1=\text { Yes } \\
& 0=\text { No } \\
& 1=\text { Very supportive } \\
& 2=\text { Supportive } \\
& 3=\text { Neutral } \\
& 4=\text { Not Supportive } \\
& 5 \text { = Unalterably Opposed }
\end{aligned}
$$

This model was repeated with support for national health insurance as the 
dependent variable, except variable $B_{20} X_{20}$ was changed to be physician's attitude toward health care rationing policies such as the Oregon Health Plan. This attitude was measured on the same five point Likert Scale. As well, the model was repeated for each primary care specialty physician; pediatrics, internal medicine, $O B / G Y N$, family practice, and the general other category.

While actual probability statistics are reported throughout this dissertation, the a priori level of significance was set at an alpha of 0.10 . Thus, a variable that had a $\mathrm{p}$ equal to or less than 0.10 was considered a significant variable in explaining variation in the dependent variable.

The data set and questionnaire design are discussed in the next chapter. The data analysis discussed in Chapter 8 form the statistics applied to the conceptual force field model outlined in Chapter 5. 


\section{CHAPTER VII \\ RESEARCH DESIGN}

The research design of this study was rather straight forward. The database used to test the hypotheses discussed in Chapter 6 was originally gathered for a 1991 economic study of Oregon primary care physicians fee charges conducted by Julnes and Baker (1991). The use of the survey results for this study represents a secondary use of the data. However, the questions examined for this study have not previousiy been analyzed. The original survey instrument was coded and entered into the SYSTAT database by the author of this study. SYSTAT is a computer software program designed to allow for statistical analysis of computerized data (Wilkinson 1990).

The original survey instrument was designed by Theresa Julnes, Ph.D., School of Urban and Public Affairs, Portland State University, and was mailed to all 2,843 primary care physicians licensed to practice medicine or osteopathy in the State of Oregon. The first survey was mailed in January 1991. A second, identical survey was mailed to non-respondents to the first mailing in February 1991. Responses were received back from the physicians from the period of the first mailing until June 1991.

The referent group was generated from a list of all licensed physicians 
obtained from the Oregon State Board of Medical Examiners, Portland, Oregon. Thus, sampling was not used to create this database as the responses were mailed to the population of Oregon primary care physicians.

This cross sectional attitude survey was administered to all primary care physicians in Oregon, as defined by the American Medical Association (Julnes and Baker 1991). The AMA defines primary care as: 1) family and general practice; 2) (general) internal medicine; 3) pediatrics; 4) obstetrics and/or gynecology, and 5) other types of physicians practicing urgent-care, emergency medicine, and preventive care (Julnes and Baker 1991).

The survey instrument was mailed in January 1991 and again, to nonrespondents, in March 1991. Both mailings were with identical surveys. In all, 1,365 responses were received as late as June 1991, representing a 48.0 percent rate of return. Data were analyzed from the period of April 1991 to July 1993.

Because cost and time were not significant factors in the determination of the sample size to be used in the primary research effort, the decision to reduce sampling error to a minimum was the pivotal reason behind the population size survey. This decision also negated the requirement to stratify the sample for sample representation purposes. Since this research effort was taken from part of a larger study, the sample size was determined by the earlier research effort. The benefit of this larger sample size is it reduces the potential for Type II or Beta error -- that is, failing to reject a null hypothesis when it should be rejected (Triola 1993).

While the data source used in this survey represents a primary data collection 
effort as part of a larger study on health care costs in the State of Oregon (Julnes and Baker 1991), the analyses of these data for this research effort represents a secondary use of the database.

\section{Response Bias}

Just over 48.5 percent of the primary care physicians in the sample were from urban cities; 9.1 percent were from suburban cities; and 42.3 percent were from small cities or rural communities. The sample appears representative of the general geographic distribution of Oregon primary care physicians. According to the Oregon Office of Rural Health (Baker and Julnes 1991), in 1991, 52.3 percent of the physicians practicing in Oregon were in urban centers, 11.2 were in suburban cities, and 36.5 percent are in rural areas of the state. A strong correlation $(r=0.92)$ between the sample used in this study and the population in the state suggests that the sample adequately represents the distribution of physicians throughout Oregon. Thus, significant selection factors are not present in the database (Wilkinson 1990). This finding allows for generalization of the results of the study to the Oregon primary care population.

\section{Questionnaire Design}

To determine support for health care rationing and national health insurance, 
two questions were added to a questionnaire designed to provide data for the study of Oregon family practice and internal medicine physician fees (Julnes and Baker 1991). As such, an original questionnaire was not developed for this dissertation. A copy of the Oregon primary care physician survey is included in Appendix A. The results of the data analysis are reported in the next chapter. 


\section{CHAPTER VIII}

\section{RESULTS OF DATA ANALYSIS}

Prior to reporting the results of the hypotheses tests, a review of the descriptive characteristics of the primary care physicians responding to the survey is in order. Of the 1,365 primary care physicians responding to the fee survey study, 44.2 percent practiced in solo/partnership practices. Another 28.8 percent of the respondents practiced in group practice clinics. Just over 12.4 percent of the physicians practiced in specialty clinics or hospitals and 11.7 percent were not practicing. Another 2.8 percent of the respondents reported they practiced in other types of practice arrangements.

Of the 1,365 primary care physicians responding, 973 physicians answered the question regarding managed care arrangements. Of this group, 66.1 percent indicated that they participate in a managed care organization (MCO), either an PPO, IPA, or HMO. Another 33.9 percent did not participate in an MCO.

Just under 31 percent of the primary care physicians practiced in large urban cities. Another 17.9 percent practiced in medium sized urban cities, 9.1 percent practiced in suburban cities, 26.4 percent practiced in smaller cities, and $\mathbf{1 5 . 9}$ reported rural practice locations. Combining the urban and suburban respondents as one urban category, 57.6 percent of the physicians reported practicing in an urban 
setting, the remaining 42.3 percent practiced in a rural setting by combining the smaller city and rural practice respondents into one rural category.

Just over 21.3 percent of the physicians had been practicing less than five years and 20.4 percent had been practicing 5 years but less than 10 years. Just over 31 percent reported that they had been in practice 10 to 20 years and 27 percent had been in practice more than 20 years.

Of the primary care specialty areas self-reported by the physicians, 12.2 percent were pediatricians, 29.1 percent were internal medicine (IM) physicians, 11.6 percent were obstetrician and gynecologists (OB/GYN), and 41.3 percent were family practice (FP) physicians. Of the remaining, 2.6 percent reported that they were emergency or urgent care physicians, 2.6 percent practiced manipulative medicine (all were osteopathic physicians), 0.5 percent were in general practice, 0.4 percent were in public health, 0.2 percent practiced preventative medicine, 0.2 percent practiced occupational medicine, and the remaining 2.7 percent practiced other types of unspecified primary care.

Of the 1,180 physicians answering the question regarding their type of medical training, 92.8 percent reported they were allopathic (M.D.) physicians. The remaining 7.2 percent of the respondents were osteopathic (D.O.) physicians.

Just under 14 percent of the physicians reported none of their patients were on Medicaid, the federal/state health insurance program for the poor. However, 71.4 percent of the physicians reported that from 1 to 20 percent of their patients were on Medicaid. Another 11.7 percent of the physicians said that 21 to 40 percent of their 
patients were on Medicaid. The remaining 3.3 percent of the physicians reported that greater than 40 percent of their patients were insured by Medicaid.

Of the physicians' patients insured by Medicare, the federal health insurance program for citizens over the age of $65,16.7$ percent of the physicians reported none of their patients were insured by Medicare. However, 41.0 percent reported that from 1 to 20 percent were on Medicare and 25.9 percent said that 21 to 40 percent of their patients were on Medicare. Another 15.6 percent of the physicians reported that from 41 to 60 percent of their patients were on Medicare and the remaining 3.7 percent of the physicians reported that greater than 60 percent of their patients were insured by Medicare.

Just under 11 percent of the physicians reported that none of their patients had private, fee-for-service (FFS) medical insurance. Yet, 31.4 percent reported that from 1 to 20 percent were insured by private FFS insurance. Another 35.3 percent said that 21 to 40 percent of their patients had private FFS insurance, 16.9 percent reported that from 41 to 60 percent of their patients had private FFS insurance, and the remaining 5.6 percent of the physicians reported that greater than 60 percent of their patients were insured by private FFS insurance.

Just over one third ( 33.5 percent) of the physicians reported that none of their patients were insured by health maintenance type of insurance (HMO). Another 39.0 percent reported that from 1 to 20 percent were insured by HMO insurance. Just under 16 percent of the physicians said that 21 to 40 percent of their patients had HMO insurance, 2.4 percent reported that from 41 to 60 percent of their patients had 
HMO insurance, and the remaining 9.4 percent of the physicians reported that greater than 60 percent of their patients had HMO insurance.

Of the physicians answering the question regarding the percentage of their patients who belonged to preferred provider organizations (PPO), almost one-half, or 45.8 percent, had patients who were covered by PPOs. Another 44.1 percent of the physicians had from 1 to 20 percent of their patients covered by PPO insurance. Just 8.9 percent of the physicians reported from 21 to 40 percent of their patients conveyed by this type of insurance, and 0.9 percent had from 41 to 60 percent covered by PPO insurance.

Of the physicians responding to the question regarding the number of their patients without health insurance, 13.3 percent had no uninsured patients. However, 74.3 percent reported from 1 to 20 percent of their patients were uninsured. Another 8.4 percent of the physicians had from 21 to 40 percent of their patients uninsured and the remaining 4 percent of the physicians had patient loads with more than 41 percent without health insurance.

Just over 51.2 percent of the primary care physicians reported that from 0 to 20 percent of their practice was devoted to specialty medicine (as compared to general practice primary care). Another 9.5 percent of the physicians reported from 21 to 40 percent of their practice was devoted to specialty medicine. Another 11.3 percent said that from 41 to 60 percent of their practice was devoted to such care. However, 8.4 percent reported from 61 to 80 percent and 19.6 percent reported from 81 to 100 percent of their practice was specialty medicine, even though these physicians 
reported they were primary care doctors.

In contrast to the percentage of their patients seen in the hospital, 81.6 percent of all the physicians reported that from 81 to 100 percent of their patient encounters occurred in their clinic or doctor's office. Another 9.89 reported from 61 to 80 percent of their patients were seen in their clinic office and 8.37 percent reported that from 0 to 60 percent of their patient encounters occurred in the clinic office.

Of the primary care physicians responding to the questions regarding the percentage of their patients seen for preventive care (PC), 13.1 percent reported that from 1 to 20 percent of their patients were seen for preventive care, while 63.4 percent reported that from 21 to 40 percent were seen for PC. Another 23.7 percent said that from 21 to 100 percent of their patients were seen for preventive care.

Of the same physicians responding to the questions regarding the percentage of their patients seen for maternity care (MC), 72.0 percent reported that none of their patients were seen for MC. Another 18.2 percent reported that from 1 to 20 percent of their patients were seen for maternity care, while 9.8 percent of the physicians reported from 21 to 100 percent of their patients were seen for maternity care.

Exactly 8.0 percent of the physicians reported that none of their patients were seen for acute care, non-fatal type problems ( $\mathrm{ACN})$. Another 34.9 percent reported that from 1 to 20 percent of their patients were seen for $\mathrm{ACN}$ problems, while 28.5 percent reported that from 21 to 40 percent were seen for this type of medical problems. Still another 16.5 percent of the physicians reported that from 21 to 40 percent of their patients, and 8.4 percent reported that from 61 to 80 percent of their 
patients were seen for ACN problems. The remaining 3.8 percent said that from 81 to 100 percent of their patients were seen for this category of medical problems.

Exactly 31.0 percent of the primary care physicians reported that none of their patients were seen for acute care, potentially fatal medical problems (ACF). Another 66.4 percent reported that from 1 to 20 percent of their patients were seen for ACF problems, while only 1.8 percent reported that from 21 to 40 percent were seen for this type of medical condition. Only 0.9 percent of the physicians reported that over 41 percent of their patients were treated for ACF type medical problems.

Eleven percent of the physicians reported that none of their patients were seen for chronic care, non-fatal type problems (CCN). Another 53.4 percent reported that from 1 to 20 percent of their patients were seen for CCN problems, while 26.7 percent reported that from 21 to 40 percent were seen for this type of medical problems. Still another 9.0 percent of the physicians reported that from 21 to 100 percent of their patients were seen for CCN problems.

Just under 29.8 percent of the primary care physicians reported that none of their patients were seen for chronic care, potentially fatal medical problems (CCF). Another 43.4 percent reported that from 1 to 20 percent of their patients were seen for CCF problems, and 23.9 percent reported that from 21 to 40 percent of their patients were seen for this category of medical problems. The remaining 9.1 percent reported that from 41 to 100 percent of their patients were seen for CCF medical conditions. Table 15, next four pages, shows the practice characteristics of the Oregon primary care physicians studied for this dissertation. 
TABLE 15

PRACTICE CHARACTERISTICS OF OREGON PRIMARY CARE PHYSICIANS PARTICIPATING IN THIS STUDY, $\mathbf{N}=1365$

Variable

Practice Type $(\mathrm{n}=1290)$

Solo/Partnership

Group Primary Care Clinic

Group Practice HMO

Not practicing

Specialty Clinic

Public Hospital

Private Hospital

Other
Percent N

$44.2 \% \quad 570$

16.9218

$11.9 \quad 153$

$11.7 \quad 150$

$6.5 \quad 84$

$4.6 \quad 59$

$1.3 \quad 17$

$2.8 \quad 36$

Participation in PPO, IPA, or HMO $(n=973)$ Yes

No

$66.1 \%$

33.9

643

330

City Size of Practice $(n=1150)$

Urban - Large City

$30.6 \% \quad 352$

Urban - Medium City

17.9

9.1

26.4

15.9

206

Suburban

Smaller City

Rural

$57.6 \%$

42.3

662

488
Urban
Rural

How Many Years Practicing $(n=1167)$

Less than 5

5 years but less than 10

10 to 20 years

More than 20 years
$21.3 \% \quad 249$

$20.4 \quad 239$

$31.3 \quad 364$

$27.0 \quad 316$ 
TABLE 15 , CONTINUED

PRACTICE CHARACTERISTICS OF OREGON PRIMARY

CARE PHYSICIANS PARTICIPATING IN THIS STUDY, $\mathbf{N}=1365$

Type of Medical Training $(n=1180)$

Allopathic (M.D.)

$92.8 \% \quad 1095$

Osteopathic (D.O.)

$7: 2$

85

Area of Primary Care Practiced $(n=1173)$

Pediatrics

$12.2 \% \quad 143$

Internal Medicine (IM)

29.1

341

OB/GYN or GYN

11.6

129

Family Practice (FP)

41.3

Emergency or Urgent Care

2.6

484

Public Health

0.4

30

Manipulative Medicine

2.6

5

Prevention

0.2

30

Occupational Medicine

0.2

2

General Practice

0.5

Other

2.7

6

32

Percentage of Patients Covered by Medicaid $(n=967)$

None

$13.6 \%$

131

$1-20 \%$

71.4

690

$21-40 \%$

11.7

113

$41-60 \%$

2.3

22

$61-80 \%$

0.8

8

$81-100 \%$

0.2

2

Percentage of Patients Covered by Medicare $(\mathrm{n}=961)$

None
$1-20 \%$
$21-40 \%$
$41-60 \%$
$61-80 \%$
$81-100 \%$

$16.7 \%$

41.0

160

25.9

394

15.6

249

3.9

150

0.7

37 
TABLE 15, CONTINUED

PRACTICE CHARACTERISTICS OF OREGON PRIMARY

CARE PHYSICIANS PARTICIPATING IN THIS STUDY, $\mathbf{N}=1365$

Percentage of Patients Covered by

Private Fee for Service Insurance $(n=950)$

None

$1-20 \%$

$21-40 \%$

$41-60 \%$

$61-80 \%$

$81-100 \%$
$10.8 \% \quad 103$

$31.4 \quad 298$

$35.3 \quad 335$

$16.9 \quad 161$

$5.1 \quad 48$

$0.5 \quad 5$

Percentage of Patients Covered

by HMO Insurance $(n=952)$

None

$1-20 \%$

$21-40 \%$

$41-60 \%$

$61-80 \%$

$81-100 \%$

Percentage of Patients Covered

by Paid Provider Insurance $(n=937)$

$$
\begin{aligned}
& \text { None } \\
& 1-20 \% \\
& 21-40 \% \\
& 41-60 \% \\
& 61-80 \% \\
& 81-100 \%
\end{aligned}
$$

Percentage of Patients With No

Health Insurance $(n=941)$

$$
\begin{aligned}
& \text { None } \\
& 1-20 \% \\
& 21-40 \% \\
& 41-60 \% \\
& 61-80 \% \\
& 81-100 \%
\end{aligned}
$$

$13.3 \%$

$45.8 \%$

44.1

8.9

0.9

0.0

0.0

318

39.0

15.9

2.4

1.6

7.8

371

151

23

15

74
74.3

8.4

1.5

1.8

0.7
429

413

37

4

0

0

\footnotetext{
$81-100 \%$
} 
TABLE 15, CONTINUED

PRACTICE CHARACTERISTICS OF OREGON PRIMARY CARE PHYSICIANS PARTICIPATING IN THIS STUDY, $\mathrm{N}=1365$

Percentage of Practice Devoted to Specialty Medicine (other than general practice medicine) $(n=935)$

$\begin{array}{lcr}0-20 \% & 51.2 \% & 478 \\ 21-40 \% & 9.5 & 89 \\ 41-60 \% & 11.3 & 106 \\ 61-80 \% & 8.4 & 79 \\ 81-100 \% & 19.6 & 183\end{array}$

Percentage of Patient Encounters

Seen in Doctor's Office (rather than seen in hospital) $(\mathrm{n}=1057)$

$$
\begin{aligned}
& 0-20 \% \\
& 21-40 \% \\
& 41-60 \% \\
& 61-80 \% \\
& 81-100 \%
\end{aligned}
$$

1.1

12

1.8

9.9

105

81.6

Percentage of Patients Seen for

Preventive Care (PC) $(n=1035)$

$$
\begin{aligned}
& \text { None } \\
& 1-20 \% \\
& 21-40 \% \\
& 41-60 \% \\
& 61-80 \% \\
& 81-100 \%
\end{aligned}
$$

$\begin{array}{lr}13.1 \% & 132 \\ 63.4 & 656 \\ 16.5 & 171 \\ 5.5 & 57 \\ 1.1 & 11 \\ 0.6 & 6\end{array}$

Percentage of Patients Seen for

Maternity Care (MC) $(n=1033)$

$$
\begin{aligned}
& \text { None } \\
& 1-20 \% \\
& 21-40 \% \\
& 41-60 \% \\
& 61-80 \% \\
& 81-100 \%
\end{aligned}
$$

$\begin{array}{cr}72.0 \% & 744 \\ 18.2 & 188 \\ 5.2 & 54 \\ 3.8 & 39 \\ 0.4 & 4 \\ 0.4 & 4\end{array}$


TABLE 15, CONTINUED

PRACTICE CHARACTERISTICS OF OREGON PRIMARY

CARE PHYSICIANS PARTICIPATING IN THIS STUDY, $\mathrm{N}=1365$

Percentage of Patients Seen for

Acute Care, Nonfatal Conditions

(ACN) $(\mathrm{n}=1029)$

None

$1-20 \%$

$21-40 \%$

$41-60 \%$

$61-80 \%$

$81-100 \%$

$\begin{array}{rr}8.0 \% & 82 \\ 34.9 & 359 \\ 28.5 & 293 \\ 16.5 & 170 \\ 8.4 & 86 \\ 3.8 & 39\end{array}$

Percentage of Patients Seen for

Acute Care, Potentially Fatal

Conditions (ACF) $(n=1022)$

$$
\begin{aligned}
& \text { None } \\
& 1-20 \% \\
& 21-40 \% \\
& 41-60 \% \\
& 61-80 \% \\
& 81-100 \%
\end{aligned}
$$

$31.0 \% \quad 317$

$66.4 \quad 677$

$1.8 \quad 18$

$0.5 \quad 5$

$0.2 \quad 2$

$0.2 \quad 2$

Percentage of Patients Seen for

Chronic Care, Nonfatal Conditions

(CCF) $(\mathrm{n}=1027)$

$$
\begin{aligned}
& \text { None } \\
& 1-20 \% \\
& 21-40 \% \\
& 41-60 \% \\
& 61-80 \% \\
& 81-100 \%
\end{aligned}
$$

$11.0 \% \quad 113$

$53.4 \quad 548$

$26.7 \quad 274$

$5.5 \quad 56$

$2.3 \quad 24$

$1.2 \quad 12$

Percentage of Patients Seen for

Chronic Care, Potentially Fatal

Conditions $(\mathrm{CCN})(\mathrm{n}=1017)$

$$
\begin{aligned}
& \text { None } \\
& 1-20 \% \\
& 21-40 \% \\
& 41-60 \% \\
& 61-80 \% \\
& 81-100 \%
\end{aligned}
$$

$23.8 \% \quad 242$

$43.4 \quad 441$

$23.9 \quad 243$

$6.3 \quad 64$

$1.8 \quad 18$

$1.0 \quad 10$ 


\section{Support for Health Care Rationing Policies}

Strong support for health care rationing policies such as that proposed under the Oregon Health Plan was found among the state's primary care physicians. Of the 1,133 physicians responding to the question "Do you support health care rationing policies such as the Oregon Health Plan," over 70.3 percent expressed some measure of support. Just over 41 percent of the primary care physicians $(n=465)$ were supportive and 29.2 percent $(\mathrm{n}=331)$ were very supportive of such policies. Another 16.6 percent $(n=188)$ of the primary care physicians expressed neutrality toward health care rationing, and 13.2 percent were either not supportive of rationing policies or they were unalterably opposed to the idea $(\mathrm{n}=149)$. These findings are displayed in Table 16, below.

TABLE 16

OREGON PRIMARY CARE PHYSICIAN

RESPONDENTS' SUPPORT FOR HEALTH CARE RATIONING POLICIES SUCH AS THE OREGON HEALTH PLAN, $\mathbf{N}=1133$

\begin{tabular}{lcc}
\hline Support Level & Percent Responding & $N$ \\
& $29.21 \%$ & 331 \\
Very Supportive & 41.04 & 465 \\
Supportive & 16.59 & 188 \\
Neutral & 9.44 & 107 \\
Not Supportive & 3.71 & 42 \\
Unalterably Opposed & $100.00 \%$ & 1133 \\
Total & & \\
\hline
\end{tabular}




\section{Rationing Support: by Primary Care Specialty}

As a group, internal medicine (IM) physicians expressed the most support for health care rationing policies of any primary care specialty examined, with 75.6 percent $(n=242)$ indicating that they were either very supportive (28.9 percent) or supportive (40.6 percent) of the idea. A smaller percentage of physicians who practice obstetrics \& gynecology (OB/GYN) expressed support for health care rationing policies, however strong support was still evident with 67.2 percent $(n=84)$ of the OB/GYN physicians indicating that they were either very supportive (34.4 percent) or supportive (32.8 percent) of health care rationing policies. However, OB/GYN physicians, as a group, expressed the highest order of support of any primary care physician group, with 34.4 percent $(n=43)$ being very supportive of the concept.

Family practice physicians and pediatricians fell in the middle of these two specialty groups as a measure of their support, with $69.4(n=319)$ percent of the family practice physicians and 70.9 percent $(n=95)$ of the pediatricians reporting that they were either very supportive or supportive of the idea of health care rationing policies. These support differences among specialty groups are significant $(\mathrm{p}=$ 0.05). Table 17 displays these findings.

On the other end of the spectrum, pediatricians expressed the greatest amount of non-support or opposition to health care rationing policies. While still in the minority, just over 15 percent $(n=20)$ of pediatricians indicated that they were either 
TABLE 17

\section{OREGON PRIMARY CARE PHYSICIAN RESPONDENTS' SUPPORT FOR HEALTH CARE} RATIONING POLICIES, BY PRACTICE SPECIALTY, $N=1103$

\begin{tabular}{|c|c|c|c|c|c|}
\hline Support Level & Peds & $I M$ & $O B / G Y N$ & $F P$ & Other \\
\hline Very Supportive & $19.6 \%$ & 32.8 & 34.4 & 28.9 & 20.3 \\
\hline Supportive & 51.1 & 42.8 & 32.8 & 40.6 & 40.6 \\
\hline Neutral & 14.3 & 15.0 & 18.4 & 15.8 & 20.0 \\
\hline Not Supportive & 13.5 & 6.9 & 12.0 & 9.3 & 9.4 \\
\hline Unalterably Oppose & d 1.5 & 2.5 & 2.4 & 5.4 & 4.7 \\
\hline $\mathbf{N}$ & 133 & 320 & 125 & 461 & 64 \\
\hline$X^{2}=31.000$ & \multicolumn{2}{|c|}{ Model $\mathrm{p}=0.013$} & \multicolumn{2}{|c|}{$\mathrm{Df}=16$} & \\
\hline
\end{tabular}

not supportive (13.5 percent) of the concept or unalterably opposed (1.5 percent) to the idea. Family practice physicians expressed the greatest opposition to health care rationing policies with just over 5.4 percent $(n=25)$ unalterably opposed to the concept. OB/GYN physicians were most neutral to the idea, with 18.4 percent $(n=23)$ of the OB/GYN physicians indicating neutrality to health care rationing policies. These findings are displayed in Table 17, above.

\section{Rationing Support: by Geographic Location}

No significant differences were found among rural and urban primary care physicians and their support for health care rationing policies. Just over 73 percent 
$(n=458)$ of the urban primary care physicians expressed support for rationing policies, with 30.3 percent of those being very supportive and 42.0 being supportive of the idea. Just over 67.3 percent $(n=308)$ of rural primary care physicians expressed support for rationing policies, with 27.7 being very supportive. Slightly more rural physicians were unalterably opposed to the idea of rationing policies $(5.2$ percent) than were urban primary care physicians ( 2.7 percent), however these differences were not statistically significant. See Table 18 for these findings.

TABLE 18

OREGON PRIMARY CARE PHYSICIAN RESPONDENTS' SUPPORT FOR HEALTH CARE RATIONING POLICIES, BY PRACTICE LOCATION, $\mathbf{N}=1086$

\begin{tabular}{lccr}
\hline Support Level & Rural & Urban & $N$ \\
& & & \\
Very Supportive & $27.7 \%$ & $30.3 \%$ & 317 \\
Supportive & 39.7 & 42.9 & 451 \\
Neutral & 16.8 & 15.5 & 174 \\
Not Supportive & 10.7 & 8.6 & 103 \\
Unalterably Opposed & 5.2 & 2.7 & 41 \\
Total & $100.0 \%$ & $100.0 \%$ & \\
$\mathrm{~N}$ & 459 & 627 & 1086 \\
$\mathrm{X}^{2}=7.224$ & $\mathrm{P}=0.125$ & $\mathrm{Df}=4$ & \\
\hline
\end{tabular}


Rationing Support: by City Size

Despite no significant differences between rural and urban physicians' support for health care rationing, significant differences $(p<0.01)$ were found in the percentage of physicians supporting health care rationing policies when the size of the city in which the physician practices was examined. As a group, primary care physicians who practiced in large and medium urban cities expressed more support for rationing policies than did physicians in small cities and rural towns. Just over 31.7 percent $(n=105)$ of the physicians in large cities and 32.5 percent $(n=63)$ of the medium city physicians were very supportive of health care rationing policies. In contrast, only 20.1 percent of the rural primary care physicians were very supportive of the concept. However, physicians in small cities appeared to support health care rationing policies as much as their large city colleagues. Just over 32.2 percent $(n=92)$ of the small city physicians expressed that they were very supportive of rationing policies. Interestingly, primary care physicians in suburban areas of the state also were less supportive of rationing policies than were their larger city counterparts. Only 21.6 percent $(n=22)$ of the suburban primary care physicians indicated that they were very supportive of health care rationing policies.

Like earlier findings, a majority of primary care physicians, regardless of their city of practice, expressed some measure of support for the concept, with medium city urban physicians expressing the greatest percentage of overall support $(76.8$ percent), followed by large city urban (70.02 percent), small city ( 69.5 percent), rural (63.8), and suburban (63.7 percent). These findings are shown in Table 19. 
TABLE 19

\section{OREGON PRIMARY CARE PHYSICIAN RESPONDENTS' SUPPORT FOR HEALTH CARE RATIONING POLICIES, BY CITY SIZE OF PRACTICE, $\mathbf{N}=1105$}

\begin{tabular}{llllll}
\hline & & & & & \\
Support Level & Large & Med. & Sub. & Small & Rural \\
& & & & & \\
Very Supportive & $31.7 \%$ & $32.5 \%$ & $21.6 \%$ & $32.3 \%$ & $20.1 \%$ \\
Supportive & 42.3 & 44.3 & 42.2 & 37.2 & 43.7 \\
Neutral & 14.8 & 13.9 & 20.6 & 16.1 & 17.8 \\
Not Supportive & 9.7 & 7.2 & 7.8 & 9.8 & 12.1 \\
Unalterably Opposed & 1.5 & 2.1 & 7.8 & 4.6 & 6.3 \\
Total & $100.0 \%$ & $100.0 \%$ & $100.0 \%$ & $100.0 \%$ & $100.0 \%$ \\
$\mathrm{~N}$ & 331 & 194 & 102 & 285 & 174 \\
$\mathrm{X}^{2}=10.33$ & & $\mathrm{p}<0.01$ & & Df $=3$ & \\
\end{tabular}

Rationing Support: by Type of Practice

A significant difference $(p<0.05)$ in support for health care rationing policies was found between primary care physicians who practiced in a solo/partnership or a non-solo/partnership practice arrangement. Solo/partnership based primary care physicians were significantly $(p=0.05)$ more supportive of health care rationing policies than were group practice physicians, with 36.8 percent $(n=77)$ being very supportive of the concept, in contrast to 25.4 percent $(n=137)$ of the non-solo/partnership physicians being very supportive. However, both groups were supportive of the concept, overall, with 71.6 percent of the solo/partnership 
based physicians and 65.9 percent of the non-solo/partnership based physicians being very supportive or supportive of health care rationing policies. In contrast, nonsolo/partnership primary care physicians tended to be more non-supportive and opposed to the idea, with 16.1 percent falling within those two categories, compared to 12.0 percent of the solo/partnership primary care physicians being non-supportive or opposed to the idea. These findings are shown in Table 20, below.

\section{TABLE 20}

\section{OREGON PRIMARY CARE PHYSICIAN \\ RESPONDENTS' SUPPORT FOR HEALTH CARE RATIONING \\ POLICIES, BY PRACTICE TYPE, $\quad \mathrm{N}=748$}

\begin{tabular}{lccc} 
Support Level & Solo/partner & Non-Solo/part & $N$ \\
Very Supportive & $36.84 \%$ & 25.42 & 214 \\
Supportive & 34.45 & 40.45 & 290 \\
Neutral & 16.75 & 18.00 & 132 \\
Not Supportive & 9.09 & 11.13 & 79 \\
Unalterably Opposed & 2.87 & 5.01 & 33 \\
N & 209 & 539 & 748 \\
$\mathrm{X}^{2}=10.555$ & $\mathrm{p}=0.05$ & & $\mathrm{Df}=3$ \\
\hline
\end{tabular}


Rationing Support: by Managed Care Affiliation

Small, but non-significant $(p=0.15)$ differences were found in support for health care rationing policies between primary care physicians practicing in (or affiliated with) managed care associations (MCA) and those primary care physicians not affiliated with an MCA. A majority of both groups were either supportive or very supportive of health care rationing. Just under 70.5 percent $(n=212)$ of nonMCA affiliated physicians supported health care rationing (30.2 were very supportive), compared to 65.7 percent $(n=416)$ of the MCA affiliated primary care physicians (26.5 were very supportive) expressing support. These findings are displayed in Table 21.

\section{TABLE 21}

OREGON PRIMARY CARE PHYSICIAN

RESPONDENTS' SUPPORT FOR HEALTH CARE

RATIONING POLICIES, BY AFFILIATION WITH MANAGED CARE

ORGANIZATIONS -- HMO, PPO, or IPA -- (MCA) Status, N = 919

\begin{tabular}{lcc}
\hline Support Level & Non-MCA & $M C A$ \\
Very Supportive & 30.18 & 26.47 \\
Supportive & 40.29 & 39.22 \\
Neutral & 16.64 & 17.65 \\
Not Supportive & 9.95 & 10.46 \\
Unalterably Opposed & 2.94 & 6.21 \\
$\mathrm{~N}$ & 306 & 613 \\
$\mathrm{X}^{2}=6.633$ & $\mathrm{P}=0.157$ & $\mathrm{Df}=4$ \\
\hline
\end{tabular}


Slightly more managed care affiliated (MCA) physicians were opposed to health care rationing policies than were non-MCA physicians, however this difference was not statistically significant $(p=0.157)$. Just over 6 percent of the MCA affiliated primary care physicians expressed unalterable opposition to health care rationing policies in comparison to 2.94 percent of the non-MCA affiliated primary care physicians.

\section{Rationing Support: by Years Practicing}

A greater percentage of newly practicing physicians (those in practice less than five years) were supportive of health care rationing than were established physicians. However, a greater percentage of established physicians were very supportive of the concept. Just over 70.4 percent $(n=230)$ of the newly practicing physicians were either supportive or very supportive of health care rationing policies. Just under 65.7 percent $(n=875)$ of established physicians were very supportive or supportive of health care rationing policies. This difference is significant $(p<0.05)$. See Table 22 , next page.

In contrast, established physicians were somewhat more split in their opposition and neutrality to the concept of health care rationing. While 14.8 percent of the newly established physicians were neutral to the concept, 16.8 percent of the established physicians were neutral. As well, while 10.4 percent of the newly established physicians did not support or were opposed to the concept of health care 
TABLE 22

OREGON PRIMARY CARE PHYSICIAN
RESPONDENTS' SUPPORT FOR HEALTH CARE
RATIONING POLICIES, BY NEWLY ESTABLISHED
AND ESTABLISHED PRACTICES, N $=1105$

\begin{tabular}{lcc}
\hline Support Level & Newly Est. & Established \\
Very Supportive & $25.65 \%$ & $29.83 \%$ \\
Supportive & 49.13 & 39.31 \\
Neutral & 14.78 & 16.80 \\
Not Supportive & 9.13 & 9.60 \\
Unalterably Opposed & 1.30 & 4.46 \\
Total & $100.0 \%$ & $100.0 \%$ \\
$\mathrm{~N}$ & 230 & 875 \\
$\mathrm{X}^{2}=10.60$ & $\mathrm{p}=0.031$ & $\mathrm{Df}=4$
\end{tabular}

Newly Established Physicians = physicians in practice less than 5 years Established Physicians = physicians in practice five years or more

rationing policies, 16.7 percent of the established physicians were not supportive or opposed to the idea. Again, as is shown in Table 19, above, these differences were significant $(\mathrm{p}<0.05)$.

When these trends are broken down further, primary care physicians who were in practice more than 20 years expressed the least support for health care rationing. Just under 62.6 percent of those physicians were supportive, while 74.6 percent of those in practice less than five years were supportive. Interestingly, support for health care rationing policies drops in an almost liner fashion with the number of years a physician has been in practice. These differences are statistically significant $(\mathrm{p}<0.005)$, and are displayed in Table 23, next page. 
TABLE 23

OREGON PRIMARY CARE PHYSICIAN RESPONDENTS'

SUPPORT FOR HEALTH CARE RATIONING POLICIES, BY

LENGTH OF YEARS IN PRACTICE, $\mathrm{N}=1105$

\begin{tabular}{lcccc}
\hline \multirow{2}{*}{ Support Level } & \multicolumn{4}{c}{ Years in practice } \\
\cline { 2 - 5 } & $<5$ yrs & $5-10 y r s$ & $>10-20 y r s$ & $>20 y r s$ \\
Very Supportive & $25.65 \%$ & $29.52 \%$ & $31.64 \%$ & $27.89 \%$ \\
Supportive & 49.13 & 42.73 & 40.96 & 34.69 \\
Neutral & 14.78 & 17.62 & 14.41 & 19.05 \\
Not Supportive & 9.13 & 6.61 & 10.45 & 10.88 \\
Unalterably Opposed & 1.30 & 3.52 & 2.54 & 7.48 \\
Total & $100.0 \%$ & $100.0 \%$ & $100.0 \%$ & $100.0 \%$ \\
$\mathrm{~N}$ & 230 & 227 & 354 & 294 \\
$\mathrm{X}^{2}=29.95$ & \multicolumn{4}{c}{$\mathrm{Df}=12$} \\
\hline
\end{tabular}

Rationing Support: by M.D. and D.O. Physicians

Allopathic primary care physicians (M.D.s) were significantly $(p<0.025)$ more supportive of health care rationing policies than were osteopathic primary care physicians (D.O.s). While 29.8 percent $(n=308)$ of the M.D.s were very supportive of rationing policies, only 17.6 percent $(n=13)$ of the D.O.s were very supportive of health care rationing policies. Almost twice the percentage of D.O.s (21.6 percent) were either non-supportive or unalterably opposed to health care rationing than were M.D.s (12.8 percent). These differences were significant $(p<0.005)$. Table 24 , next page, shows these findings. 
TABLE 24

\begin{tabular}{|c|c|c|}
\hline \multicolumn{3}{|c|}{$\begin{array}{l}\text { OREGON PRIMARY CARE PHYSICIAN RESPONDENTS' } \\
\text { SUPPORT FOR HEALTH CARE RATIONING POLICIES } \\
\text { SUCH AS THE OREGON HEALTH PLAN, BY TYPE OF } \\
\text { MEDICAL DEGREE (M.D. or D.O.), } \quad \mathrm{N}=1109\end{array}$} \\
\hline Support Level & $M . D$. & D.O. \\
\hline Very Supportive & $29.76 \%$ & $17.57 \%$ \\
\hline Supportive & 41.35 & 41.89 \\
\hline Neutral & 16.14 & 18.92 \\
\hline Not Supportive & 8.99 & 18.92 \\
\hline Unalterably Opposed & 3.77 & 2.70 \\
\hline Total & $100.0 \%$ & $100.0 \%$ \\
\hline $\mathbf{N}$ & 1035 & 74 \\
\hline$X^{2}=11.154$ & & Df $=$ \\
\hline
\end{tabular}

Rationing Support: by Patient Insurance Status

Primary care physicians who treated uninsured patients were somewhat more supportive of health care rationing policies than were physicians who did not treat uninsured patients, but not significantly so. While 29.1 percent $(n=230)$ of physicians with uninsured patients were very supportive of health care rationing, just under 23.5 percent $(n=27)$ of physicians without any uninsured patients were.

Contrary to what might be expected, physicians who treat uninsured patients were somewhat more opposed to the concept of health care rationing (3.92 were unalterably opposed) than were physicians who had no uninsured patients $(0.87$ percent). These differences were not statistically significant, however. These findings are displayed in Table 25. 
TABLE 25

\begin{abstract}
OREGON PRIMARY CARE PHYSICIAN RESPONDENTS' SUPPORT FOR HEALTH CARE RATIONING POLICIES, BY PHYSICIANS WITH UNINSURED PATIENTS AND PHYSICIANS WITH NO UNINSURED PATIENTS, $\mathrm{N}=906$
\end{abstract}

\begin{tabular}{lcc}
\hline & $\begin{array}{l}\text { No Unins. } \\
\text { Patients }\end{array}$ & $\begin{array}{l}\text { With Unins. } \\
\text { Patients }\end{array}$ \\
Support Level & $23.48 \%$ & $29.08 \%$ \\
Very Supportive & 49.57 & 40.46 \\
Supportive & 16.52 & 16.56 \\
Neutral & 9.57 & 9.99 \\
Not Supportive & 0.87 & 3.92 \\
Unalterably Opposed & $100.0 \%$ & $100.0 \%$ \\
Total & 115 & 791 \\
$\mathrm{~N}$ & $\mathrm{p}=0.217$ & $\mathrm{Df}=4$ \\
$\mathrm{X}^{2}=5.774$ & & \\
\hline
\end{tabular}

Rationing Support: by Physicians With Medicaid Patients

More primary care physicians who treat patients on Medicaid expressed support for health care rationing policies than did primary care physicians who did not accept Medicaid patients. While 29.46 percent of the physicians with Medicaid patients were very supportive of rationing, just over 21.7 percent of the physicians who did not accept Medicaid patients were very supportive of the concept. These differences were not significant, however. This finding is shown in Table 26. 
TABLE 26

OREGON PRIMARY CARE PHYSICIAN RESPONDENTS' SUPPORT FOR HEALTH CARE RATIONING POLICIES, BY PHYSICIANS WITH MEDICAID PATIENTS AND PHYSICIANS WITH NO MEDICAID PATIENTS, $\mathrm{N}=932$

\begin{tabular}{lcc}
\hline & $\begin{array}{c}\text { No Medicaid } \\
\text { Patients }\end{array}$ & $\begin{array}{c}\text { With Medicaid } \\
\text { Patients }\end{array}$ \\
Very Supportive & $21.77 \%$ & $29.46 \%$ \\
Supportive & 41.94 & 41.83 \\
Neutral & 20.16 & 15.72 \\
Not Supportive & 10.48 & 9.99 \\
Unalterably Opposed & 5.65 & 3.09 \\
Total & $100.0 \%$ & $100.0 \%$ \\
$\mathrm{~N}$ & 124 & 808 \\
$\mathrm{X}^{2}=5.604$ & $\mathrm{p}=0.231$ & $\mathrm{Df}=4$ \\
\hline
\end{tabular}

Mean Support Measures

While large proportional differences were found among the primary care specialty groups studied, mean support scores provide us a conceptual measure of support for changing the Oregon health care system to include health care rationing such as that proposed by the Oregon Health Plan. It is to those mean support measures that this study now examines. 


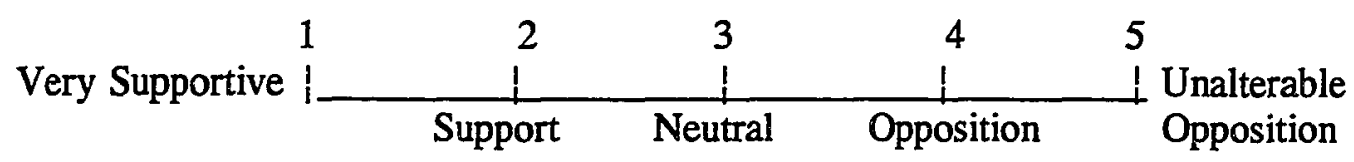

Figure 6. Health Care Rationing Support Likert Scale

\section{Mean Levels of Support}

Respondents who were internal medicine (IM) primary care physicians had the lowest mean health care rationing support measure of any primary care physician group surveyed, ${ }^{6}$ indicating the highest level of support among the physician groups (See Figure 6). Collectively, IM physicians reported a mean support score of 2.03 on a scale of $1=$ very supportive to $5=$ unalterably opposed. OB/GYN and family practice (FP) physicians were second and third, respectively, in their mean support, with measures of 2.15 and 2.22. Except for the general Other category of physicians, pediatricians had the highest mean support measure of 2.26 , indicating the lowest level of support. These differences are significant $(p<0.05)$. See Table 24 .

Despite this variation in support measures, all four primary care specialty groups revealed mean support measures between the neutral and supportive values on the scale above (See Figure 6). None of the physician groups had mean scores that fell on or near the neutral value of 3 .

There was a significant difference $(p<0.05)$ in mean support measures

6 A high mean support score is one that approaches 1 , on a scale of $1=$ very supportive to $5=$ unalterable opposition. 
between family practice (FP) physicians and internal medicine (IM) physicians.

However, none of the other differences were statistically significant. Mean support measures are displayed in Table 27.

TABLE 27

MEAN SUPPORT MEASURES FOR HEALTH CARE RATIONING POLICIES, BY OREGON PRIMARY PHYSICIANS

$(1$ = VERY SUPPORTIVE TO 5 = UNALTERABLY OPPOSED)

$\mathrm{N}=1103$

\begin{tabular}{lcccc}
\hline & Rank & $\begin{array}{c}\text { Mean } \\
\text { Support Score }\end{array}$ & $S D$ & $N$ \\
All physicians & & 2.209 & 1.069 & \\
& & & & \\
Internal Medicine & 1 & 2.034 & 0.990 & 320 \\
OB/GYN & 2 & 2.152 & 1.100 & 125 \\
Family Practice & 3 & 2.219 & 1.124 & 461 \\
Pediatrics & 4 & 2.263 & 0.976 & 133 \\
Other & 5 & 2.375 & 1.062 & 64 \\
& & & & \\
$\mathrm{R}^{2}=0.009$ & ANOVA F $=2.407 \mathrm{P}=0.048$ & $\mathrm{Df}=4$ \\
& & & \\
\hline
\end{tabular}

Internal medicine (IM) physicians had significantly $(\mathrm{p}<0.001)$ lower scores than did family practice physicians (a lower score indicated more support). No significant differences were found between family practice physicians and the other primary care specialty groups, however. As well, mean support scores were not significantly different between IM and OB/GYN primary care physicians. However, the mean support measures between the family practice, pediatricians, and other 
primary care physician specialties were significantly different $(p<0.05)$ from the IM physicians' mean support measures.

\section{Rationing Mean Support: by Rural Physicians}

In general, rural primary care physicians reported significantly $(p<0.05)$ lower mean support measures than did their urban counterparts. As a group, rural physicians reported mean support measures of 2.26 and the urban physicians reported mean support measures of 2.11. However, despite these differences, both groups were found to have mean support measures that fell within the support range for health care rationing policies.

That trend continued when rural and urban physicians were compared as members of their respective primary care specialty. Except for the Other category of physicians, the urban primary care physicians, regardless of their specialty, reported higher mean support measures that did their rural colleagues. This finding is summarized in Table 28. 
TABLE 28

\begin{tabular}{|c|c|c|}
\hline \multicolumn{3}{|c|}{$\begin{array}{c}\text { MEAN SUPPORT FOR HEALTH } \\
\text { CARE RATIONING POLICIES BY } \\
\text { OREGON RURAL AND URBAN PRIMARY } \\
\text { PHYSICIANS, ( } 1=\text { VERY SUPPORTIVE TO } \\
5=\text { UNALTERABLY OPPOSED) } \mathrm{N}=1084\end{array}$} \\
\hline & Rural & Urban \\
\hline All Physicians & 2.261 & $2.105^{*}$ \\
\hline Pediatrics & 2.390 & 2.170 \\
\hline Internal Medicine & 2.165 & 1.972 \\
\hline OB/GYN & 2.365 & 2.071 \\
\hline Family Practice & 2.291 & 2.134 \\
\hline Other & 2.069 & $2.629 *$ \\
\hline
\end{tabular}

Rationing Mean Support: by City Size

As a function of city size, the greatest measure of opposition to health care rationing was found among rural OB/GYN physicians. With a mean support measure of 3.400, this group of physicians is strongly opposed to health care rationing. The highest level of support was found among suburban internal medicine (IM) physicians, with mean support measures of 1.902 , clearly within the support range. Suburban pediatricians and small town family practice physicians were also strongly supportive of health care rationing, with mean scores of 1.979 and 1.929 , respectively.

While the model shows significance $(p<0.10)$, when scores as a function of city size were measured between the groups of primary care physicians, pediatric and 
the other group of primary care physicians' mean support scores were not found to be significantly different $(p=0.25)$. However, internal medicine (IM) and OB/GYN mean support scores were significantly different $(p<0.10)$, and negatively correlated with the size of the city in which the primary care physician practiced. Among these two groups, the smaller the city, the lower the mean support for rationing.

Within city size groups, the mean support scores of the urban-large city, urban-medium city, small town, and rural physicians were not significantly different. However, the mean support scores between suburban physicians was significantly different $(p<0.01)$, depending on the primary care specialty. Suburban pediatricians and IM physicians had significantly $(\mathrm{p}<0.01)$ more support for health care rationing than did their other colleagues who practiced FP, OB/GYN, or other types of primary care. Table 29 shows these findings.

TABLE 29

MEAN SUPPORT FOR HEALTH CARE RATIONING POLICIES, BY CITY SIZE, $N=1084$

Urban Lge. Urban Med. Suburban* Small Town Rural

$\begin{array}{lrrrrr}\text { All Physicians } & 2.162 & 2.074 & 2.567 & 2.181 & 2.462 \\ \text { Pediatricians } & 2.178 & 1.979 & 2.021 & 2.055 & 2.575 \\ \text { Internal Medicine** } & 2.154 & 1.902 & 1.929 & 2.023 & 2.364 \\ \text { OB/GYN** } & 2.176 & 2.033 & 2.700 & 2.525 & 3.400 \\ \text { Family Practice } & 2.333 & 2.061 & 2.242 & 2.180 & 2.091 \\ \text { Other } & 2.800 & 2.387 & 2.714 & 2.407 & 2.000\end{array}$

$\mathbf{R}^{2}=0.039$

ANOVA $F=2.212$

$P=0.066$

* Significant difference between physician scores $\mathrm{p}<0.01$

**Significant difference within physician groups $\mathrm{p}<0.001$. 
Rationing Mean Support: by Type of Practice

Primary care physicians who practice in group settings were significantly $(\mathrm{p}<$ 0.001) more supportive of health care rationing polices than were their counterparts who practice in solo/partnerships. As shown in Table 30, group practice physicians had a mean health care rationing support measure of 2.089 , and the solo/partnership physicians had a mean health care rationing support of 2.321. In all specialties of primary care physicians, group-practice physicians were more supportive of health care rationing than were their solo/partnership colleagues. Significant differences ( $p$ $<0.05$ ) were found between internal medicine, OB/GYN, and family practice physicians. No significant difference was found between pediatricians and the other category of primary care physicians. The difference were not significant, however.

TABLE 30

MEAN SUPPORT FOR HEALTH CARE RATIONING, BY SOLO/PARTNERSHIP AND GROUP PRACTICE OREGON PRIMARY PHYSICIANS

$(1=$ VERY SUPPORTIVE TO $5=$ UNALTERABLY OPPOSED), $\mathrm{N}=1084$

\begin{tabular}{lcl}
\hline & Solo/Partner & Group \\
All Physicians & 2.321 & $2.089^{* * *}$ \\
Pediatrics & 2.350 & \\
Internal Medicine & 2.175 & 2.192 \\
OB/GYN & 2.324 & $1.929^{*}$ \\
Family Practice & 2.336 & $1.926^{*}$ \\
Other & 2.421 & $2.082^{* *}$ \\
& & 2.318 \\
\hline${ }^{*} \mathrm{p}<0.05 \quad{ }^{* *} \mathrm{p}<0.01$ & ${ }^{* * *} \mathrm{p}<0.001$ &
\end{tabular}


Rationing Support: by M.D. and D.O. Physicians

Osteopathic physicians (D.O.s) were somewhat less supportive of health care rationing policies than were allopathic physicians (M.D.s). While significant $(p<$ 0.01), the difference is not great. M.D.s had a mean rationing support measure of 2.202, while D.O.s were found to have a mean support measure of 2.268 .

As Table 31 shows, when support was examined between primary care physicians specialties, only family practice (FP) osteopathic physicians were found to have significantly less support for rationing policies than did their M.D. counterparts. While D.O. family practice physicians reported mean rationing support measures of 2.519, M.D. family practice physicians were found to have a mean rationing support measure of 2.179 .

TABLE 31

MEAN SUPPORT FOR HEALTH CARE RATIONING, BY ALLOPATHIC (M.D.) AND OSTEOPATHIC (D.O.) OREGON PRIMARY PHYSICIANS

$(1=$ VERY SUPPORTIVE TO $5=$ UNALTERABLY OPPOSED $), \quad \mathrm{N}=1084$

$$
\text { M.D. D.O. }
$$

$\begin{array}{lll}\text { All Physicians } & 2.202 & 2.268^{* *} \\ \text { Pediatrics } & 2.262 & 2.333 \\ \text { Internal Medicine } & 2.026 & 2.200 \\ \text { OB/GYN } & 2.156 & 2.000 \\ \text { Family Practice } & 2.179 & 2.519^{*} \\ \text { Other } & 2.386 & 2.286\end{array}$

$* \mathrm{p}<0.05 \quad * * \mathrm{p}<0.01 \quad * * * \mathrm{p}<0.001$ 
Rationing Mean Support: by Managed Care Affiliation

Primary care physicians with a managed care affiliation (MCA) were significantly $(p<0.01)$ more supportive of health care rationing policies than were their counterparts who were not affiliated with MCAs. While the MCA group reported mean rationing support measures of 2.198 , the non-MCA group reported mean support measures of 2.354. While both measures were within the support range for health care rationing, the managed care group was more supportive of health care rationing than was the non-managed care group.

When health care rationing measures were examined between primary care specialty groups, no significant differences in support were found between pediatricians, internal medicine (IM) physicians, and other primary care physicians' mean support measure. However, $\mathrm{OB} / \mathrm{GYN}$ physicians and family practice physicians with managed care affiliations were significantly $(p<0.05)$ more supportive of health care rationing policies than were their non-affiliated colleagues. This finding is shown in Table 32. 
TABLE 32

\begin{tabular}{|c|c|c|}
\hline $\begin{array}{r}\text { MEAN SUPP } \\
\text { CARE RATIO } \\
\text { CARE AFFILIATI } \\
\text { TO } 5=\text { UNAL }\end{array}$ & $\begin{array}{l}\text { URES FOF } \\
\text { CIES, BY } \\
(1=\text { VER } \\
\text { OPPOSED) }\end{array}$ & $\begin{array}{l}\text { H } \\
\text { ED } \\
\text { RTIVE } \\
99\end{array}$ \\
\hline & Man & Affiliation \\
\hline & Affiliated & Not Affiliated \\
\hline All Physicians & 2.198 & $2.358 * *$ \\
\hline Pediatrics & 2.295 & 2.385 \\
\hline Internal Medicine & 2.037 & 2.143 \\
\hline $\mathrm{OB} / \mathrm{GYN}$ & 2.089 & $2.522^{*}$ \\
\hline Family Practice & 2.186 & $2.314^{* * *}$ \\
\hline Other & 2.385 & 2.429 \\
\hline
\end{tabular}

Rationing Support: by Patient Insurance Status

When mean rationing support measures for primary care physicians who have patients without health insurance were compared with primary care physicians who have no uninsured patients, no significant difference in mean support for health care rationing was found. While those physicians with no insured patients were somewhat more supportive of NHI, this difference was not statistically significant.

Likewise, no significant differences were found between primary care specialty groups with and without uninsured patients. These findings are displayed in Table 33, next page. 
TABLE 33

MEAN SUPPORT MEASURES FOR HEALTH CARE RATIONING POLICIES, BY PATIENT INSURANCE STATUS $(1=$ VERY SUPPORTIVE TO 5 = UNALTERABLY OPPOSED) $\mathrm{N}=1089$

\begin{tabular}{lcc}
\hline & \multicolumn{2}{c}{ Patient Insurance Status } \\
\cline { 2 - 3 } & $\begin{array}{c}\text { Some Without } \\
\text { Insurance }\end{array}$ & $\begin{array}{c}\text { All Patients } \\
\text { Insured }\end{array}$ \\
All Physicians & 2.228 & \\
Pediatrics & 2.273 & 2.170 \\
Internal Medicine & 2.096 & 2.000 \\
OB/GYN & 2.170 & 2.054 \\
Family Practice & 2.190 & 2.300 \\
Other & 2.413 & 2.370 \\
& & 2.125 \\
\hline${ }^{*}<0.05{ }^{* * p}<0.01$ & $* * * p<0.001$ &
\end{tabular}

Rationing Support: by Medicaid Status

Primary care physicians who treat Medicaid patients and those who do not, were equally supportive of health care rationing policies. While physicians who have Medicaid patients were found to have a mean rationing support measure of 2.192 (indicating support), their counterparts who have no Medicaid patients were found to have mean support measures of 2.148 . The difference is not significant.

Family practice physicians were found to have a significantly lower rating support measure than were their colleagues who treat Medicaid patients. This difference was significant $(p<0.05)$. No differences in support measures were found between the other primary care specialties. Table 34 displays these findings. 
TABLE 34

\section{MEAN SUPPORT MEASURES FOR HEALTH CARE RATIONING POLICIES, BY MEDICAID INSURANCE STATUS $(1=$ VERY SUPPORTIVE TO 5 = UNALTERABLY OPPOSED) $\quad \mathrm{N}=1089$}

\begin{tabular}{lcc}
\hline & \multicolumn{2}{c}{ Physician Practice Status } \\
\cline { 2 - 3 } & $\begin{array}{c}\text { Has } \\
\text { Medicaid Pts. }\end{array}$ & No Medicaid Patients \\
All Physicians & 2.192 & 2.148 \\
Pediatrics & 2.235 & 2.300 \\
Internal Medicine & 2.048 & 2.200 \\
OB/GYN & 2.153 & 2.636 \\
Family Practice & 2.159 & $2.514^{*}$ \\
Other & 2.372 & 2.364 \\
\hline
\end{tabular}

${ }^{*} \mathrm{p}<0.05{ }^{* *} \mathrm{p}<0.01 \quad * * * \mathrm{p}<0.001$

\section{Rationing Support: by New and Established Physicians}

No significant difference in support for health care rationing policies was found between newly practicing physicians and their established counterparts. Both groups reported mean rationing support measures that indicated support for health care rationing.

However, family practice (FP) physicians who had been in practice five years or more were significantly $(p<0.05$ ) more supportive of health care rationing than were the newly practicing FP physicians. This was an unexpected finding. See Table 35, next page. 
TABLE 35

\begin{tabular}{|c|c|c|}
\hline & $\begin{array}{c}\text { Newly } \\
\text { Established }\end{array}$ & Established ${ }^{1}$ \\
\hline All Physicians & 2.208 & 2.189 \\
\hline Pediatrics & 2.292 & 2.243 \\
\hline Internal Medicine & 2.066 & 2.022 \\
\hline $\mathrm{OB} / \mathrm{GYN}$ & 2.105 & 2.160 \\
\hline Family Practice & 2.336 & $2.264 *$ \\
\hline Other & 2.421 & 2.348 \\
\hline
\end{tabular}

To test for health care rationing support further, support for health care rationing was examined across several categories of years practicing. As can be seen in Table 35 support for health care rationing is essentially the same regardless of the number of years a physician has been in practice.

However, on closer examination, significant differences were found between some primary care specialty groups. Internal medicine (IM) physicians who have been in practice 5 to 10 years were significantly $(p<0.01)$ more supportive of health care rationing that were their colleagues practicing less than five years and ten years of more. In fact, this group of IM physicians reported the greatest support measure for health care rationing found in this study, with a mean of 1.797 , clearly in the range of support for health care rationing policies. 
OB/GYN physicians who have been in practice 10 to 20 years were also found to be significantly $(\mathrm{p}<0.05$ ) more supportive of health care rationing than their counterparts practicing less than 10 years and over 20 years. OB/GYN physicians in this group were found to have mean rationing support measures of 1.907 , again clearly within the support range for health care rationing.

TABLE 36

MEAN SUPPORT MEASURE FOR HEALTH CARE RATIONING POLICIES, BY LENGTH OF YEARS IN PRACTICE, (1=VERY SUPPORTIVE TO $5=$ UNALTERABLY OPPOSED) $\mathrm{N}=1101$

\begin{tabular}{lllll}
\hline & \multicolumn{4}{c}{ Years in practice } \\
\cline { 2 - 5 } Physician Type & $<5$ yrs & $5-10 y r s$ & $>10-20 y r$ & $>20 y r s$ \\
All Physicians & 2.189 & 2.151 & 2.179 & 2.269 \\
& & & & \\
Pediatricians & 2.292 & 2.138 & 2.392 & 2.074 \\
Internal Medicine & 2.066 & $1.797^{* *}$ & 2.062 & 2.179 \\
OB/GYN & 2.013 & 2.222 & $1.907^{*}$ & 2.333 \\
Family Practice & 2.013 & 2.255 & 2.063 & 2.472 \\
\hline
\end{tabular}

$* \mathrm{p}<0.05 \quad * * \mathrm{p}<0.01$ 
Analysis of All Independent Variables

A regression analysis of all of the independent variables in this study found that three $X$ variables significantly $(p<0.10$ ) explain variation in Oregon primary care physicians' support measures for health care rationing policies. As Table 37, next page, shows, 11.5 percent of the physicians' support measures can be explained by the regression analysis. However, the three significant variables $(p<0.10)$ in the model were:

1) Physicians' attitudes toward national health insurance.

2) Type of Clinical Practice (Solo/partnership or Group Practice).

3) Percentage of a physician's practice devoted to maternity care.

None of the other variables in the model significantly explained variation in the physicians' support measure for health care rationing.

Physicians' attitudes towards national health insurance (NHI) explained the most variation in support measure for health care rationing policies $(p<0.001)$. This regression analysis reveals that physicians who expressed a lower level of support for NHI would have a significantly higher support measure of health care rationing policies. For example, according to this finding, holding all other variables constant, a physician with a support for NHI measure of 2.00 would be predicted to have a support for health care rationing measure of 1.844 , somewhat more supportive. Even a physician who was unalterably opposed to NHI (with a support measure of 5), would be predicted to have a health care rationing support measure of 
2.519, again clearly within the support range for heath care rationing.

\section{TABLE 37}

REGRESSION ANALYSIS OF OREGON PRIMARY CARE PHYSICIANS' MEASURE OF SUPPORT FOR HEALTH CARE RATIONING POLICIES SUCH AS THE OREGON HEALTH PLAN ( $1=$ VERY SUPPORTIVE TO $5=$ UNALTERABLE OPPOSITION), LISTED IN ORDER OF STRENGTH, ${ }^{1} \mathrm{~N}=$ 665

Y Variable: Measure of Support for Health Care Rationing Policies

Independent Variables $(X)$

Constant

Support for National Health Insurance

Percent of Practice: Maternity Care

Type of Practice ( $1=$ Solo $0=$ Group)

MCA Affiliation $(0=$ No $0=$ Yes)

Years Practicing Medicine

Percent of Patients: Charged Fee-for-Service

Percent of Patients: Without Health Insurance

Percent of Practice: Preventative Care

Percent of Practice: Chronic Care-Nonfatal

Percent of Patients: On Medicare

Geographic Location ( $0=$ Urban $1=$ Rural)

Percent of Practice: Acute Care-Fatal

Percent of Practice: Chronic Care-Fatal

Percent of Practice: Acute Care Nonfatal

Percent of Practice in Office

Percent of Patients: On Medicaid

Percent of Practice Devoted to Specialty
Coefficient $\quad P(2$ Tail $)$

$1.394 \quad 0.001$

$0.225 \quad 0.000^{*}$

$-0.008 \quad 0.074^{*}$

$0.185 \quad 0.045^{*}$

$-0.168$

0.122

0.003

0.327

0.002

0.004

0.360

$-0.002$

0.312

$-0.002$

0.497

$-0.002$

0.550

0.067

0.626

$-0.001$

0.499

$-0.002$

0.844

$-0.001$

0.544

0.001

0.647

$-0.000$

0.685

$-0.000$

0.997

0.737

$\mathbf{R}^{2}=0.115 \quad$ Adjusted Multiple $\mathbf{R}^{2}=0.088$

MODEL ANOVA

Model $F=4.670 \quad$ Model $p<0.001$

1 - Strength is measured by the variable's standardized coefficient, not listed on this table. * significant variable. 
The model also reveals that physicians who are in solo/partnership practices are significantly $(p<0.05)$ less supportive of NHI than physicians in group practices. The model shows that for every 10 years physicians have been in practice, their opposition to health care rationing increases by 0.600 points.

None of the other variables in the model significantly explains variation in the primary care physicians' support for health care rationing policies. See Table 37, previous page.

\section{Support for Health Care Rationing by Pediatricians}

Only two variables in the regression model were found to significantly explain variation in the pediatricians' support for health care rationing. Pediatric physician's attitudes toward national health insurance $(p=0.007)$ and the percentage of their practice devoted to acute care-potentially fatal conditions $(p=0.088)$ were both significant variables in the model.

The more supportive of national health insurance (NHI), the more supportive of health care rationing the pediatricians would be predicted to be. However, like the entire group of physicians, pediatricians were more supportive of health care rationing than they were of NHI. For example, all other variables held constant, pediatricians who reported scores of 4.000 (non-support) for national health insurance (NHI) would be predicted to have health care rationing scores of 2.387 , within the range of support for NHI. 
Pediatricians with high percentages of their practice devoted to acute care, potentially fatal conditions were significantly $(p<0.088)$ less supportive of health care rationing than their colleagues with less patients seen for these types of conditions. This finding may be explained because of the effect rationing of health care could have on their practice of medicine. Rationing of many expensive, but not very effective medical treatments (that would certainly fall under this category of medicine) may serve to eliminate some of the practices that these physicians perform and for which they are reimbursed (i.e., bone morrow transplants, cancer chemotherapy). More research would be needed to substantiate this finding, however. This model is delineated in Table 38, next page. 
TABLE 38

PEDIATRICIAN RESPONDENTS' MEASURE OF SUPPORT FOR HEALTH CARE RATIONING POLICIES SUCH AS THE OREGON HEALTH PLAN ( $1=$ VERY SUPPORTIVE TO $5=$ UNALTERABLE OPPOSITION), $\quad \mathrm{N}=.69$

Y Variable: Measure of Support for Health Care Rationing Policies

Independent Variables $(X)$

Constant

Support for National Health Insurance

Percent of Practice: Maternity Care

Type of Practice ( $1=$ Solo $0=$ Group)

MCA Affiliation $(0=$ No $0=$ Yes)

Years Practicing Medicine

Percent of Patients: Charged Fee-for-Service

Percent of Patients: Without Health Insurance

Percent of Practice: Preventative Care

Percent of Practice: Chronic Care-Nonfatal

Percent of Patients: On Medicare

Geographic Location ( $0=$ Urban $1=$ Rural)

Percent of Practice: Acute Care-Fatal

Percent of Practice: Chronic Care-Fatal

Percent of Practice: Acute Care Nonfatal

Percent of Practice in Office

Percent of Patients: On Medicaid

Percent of Practice Devoted to Specialty
Coefficient $\quad P(2$ Tail)

$\begin{array}{rl}0.975 & 0.678 \\ 0.353 & 0.007^{*} \\ -1.381 & 0.255 \\ -0.042 & 0.844 \\ -0.438 & 0.227 \\ -0.037 & 0.819 \\ 0.001 & 0.921 \\ -0.006 & 0.712 \\ 0.004 & 0.714 \\ 0.013 & 0.373 \\ 0.014 & 0.558 \\ -0.325 & 0.364 \\ 0.054 & 0.088^{*} \\ -0.000 & 0.989 \\ 0.006 & 0.614 \\ 0.008 & 0.610 \\ -0.014 & 0.225 \\ -0.002 & 0.582\end{array}$

$\mathrm{R}^{2}=0.279 \quad$ Adjusted Multiple $\mathrm{R}^{2}=0.039$

MODEL ANOVA

Model $\mathrm{F}=1.162 \quad$ Model $\mathrm{p}=0.328$

* Statistically significant variable 


\section{Health Care Rationing Support by IM Physicians}

Only one variable in the regression model applied to internal medicine (IM) physicians was found to significantly explain variation in their support for health care rationing. Like that found for pediatricians, IM physicians' attitudes toward national health insurance $(p=0.069)$ significantly explained variation in their support for health care rationing.

And like pediatricians, who were more supportive of health care rationing than they were of NHI, the less supportive of national health insurance (NHI) the IM physicians were, the more supportive of health care rationing they would found to be, but not the same degree as pediatricians. For example, all other variables held constant, IM physicians who reported scores of 4.000 , non-support for national health insurance (NHI), would be predicted to have health care rationing scores of $3.132,{ }^{7}$ within the range of nonsupport for health care rationing policies.

\section{Step-wise Regression}

However, none of the other variables in the model were statistically significant, and the model, shown in Table 39, next page, was not significant in the manner in which it was specified (ANOVA $\mathrm{p}=0.867$ ). To test for potential model Score).

7 Found using the following formula: $\mathrm{HCR}$ Score $=2.632+0.125(\mathrm{NHI}$ 
specification error for internal medicine physicians, a step-wise regression analysis was performed. This test confirmed the multivariate regression analysis discussed

TABLE 39

INTERNAL MEDICINE (IM) RESPONDENTS' MEASURE OF SUPPORT FOR HEALTH CARE RATIONING POLICIES SUCH AS THE OREGON HEALTH PLAN ( $1=$ VERY SUPPORTIVE TO $5=$ UNALTERABLE OPPOSITION), LISTED IN ORDER OF STRENGTH, $\mathrm{N}=158$

Y Variable: Measure of Support for Health Care Rationing Policies

Independent Variables $(X)$

Constant

Attitudes toward Support for NHI

Percent of Practice: Maternity Care

Type of Practice ( $1=$ Solo $0=$ Group)

MCA Affiliation ( $0=$ No $0=Y e s)$

Years Practicing Medicine

Percent of Patients: Charged Fee-for-Service

Percent of Patients: Without Health Insurance

Percent of Practice: Preventative Care

Percent of Practice: Chronic Care-Nonfatal

Percent of Patients: On Medicare

Geographic Location $(0=$ Urban $1=$ Rural)

Percent of Practice: Acute Care-Fatal

Percent of Practice: Chronic Care-Fatal

Percent of Practice: Acute Care Nonfatal

Percent of Practice in Office

Percent of Patients: On Medicaid

Percent of Practice Devoted to Specialty

$R^{2}=0.095$ Adjusted Multiple $R^{2}=0.000$

MODEL ANOVA

Coefficient $\quad P(2$ Tail $)$

$\begin{array}{rl}2.632 & 0.001 \\ 0.125 & 0.069^{*} \\ -0.092 & 0.486 \\ 0.311 & 0.114 \\ -0.159 & 0.477 \\ 0.062 & 0.450 \\ -0.005 & 0.465 \\ 0.002 & 0.743 \\ 0.001 & 0.863 \\ -0.009 & 0.122 \\ -0.010 & 0.112 \\ -0.133 & 0.517 \\ -0.022 & 0.150 \\ -0.003 & 0.644 \\ -0.009 & 0.116 \\ -0.001 & 0.850 \\ 0.005 & 0.582 \\ 0.002 & 0.518\end{array}$

Model $F=0.867 \quad$ Model $p=0.614$

* Significant variable 
above: an IM physicians' attitude toward national health insurance was the only significant variable in the model, explaining 3.6 percent of the variance in their support for health care rationing. The step-wise regression is shown in Table 40.

TABLE 40

STEP-WISE REGRESSION ANALYSIS OF VARIABLES IN THE INTERNAL MEDICINE PHYSICIANS' SUPPORT FOR HEALTH CARE RATIONING REGRESSION ANALYSIS IN TABLE 39, N = 317

Y Variable: Physicians Support for Health Care Rationing

Independent Variable $\quad$ Coefficient $\quad P(2$ Tail $)$

$\begin{array}{lll}\text { Constant } & 1.658 & 0.000\end{array}$

Physicians Support Measure for National Health Insurance

0.139

0.001

$R^{2}=0.036 \quad$ Adjusted $R^{2}=0.330 \quad F=11.932 \quad P=0.001$

Support for Health Care Rationing by $O B / G Y N$ Physicians

Only one variable in the regression model applied to OB/GYN physicians was found to significantly explain variation in their support for health care rationing. However, unlike that found for pediatricians and internal medicine (IM) physicians, the type of clinical practice significantly explain variation in the OB/GYN physicians' 
TABLE 41

OB/GYN RESPONDENTS' MEASURE OF SUPPORT FOR HEALTH CARE RATIONING POLICIES SUCH AS THE OREGON HEALTH PLAN ( $1=$ VERY SUPPORTIVE TO 5=UNALTERABLE OPPOSITION), LISTED IN ORDER OF STRENGTH, $\mathbf{N}=63$

Y Variable: Measure of Support for Health Care Rationing Policies

Independent Variables $(X)$

Constant

Support for National Health Insurance

Percent of Practice: Maternity Care

Type of Practice ( $1=$ Solo $0=$ Group)

MCA Affiliation $(0=$ No $0=$ Yes)

Years Practicing Medicine

Percent of Patients: Charged Fee-for-Service

Percent of Patients: Without Health Insurance

Percent of Practice: Preventative Care

Percent of Practice: Chronic Care-Nonfatal

Percent of Patients: On Medicare

Geographic Location ( $0=$ Urban $1=$ Rural)

Percent of Practice: Acute Care-Fatal

Percent of Practice: Chronic Care-Fatal

Percent of Practice: Acute Care Nonfatal

Percent of Practice in Office

Percent of Patients: On Medicaid

Percent of Practice Devoted to Specialty
Coefficient $\quad P(2$ Tail $)$

$\begin{array}{rl}1.465 & 0.405 \\ 0.155 & 0.282 \\ 0.000 & 0.973 \\ 0.646 & 0.093^{*} \\ -0.764 & 0.129 \\ 0.170 & 0.309 \\ 0.012 & 0.258 \\ -0.023 & 0.411 \\ 0.003 & 0.807 \\ -0.007 & 0.633 \\ -0.011 & 0.557 \\ 0.351 & 0.463 \\ -0.021 & 0.554 \\ 0.021 & 0.387 \\ -0.007 & 0.633 \\ -0.008 & 0.456 \\ -0.005 & 0.737 \\ 0.002 & 0.850\end{array}$

$\mathrm{R}^{2}=0.250 \quad$ Adjusted Multiple $\mathrm{R}^{2}=0.000$

MODEL ANOVA

Model $F=0.598 \quad$ Model $p=0.881$

* Significant variable 
support for health care rationing.

$\mathrm{OB} / \mathrm{GYN}$ physicians who practiced in group practice settings were significantly $(p<0.093)$ more supportive of health care rationing than were their solo/partnership colleagues. Group practice $\mathrm{OB} / \mathrm{GYN}$ physicians had mean health care rationing measures 0.646 higher than solo/partnership OB/GYN physicians.

\section{Step-wise Regression}

None of the other variables in the model significantly explained variation in their support for NHI. As well, the model in Table 41, was not significant in the manner in which it was specified (ANOVA $\mathrm{p}=0.881$ ). To test for potential model specification error for $\mathrm{OB} / \mathrm{GYN}$ physicians, a step-wise regression analysis was performed. This test found evidence of model specification error in the multivariate regression analysis discussed above, finding two other variables that significantly explain variation in the OB/GYN physician's support for health care rationing: their support measure for national health insurance (NHI), and the percentage of their practice devoted to acute care, potentially fatal medical conditions. The OB/GYN physician's clinical practice location was no longer significant. The step-wise regression is shown in Table 42, next page. 
TABLE 42

\section{STEP-WISE REGRESSION ANALYSIS OF VARIABLES IN THE OB/GYN PHYSICIANS' SUPPORT FOR HEALTH CARE RATIONING REGRESSION ANALYSIS IN TABLE $41, \mathrm{~N}=124$}

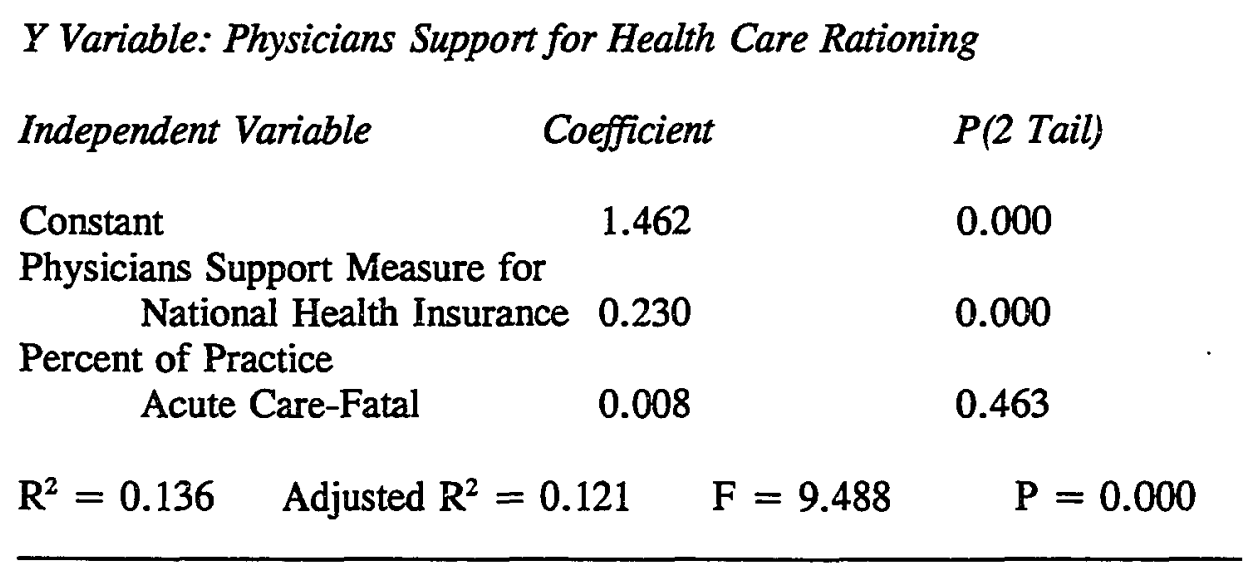

Thus, the multivariate regression analysis for OB/GYN appears to be specified incorrectly, with the step-wise regression confirming regression findings for pediatrician and internal medicine physicians: an OB/GYN physicians' attitude toward national health insurance was the only significant variable in the model, explaining 1.36 percent of the variance in their support for health care rationing.

Support for Health Care Rationing by Family Practice Physicians

Two variables in the regression model applied to family practice (FP) physicians were found to significantly explain variation in their support for health care rationing. Like that found for the other primary care physicians, FP physicians' 
attitudes toward national health insurance $(p=0.000)$ significantly explained variation in their support for health care rationing. Also, the type of FP clinical practice significantly $(p=0.088)$ explained variation in the physicians' health care rationing support score. See Table 43 , next page.

And like pediatricians, who were significantly more supportive of health care rationing than they were of $\mathrm{NHI}$, the more non-supportive of national health insurance (NHI) the FP physicians were, the more supportive of health care rationing they were found to be. For example, all other variables held constant, FP physicians who reported scores of 4.000 , non-support for national health insurance (NHI), would be predicted to have health care rationing scores of $1.862,{ }^{8}$ well within the range of support for health care rationing.

The model also showed that family practice physicians who practice in group practice settings were significantly $(p<0.093)$ more supportive of health care rationing than were their solo/partnership colleagues.

The model for family practice physicians did not appear to suffer from specification error. Step-wise regression conducted on this model confirmed the model was correctly specified $(p<0.001)$ for this group of physicians.

${ }^{8}$ Found using the following formula: HCR Score $=0.758+0.322(\mathrm{NHI}$ Score). 
TABLE 43

\begin{abstract}
FAMILY PRACTICE PHYSICIAN RESPONDENTS' MEASURE OF SUPPORT FOR HEALTH CARE RATIONING POLICIES SUCH AS THE OREGON HEALTH PLAN ( $1=$ VERY SUPPORTIVE TO $5=$ UNALTERABLE OPPOSITION), LISTED IN ORDER OF STRENGTH, $\mathrm{N}=265$
\end{abstract}

Y Variable: Measure of Support for Health Care Rationing Policies

Independent Variables $(X)$

Constant

Support for National Health Insurance

Percent of Practice: Maternity Care

Type of Practice $(0=$ Solo $1=$ Group)

MCA Affiliation $(0=$ No $0=Y e s)$

Years Practicing Medicine

Percent of Patients: Charged Fee-for-Service

Percent of Patients: Without Health Insurance

Percent of Practice: Preventative Care

Percent of Practice: Chronic Care-Nonfatal

Percent of Patients: On Medicare

Geographic Location ( $0=$ Urban $1=$ Rural)

Percent of Practice: Acute Care-Fatal

Percent of Practice: Chronic Care-Fatal

Percent of Practice: Acute Care Nonfatal

Percent of Practice in Office

Percent of Patients: On Medicaid

Percent of Practice Devoted to Specialty

$\mathrm{R}^{2}=0.185 \quad$ Adjusted Multiple $\mathrm{R}^{2}=0.129$

MODEL ANOVA

$\begin{array}{cc}\text { Coefficient } & P(2 \text { Tail }) \\ 0.758 & 0.322 \\ 0.276 & 0.000^{*} \\ 0.002 & 0.856 \\ 0.243 & 0.088^{*} \\ -0.070 & 0.664 \\ 0.055 & 0.404 \\ 0.004 & 0.353 \\ 0.005 & 0.313 \\ -0.008 & 0.189 \\ -0.003 & 0.596 \\ 0.007 & 0.189 \\ 0.155 & 0.307 \\ 0.004 & 0.799 \\ -0.005 & 0.508 \\ 0.001 & 0.911 \\ 0.002 & 0.738 \\ 0.001 & 0.829 \\ -0.003 & 0.332\end{array}$

Model $\mathrm{F}=3.292 \quad$ Model $\mathrm{p}<0.000$

* Significant variable 
Support for Health Care Rationing by Other Primary Care Physicians

Like that found for the other four primary care physician groups, the primary care physicians in the other category, mostly emergency, urgent care, and public health physicians, were found to have one variable that significantly $(p<0.10)$ explained their support for health care rationing. That variable was their attitude toward national health insurance (NHI).

And like the other primary care physician groups, the more non-supportive this group tended to report for national health insurance, the more support they reported for health care rationing policies. For example, all other variables held constant, the Other group of physicians who reported scores of 4.000 , non-support for national health insurance (NHI), would be predicted to have health care rationing scores of $1.690,{ }^{9}$ well within the range of support for health care rationing, and the highest mean health care rationing score of any of the five primary care specialty groups examined. This model is shown in Table 44, next page.

\section{Step-wise Regression}

None of the other variables in the model significantly explained variation in the other group's support for health care rationing. As well, the model in Table 44 .

\footnotetext{
9 Found using the following formula: HCR Score $=0.758+0.322$ (NHI Score).
} 
TABLE 44

OTHER TYPE OF PHYSICIAN RESPONDENTS' MEASURE OF SUPPORT FOR HEALTH CARE RATIONING POLICIES SUCH AS THE OREGON HEALTH PLAN ( $1=$ VERY SUPPORTIVE TO $5=$ =UNALTERABLE OPPOSITION), LISTED IN ORDER OF STRENGTH, $\mathrm{N}=32$

Y Variable: Measure of Support for Health Care Rationing Policies

Independent Variables (X)

Constant

Support for National Health Insurance

Percent of Practice: Maternity Care

Type of Practice ( $0=$ Solo $1=$ Group)

MCA Affiliation $(0=$ No $0=$ Yes)

Years Practicing Medicine

Percent of Patients: Charged Fee-for-Service

Percent of Patients: Without Health Insurance

Percent of Practice: Preventative Care

Percent of Practice: Chronic Care-Nonfatal

Percent of Patients: On Medicare

Geographic Location ( $0=$ Urban $1=$ Rural)

Percent of Practice: Acute Care-Fatal

Percent of Practice: Chronic Care-Fatal

Percent of Practice: Acute Care Nonfatal

Percent of Practice in Office

Percent of Patients: On Medicaid

Percent of Practice Devoted to Specialty
Coefficient $\quad P(2$ Tail $)$

$\begin{array}{rl}-0.742 & 0.322 \\ 0.608 & 0.063^{*} \\ -0.031 & 0.842 \\ 0.115 & 0.842 \\ 0.246 & 0.736 \\ -0.161 & 0.461 \\ 0.005 & 0.774 \\ 0.031 & 0.182 \\ 0.009 & 0.570 \\ 0.012 & 0.307 \\ 0.006 & 0.790 \\ 0.460 & 0.409 \\ 0.005 & 0.803 \\ 0.011 & 0.641 \\ 0.009 & 0.471 \\ -0.161 & 0.461 \\ -0.001 & 0.949 \\ 0.001 & 0.736\end{array}$

$\mathbf{R}^{2}=0.569 \quad$ Adjusted Multiple $\mathbf{R}^{2}=0.045$

MODEL ANOVA

Model F $=1.086 \quad$ Model $\mathrm{p}=0.444$

* Significant variable 
appears not to be significant in the manner in which it was specified (ANOVA $p=$ 0.444). To test for potential model specification error for Other physicians, a stepwise regression analysis was performed.

This test found evidence of model specification error in the multivariate regression analysis discussed above, finding two other variables, besides the physicians' attitudes toward national health insurance, that significantly explain variation in the other physician's support for health care rationing: the percentage of their patients without health insurance, and their geographic location (rural or urban).

Confirming the regression model for these physicians, as the step-wise regression in Table 45, next page, shows the more non-support this group tended to report for national health insurance, the more support they reported for health care rationing policies. Additionally, the step-wise regression found that rural physicians reported less support for health care rationing than their urban colleagues. And, interestingly, the model shows that the greater the percentage of their patients without health insurance, the less supportive of health care rationing they were likely to be. For every ten percent increase in uninsured patients these physicians treat, their mean support for health care rationing would be predicted to drop 0.27 points. 
TABLE 45

\section{STEP-WISE REGRESSION ANALYSIS OF VARIABLES IN THE OTHER PHYSICIANS' SUPPORT FOR HEALTH CARE RATIONING REGRESSION ANALYSIS IN \\ TABLE $44, N=53$}

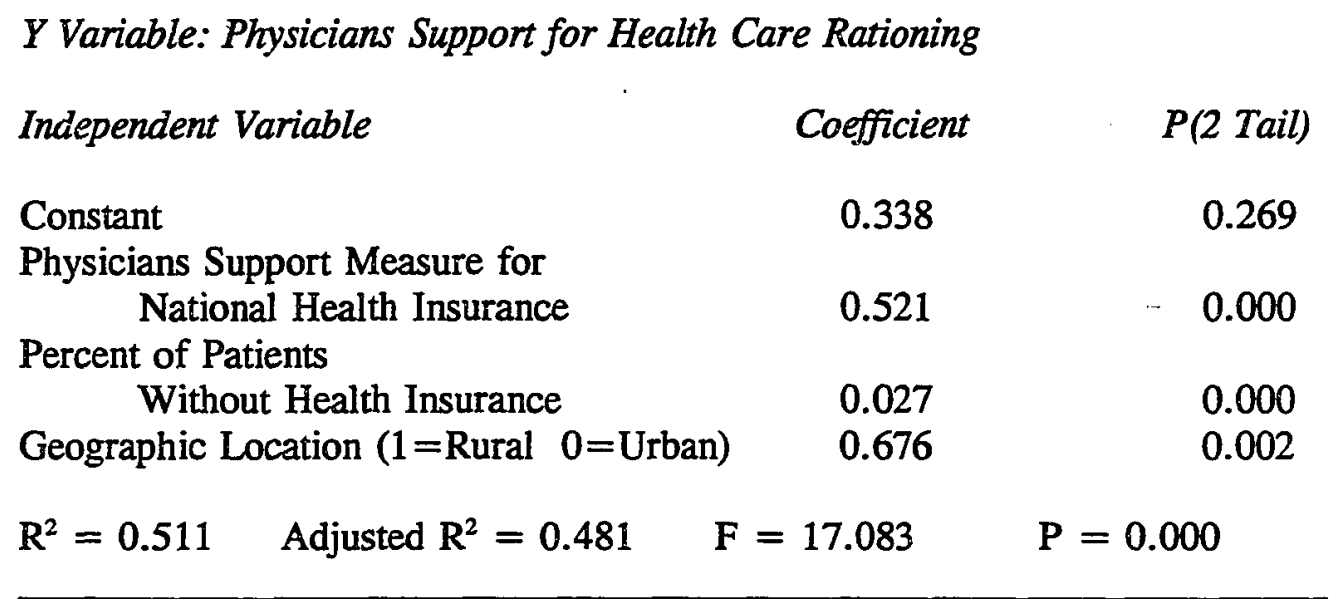

Figure 7, next page, shows all of the probabilities associated with the independent variables outlined in the hypothesis matrix discussed in Chapter 6 (See page 80). These probabilities are from each of the respective regression analyses for each Oregon primary care specialty. 


\begin{tabular}{|c|c|c|c|c|c|c|c|c|}
\hline \multirow{2}{*}{$\begin{array}{l}\text { SUPPORT FOR } \\
\text { HEALTH } \\
\text { CARE RATIONING, } \\
\text { by: }\end{array}$} & \multicolumn{8}{|c|}{ Independent Variables } \\
\hline & $\begin{array}{l}\text { Support For } \\
\text { NHI }\end{array}$ & $\begin{array}{l}\text { Percent Pts } \\
\text { Uninsured. }\end{array}$ & $\begin{array}{l}\text { Percent Pt } \\
\text { Medicare }\end{array}$ & $\begin{array}{l}\text { Percent Pts } \\
\text { Fee For Svc. }\end{array}$ & $\begin{array}{l}\text { Geographic } \\
\text { Location }\end{array}$ & $\begin{array}{l}\text { Type } \\
\text { Practice }\end{array}$ & $\begin{array}{l}\text { \% Practice } \\
\text { Maternity }\end{array}$ & $\begin{array}{c}\% \text { Practice } \\
\text { Acute-Nonfatal }\end{array}$ \\
\hline Pediatricians (Peds) & $0.007 *$ & 0.712 & 0.558 & 0.921 & 0.364 & 0.844 & 0.255 & 0.614 \\
\hline Internal Medicine (IM) & $0.069 *$ & 0.548 & $0.066^{*}$ & 0.247 & $0.053^{*}$ & 0.374 & $0.068 *$ & 0.380 \\
\hline OB/GYN & 0.282 & $0.080 *$ & 0.142 & 0.526 & $0.005 *$ & 0.995 & 0.924 & 0.155 \\
\hline Other & $0.063^{*}$ & $0.011 *$ & 0.394 & 0.324 & 0.441 & 0.813 & $0.039 *$ & 0.603 \\
\hline
\end{tabular}

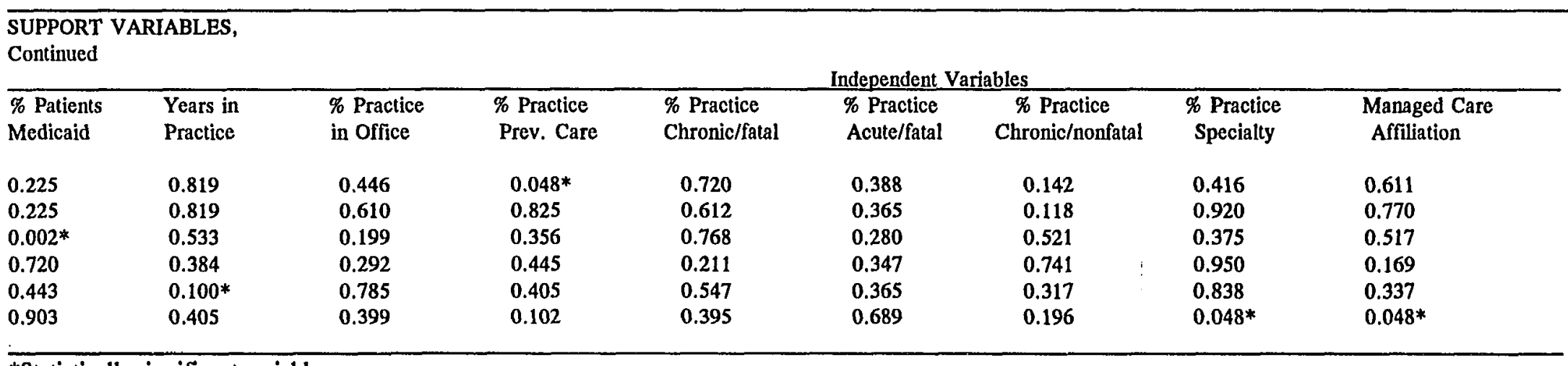

*Statistically significant variable

Figure 7. Matrix of Regression Probabilities (2 tail) for Hypothesis 1, Oregon Primary Care Physician Support for Health Care Rationing Policies, by Physician Specialty 
Hypothesis Two: Support for National Health Insurance

As a group, less than half of the Oregon primary care physicians surveyed for this study support the concept of national health insurance (NHI). This finding is summarized in Table 46 . While 47.2 percent $(n=533)$ of the respondents expressed some measure of support for NHI, another 36 percent $(n=406)$ of the respondent physicians were either not supportive or unalterably opposed to the idea. Of the 1128 primary care physicians answering the question "How supportive are you of national health insurance, $" 21.5$ percent $(n=243)$ indicated that they were very supportive of national health insurance and another 25.7 percent $(n=290)$ reported that they were supportive of the concept. Just under 17 percent $(n=189)$ of the physician respondents were neutral toward NHI, while 23.7 percent $(n=267)$ of the respondents

TABLE 46

SUPPORT FOR NATIONAL HEALTH INSURANCE (NHI) BY OREGON PRIMARY CARE PHYSICIANS, $\mathrm{N}=1159$

\begin{tabular}{lcc}
\hline Support Level & $\begin{array}{c}\text { Percent } \\
\text { Responding }\end{array}$ & $N$ \\
Very Supportive & $21.5 \%$ & 243 \\
Supportive & 25.7 & 290 \\
Neutral & 16.8 & 189 \\
Not Supportive & 23.7 & 267 \\
Unalterably Opposed & 12.3 & 139 \\
Total & $100.0 \%$ & 1128 \\
\hline
\end{tabular}


indicated that they were not supportive of $\mathrm{NHI}$, and 12.3 percent $(n=142)$ were unalterably opposed to national health insurance.

Opposition to national health insurance (NHI) is nearly as strong as support for national health insurance (NHI). As shown in Figure 8, below, this finding lends evidence of a bi-modal distribution of support for NHI. While 47.2 percent of the Oregon primary care physician respondents report support for $\mathrm{NHI}$, another 36.0 percent do not support or are opposed to NHI. This finding is contrary to the strong support found for health care rationing polices such as the Oregon Health Plan.

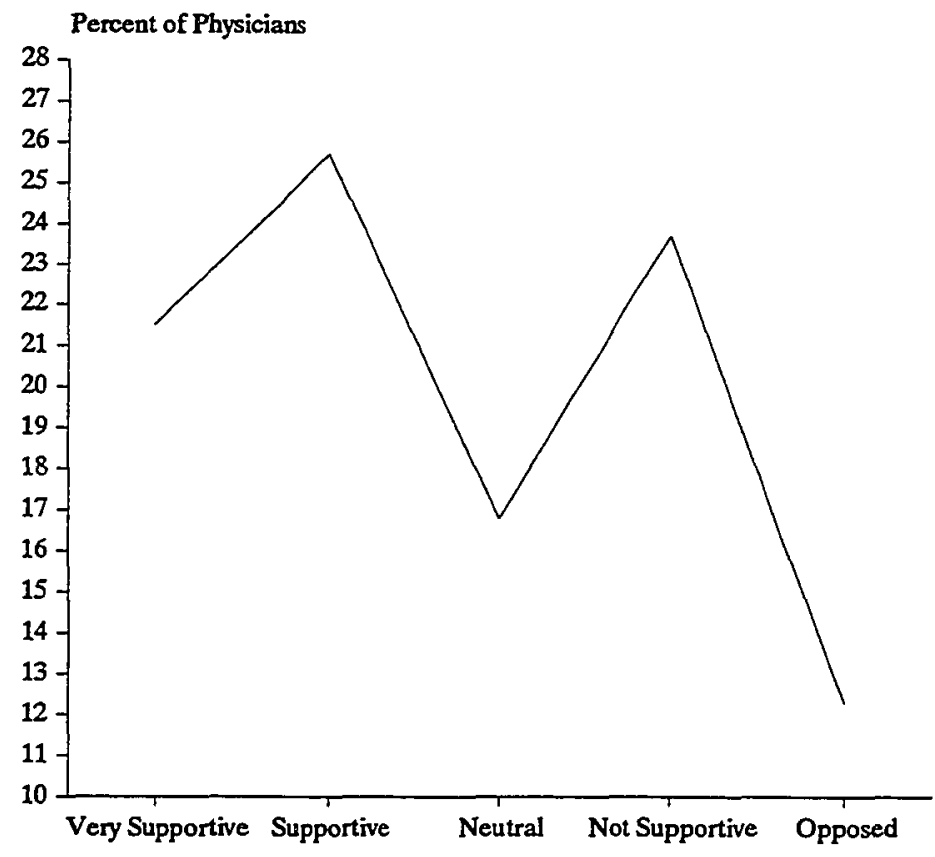

Figure 8. Oregon Primary Care Physicians Attitudes Toward National Health Insurance, $N=1159$ 
NHI Support: by Physicians' Primary Care Specialty

As a group, pediatric physicians were significantly $(p<0.001)$ more supportive of national health insurance (NHI) than any other specialty group of primary care physicians; OB/GYN physicians were the most non-supportive. Just over 62 percent of the pediatricians surveyed (over twice the percentage of OB/GYN physicians) were supportive of NHI, with 26.3 percent very supportive. In contrast, 30.9 percent of the OB/GYN physicians surveyed expressed support for NHI, with 52.9 percent indicating non-support for or, unalterable opposition to, the concept of NHI.

Among the other primary care specialties, 51.1 percent of internal medicine (IM) physicians, and 43.3 percent of the family practice physicians (FP) expressed support for national health insurance (NHI). Except for the general other category of physicians, a greater percentage of pediatricians were noncommittal toward NHI, with 19 percent indicating neutrality to the idea of NHI. These findings are displayed in Table 47, next page. 
TABLE 47

SUPPORT FOR NATIONAL HEALTH INSURANCE BY OREGON PRIMARY

CARE PHYSICIANS' SPECIALTY, $N=1123$

\begin{tabular}{|c|c|c|c|c|c|}
\hline Support Level & Peds & $I M$ & $O B / G Y N$ & $F P$ & Other \\
\hline Very Supportive & $26.28 \%$ & $23.10 \%$ & $11.38 \%$ & $20.30 \%$ & $31.82 \%$ \\
\hline Supportive & 35.77 & 27.96 & 19.51 & 23.04 & 24.24 \\
\hline Neutral & 18.98 & 13.07 & 16.26 & 17.55 & 25.76 \\
\hline Not Supportive & 15.33 & 23.10 & 37.40 & 24.10 & 15.15 \\
\hline Unalterably Opposed & 3.65 & 12.77 & 15.45 & 15.01 & 3.03 \\
\hline Total & $100.0 \%$ & $100.0 \%$ & $100.0 \%$ & $100.0 \%$ & $100.0 \%$ \\
\hline $\mathbf{n}$ & 137 & 329 & 123 & 473 & 66 \\
\hline$x^{2}=59.679$ & \multicolumn{2}{|c|}{ Model $\mathbf{p}<0.001$} & $=16$ & & \\
\hline
\end{tabular}

NHI Support: by Physicians' Geographic Location of Practice

Support for national health insurance (NHI) is not evenly distributed, geographically, throughout Oregon. Not surprisingly, significantly $(p<0.001)$ more support for $\mathrm{NHI}$ is found in the state's larger urban population centers. As a group, a significantly $(p<0.001)$ greater percentage of urban primary care physicians were supportive of $\mathrm{NHI}$ than were their rural colleagues. While over 52.8 percent $(n=640)$ of the urban physicians were supportive of NHI, just under 40.0 percent $(n=467)$ of the rural physicians were.

Conversely, a greater percentage of rural physicians expressed opposition to the idea of national health insurance (NHI) than did their urban counterparts. While 42.4 percent of the rural physicians were non-supportive of NHI (16.3 percent were 
unalterably opposed), 31.7 percent of the urban physicians expressed non-support.

This finding is summarized in Table 48 .

TABLE 48

SUPPORT FOR

NATIONAL HEALTH INSURANCE (NHI)

BY OREGON PRIMARY CARE PHYSICIANS RESPONDENTS, BY GEOGRAPHIC LOCATION OF PRACTICE, $\mathrm{N}=1107$

\begin{tabular}{lccc}
\hline Support Level & \multicolumn{3}{c}{ Percent Responding } \\
\cline { 2 - 4 } & Rural & Urban & $N$ \\
Very Supportive & $16.06 \%$ & $25.31 \%$ & 237 \\
Supportive & 22.91 & 27.50 & 283 \\
Neutral & 18.63 & 15.47 & 186 \\
Not Supportive & 26.12 & 21.88 & 262 \\
Unalterably Opposed & 16.27 & 9.84 & 139 \\
$\mathrm{~N}$ & 467 & 640 & 1107 \\
$\mathrm{X}^{2}=25.575$ & Model p $<0.001$ & Df $=4$ & \\
\hline
\end{tabular}

NHI Support: by City Size of Physicians' Practice

Varying regional support for national health insurance (NHI) is further illustrated when city size is used as an independent variable. As show in Figure 8, page 154, and Table 49, next page, support for NHI declines in an almost linear fashion as city size declines. While 29.2 percent of the large-city primary care practice physicians indicated that they were very supportive of NHI, just 15.3 percent 
of the rural physicians expressed this same level support. All together, 56.0 percent of the urban-large city, 54.8 percent of the urban-medium city, 38.2 percent of the suburban, 40.9 percent of the smaller city, and 35.8 percent of the rural primary care physicians expressed support for NHI. This difference is significant $(p<0.001)$.

TABLE 49

OREGON PRIMARY CARE PHYSICIANS' SUPPORT FOR NATIONAL HEALTH INSURANCE (NHI) BY CITY SIZE OF PRACTICE, $\quad \mathrm{N}=1107$

\begin{tabular}{|c|c|c|c|c|c|}
\hline \multirow[b]{2}{*}{ Support Level } & \multirow[b]{2}{*}{ Large City } & \multicolumn{4}{|c|}{ Physicans' Practice Location } \\
\hline & & Med. City & Suburban & Small Cty & Rural \\
\hline Very Supportive & $29.20 \%$ & $3.62 \%$ & $15.69 \%$ & $16.49 \%$ & $15.34 \%$ \\
\hline Supportive & 26.84 & 31.16 & 22.55 & 24.40 & 20.45 \\
\hline Neutral & 14.16 & 14.07 & 22.55 & 19.93 & 16.48 \\
\hline Not Supportive & 20.06 & 21.61 & 28.43 & 25.77 & 26.70 \\
\hline Unalterably Oppose & ed 9.73 & 9.55 & 10.78 & 13.40 & 21.02 \\
\hline Total & $100.0 \%$ & $100.0 \%$ & $100.0 \%$ & $100.0 \%$ & $100.0 \%$ \\
\hline $\mathbf{n}$ & 339 & 199 & 102 & 291 & 176 \\
\hline$X^{2}=47.397$ & \multicolumn{2}{|c|}{ Model $\mathrm{p}<0.001$} & \multicolumn{2}{|c|}{$\mathrm{Df}=16$} & \\
\hline
\end{tabular}

Opposition to national health insurance (NHI) increases in an almost linear fashion as a function of city size of a physicians' practice. Neutrality, on the other hand, is lower among physicians in larger cities, increases for suburban physicians, 
and declines again for small city and rural physicians. Likewise, suburban physicians were found to be more non-supportive of NHI than their small city or rural colleagues. While 28.4 percent of the suburban physicians were non-supportive of NHI, 26.7 percent of their rural colleagues and 25.7 percent of their small city counterparts were non-supportive of NHI. These differences were not significant, however. Nonetheless, a greater percentage ( 21.0 percent) of rural physicians remain unalterably opposed to NHI. These findings are displayed in Table 49, previous page, and Figure 9, below.

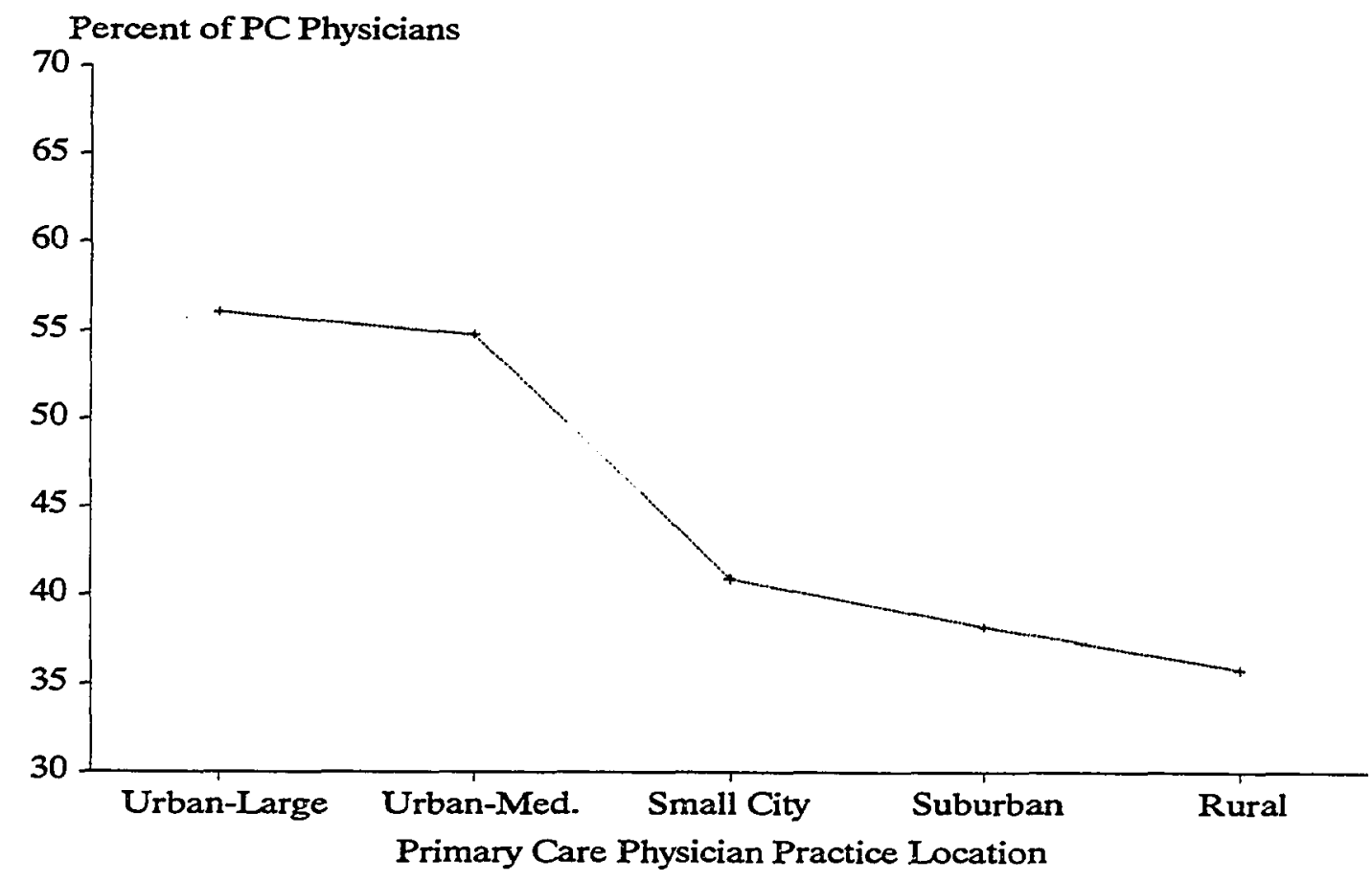

Figure 9. Percentage of Oregon Primary Care Physicians Expressing Support for National Health Insurance, by Practice Location, $\mathrm{N}=1107$ 
NHI Support: by Physicians’ Clinic Practice Type

Just under 37 percent of the physicians who practice in a solo/partnership clinic expressed support for national health insurance (NHI). In contrast, $\mathbf{5 7 . 0}$ percent of the group practice primary care physicians expressed support for NHI. This difference is significant $(p<0.001)$.

While just under 7.0 percent of the group practice primary care physicians were unalterably opposed to NHI, almost three times that amount, 18.02 percent, of the solo/partnership physicians were unalterably opposed to NHI. These findings are displayed in Table 50.

TABLE 50

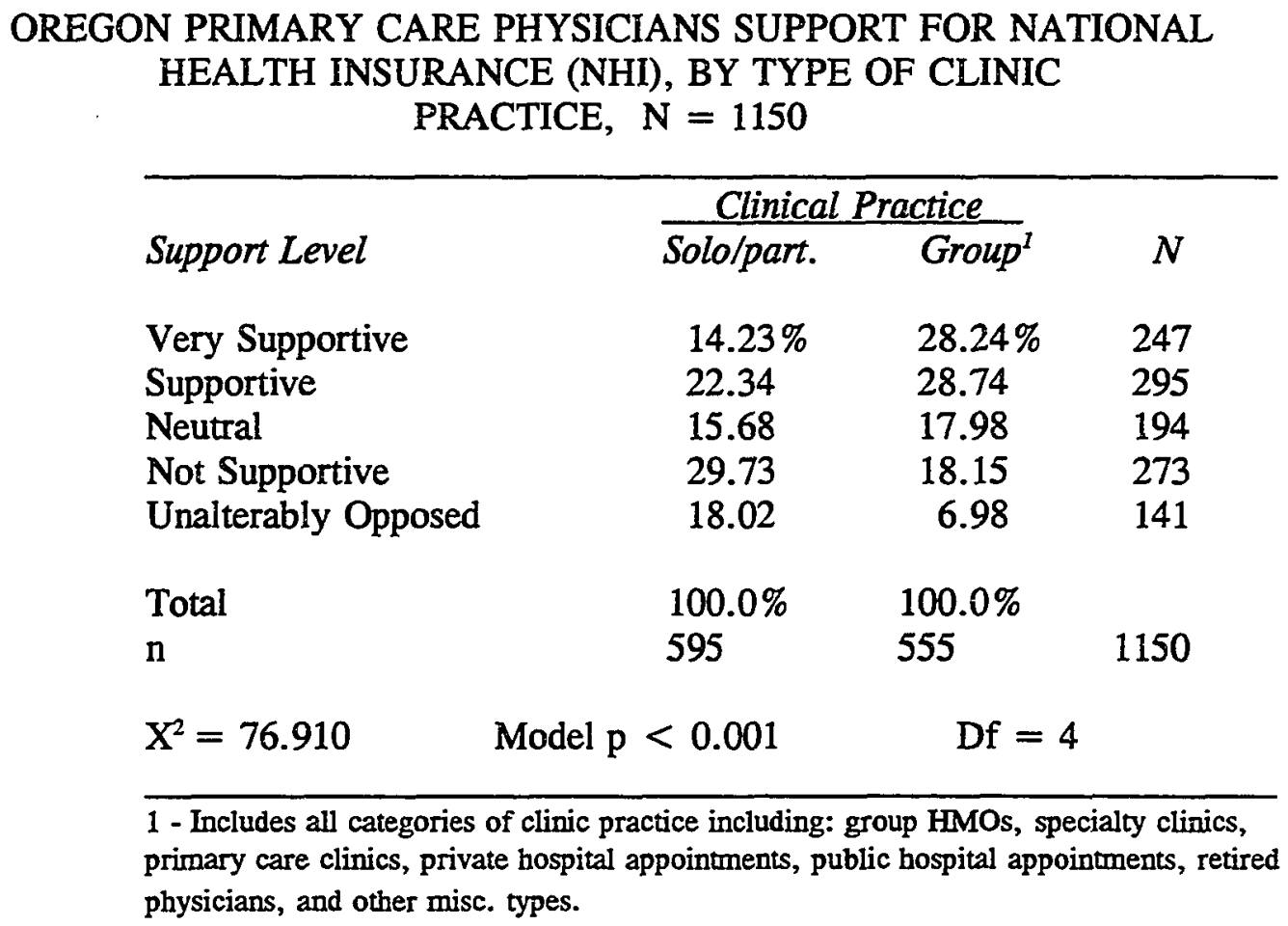


NHI Support: by Physicians with Managed Care Affiliation (MCA)

The percentage of physicians who are affiliated with a managed care association (MCA) (whether an IPA, HMO, or PPO) who support national health insurance (NHI), and the percentage of physicians who have no such affiliation who support NHI, is not significantly different. Just under 45 percent of the MCA physicians expressed support for NHI, while 45.1 percent of the non-MCA physicians expressed support. Alternately, 40.7 percent of the MCA physicians were not supportive of NHI, and 35.24 of the non-MCA affiliated physicians did not support NHI. Slightly more of the non-managed care affiliated physicians were neutral to the concept. These data are displayed in Table 51.

\section{TABLE 51}

SUPPORT FOR NATIONAL HEALTH INSURANCE (NHI), BY RESPONDENT PHYSICIANS WITH MANAGED CARE AFFILIATION (MCA), $\quad \mathrm{N}=939$

\begin{tabular}{lccc}
\hline Support Level & $M C A$ & non-MCA & $\mathrm{N}$ \\
& & & \\
Very Supportive & $18.91 \%$ & $21.59 \%$ & 186 \\
Supportive & 25.32 & 23.49 & 232 \\
Neutral & 15.06 & 19.68 & 156 \\
Not Supportive & 27.40 & 20.95 & 237 \\
Unalterably Opposed & 13.30 & 14.29 & 128 \\
Total & $100.0 \%$ & $100.0 \%$ & \\
$\mathrm{~N}$ & 624 & 315 & 939 \\
$\mathrm{X}^{2}=7.329$ & \multicolumn{2}{c}{$\mathrm{Df}=4$} & \\
\hline
\end{tabular}

1 - Indicates participation in a PPO, IPA, or free-standing HMO. 
NHI Support: by New Physicians and Established Physicians

A significantly $(p<0.001)$ greater percentage of newly established physicians (those in practice less than five years) support national health insurance (NHI) than do their more established colleagues (those physicians in practice five years or over). Just over 55 percent of newly established primary care physicians expressed support for NHI. This is the greatest percentage of support for NHI found in this study. Conversely, just under 45.0 percent $(n=887)$ of the established physicians expressed support for NHI. These data are displayed in Table 52.

TABLE 52

SUPPORT FOR NATIONAL HEALTH INSURANCE (NHI), BY NEWLY PRACTICING AND ESTABLISHED RESPONDENT PHYSICIANS, $\mathbf{N}=1128$

\begin{tabular}{lccc} 
Support Level & Newly Est. & Established & $\mathrm{N}$ \\
Very Supportive & $25.31 \%$ & $20.52 \%$ & 243 \\
Supportive & 29.88 & 24.46 & 289 \\
Neutral & 21.16 & 15.67 & 190 \\
Not Supportive & 16.60 & 25.48 & 266 \\
Unalterably Opposed & 7.05 & 13.87 & 140 \\
& & & \\
Total & $100.0 \%$ & $100.0 \%$ & \\
$\mathrm{~N}$ & 241 & 887 & 1128 \\
$\mathrm{X}^{2}=21.005$ & Model p $<0.001$ & Df $=4$ & \\
\hline
\end{tabular}


Established physicians were significantly $(p<0.001)$ more likely than newly practicing physicians to be opposed to NHI, with more than twice the percentage, 13.8 percentage, expressing unalterable opposition to the idea. However, more newly practicing physicians were found to be neutral to the concept of NHI, with 21.2 percent expressing neutrality to NHI, contrasted to 15.6 percent of the established physicians being neutral to NHI. These findings are displayed in Table 52, previous page.

Examined more closely, as a group, the percentage of support for national health insurance declines linearly with the number of years the physician has been in practice. For instance, 55.2 percent of the physicians who had been in practice less than five years supported NHI, compared to 51.7 percent of those in practice between 5 and 10 years, 44.9 percent in practice more than 10 to 20 years, and 39.8 percent of those in practice more than 20 years. This trend is shown in Table 53.

\section{TABLE 53}

RESPONDENT PHYSICIANS' SUPPORT FOR NATIONAL HEALTH INSURANCE (NHI) BY YEARS IN PRACTICE, $\quad \mathbf{N}=1128$

\begin{tabular}{lcccc}
\hline & \multicolumn{4}{c}{ Physicians' Years in Practice } \\
\cline { 2 - 5 } Support Level & $<5 y r s$ & $5-10 y r s$ & $>10-20 y r s$ & $>20 y r s$ \\
Very Supportive & $25.31 \%$ & $24.79 \%$ & $20.34 \%$ & $17.39 \%$ \\
Supportive & 29.88 & 26.92 & 24.58 & 22.41 \\
Neutral & 21.16 & 16.24 & 14.12 & 17.06 \\
Not Supportive & 16.60 & 17.95 & 29.38 & 26.76 \\
Unalterably Opposed & 7.05 & 14.10 & 11.58 & 16.39 \\
& $100.0 \%$ & $100.0 \%$ & $100.0 \%$ & $100.0 \%$ \\
Total & 241 & 234 & 354 & 299 \\
$\mathrm{~N}$ & Model p $<0.001$ & & Df $=12$ & \\
$\mathrm{X}^{2}=37.430$ & & & & \\
& & & & \\
\end{tabular}


NHI Support: by M.D. and D.O. Primary Care Physicians

A greater percentage of allopathic primary care physicians (those holding doctorate degrees in medicine), than osteopathic primary care physicians (D.O.) were supportive of national health insurance (NHI), however, not significantly so $(p=$ 0.128). While 48.24 percent of the M.D. physicians were supportive of NHI, 35.36 percent of D.O.s were. Almost an equal percentage of both physician groups were unalterably opposed to NHI, 12.2 percent, however a somewhat larger percentage of D.O.s were neutral toward NHI, with 18.3 percent of the D.O.s and 16.52 percent of the M.D.s reporting that they were neutral towards NHI. These findings are displayed in Table 54.

TABLE 54

SUPPORT FOR NATIONAL HEALTH INSURANCE (NHI), BY M.D. AND D.O. RESPONDENT PHYSICIANS, $\mathbf{N}=1135$

\begin{tabular}{lccr}
\hline Support Level & D.O. & M.D. & $\mathrm{N}$ \\
Very Supportive & $18.29 \%$ & $21.84 \%$ & 245 \\
Supportive & 17.07 & 26.40 & 292 \\
Neutral & 18.29 & 16.52 & 189 \\
Not Supportive & 34.15 & 22.98 & 270 \\
Unalterably Opposed & 12.20 & 12.25 & 139 \\
& & & \\
Total & $100.0 \%$ & $100.0 \%$ & \\
$\mathrm{~N}$ & 82 & 1053 & 1135 \\
$\mathrm{X}^{2}=7.146$ & Model $\mathrm{p}=0.128$ & $\mathrm{Df}=4$ & \\
\hline
\end{tabular}


NHI Support: by Physicians with Uninsured Patients

A greater percentage of primary care physicians who do not treat uninsured patients were supportive of national health insurance than primary care physicians who treat uninsured patients. While 53.3 percent of the physicians with no uninsured patients expressed support for NHI, 45.3 percent of the physicians with uninsured patients expressed support for NHI. This difference was not significant, however $(p=0.180)$, using Chi-square analysis. See Table 55.

TABLE 55

SUPPORT FOR NATIONAL HEALTH INSURANCE (NHI), BY RESPONDENT PHYSICIANS WHO HAVE PATIENTS WITH NO HEALTH INSURANCE AND PHYSICIANS WHOSE PATIENTS ARE ALL INSURED, $\mathrm{N}=920$

\begin{tabular}{lllc}
\hline Support Level & $\begin{array}{l}\text { No Unins. } \\
\text { Patients }\end{array}$ & $\begin{array}{c}\text { Has Unins. } \\
\text { Patients }\end{array}$ & $N$ \\
Very Supportive & $20.00 \%$ & $20.63 \%$ & 189 \\
Supportive & 33.33 & 24.63 & 237 \\
Neutral & 18.33 & 16.25 & 152 \\
Not Supportive & 18.33 & 25.13 & 223 \\
Unalterably Opposed & 10.00 & 13.38 & 119 \\
& & & \\
Total & $100.0 \%$ & $100.0 \%$ & \\
$\mathrm{~N}$ & 120 & 800 & 920 \\
$\mathrm{X}^{2}=6.270$ & Model p $=0.180$ & $\mathrm{Df}=4$ & \\
\hline
\end{tabular}


Yet, when this finding was examined using bi-variate analysis, regressing the percentage of a physician's patients without health insurance onto the physician's support measure for national health insurance, a significant $(p<0.001)$ relationship was found. As a group, the greater the percentage of uninsured patients physician have, the greater their support for national health insurance is likely to be. See Table 56.

TABLE 56

SIMPLE REGRESSION ANALYSIS OF

PHYSICIAN SUPPORT FOR NATIONAL HEALTH INSURANCE (NHI), BY PERCENTAGE OF PATIENTS WITHOUT HEALTH INSURANCE, $\mathrm{N}=\mathbf{9 4 6 .}$

$\begin{aligned} & \text { Y Variable: Support for National Health Insurance (Scale } 1 \text { to } 5 \text {, where } \\
& 1=\text { very supportive and } 5=\text { unalterable opposition) }\end{aligned}$
\begin{tabular}{lcc} 
Independent Variable & Coefficient & $P(2$ Tail) \\
Constant & 3.068 & 0.000 \\
Percent of Patients Uninsured & -0.019 & 0.000 \\
$\mathrm{R}^{2}=0.043 \quad$ ANOVA F $=40.759$ & $\mathrm{P}=0.000$ \\
\hline
\end{tabular}

However, on further examination of this finding, the relationship was found not to be linear, but curve linear. As shown in Table 57, a greater percentage of physicians who have no uninsured patients were supportive of national health insurance (NHI), with 53.3 percent of them indicating some measure of support. However, only 39.2 percent of physicians who had some, but less than 10 percent of 
their patients without health insurance, were supportive of NHI. Support increased again among the physicians with 10 percent or greater of their patients uninsured, with 48.5 percent of this group indicating support. These differences were significant $(p<0.05)$.

TABLE 57

SUPPORT FOR NATIONAL HEALTH INSURANCE (NHI), BY RESPONDENT PHYSICIANS WHOSE PRACTICE HAS NO UNINSURED PATIENTS (NO), WITH 10 PERCENT OR LESS OF PATIENTS WITHOUT HEALTH INSURANCE $(<10 \%)$, AND WITH 10 PERCENT OR MORE PATIENTS WITHOUT HEALTH INSURANCE, $\mathrm{N}=920$

\begin{tabular}{lccc}
\hline & \multicolumn{3}{c}{ Percentage of Patients Without Insurance } \\
\cline { 2 - 4 } Support Level & $N O$ & $1-10 \%$ & $>10 \%$ \\
& & & \\
Very Supportive & $20.00 \%$ & $15.88 \%$ & $23.41 \%$ \\
Supportive & 33.33 & 23.31 & 25.40 \\
Neutral & 18.33 & 16.55 & 16.07 \\
Not Supportive & 18.33 & 30.74 & 21.83 \\
Unalterably Opposed & 10.00 & 13.51 & 13.29 \\
& & & \\
Total & $100.0 \%$ & $100.0 \%$ & $100.0 \%$ \\
$\mathrm{~N}$ & 120 & 296 & 504 \\
$\mathrm{X}^{2}=17.890$ & Model $\mathrm{p}=0.022$ & $\mathrm{Df}=8$ & \\
\hline
\end{tabular}

NHI Support: by Physicians Who Accept Medicaid Patients

A greater percentage of primary care physicians who do not accept Medicaid patients were supportive of national health insurance (NHI) than were their primary care colleagues who do accept Medicaid patients. While 57.6 percent of the 
physicians with no Medicaid patients expressed support for NHI, just over 44.3

percent of the physicians with Medicaid patients expressed support for NHI. This difference was significant $(p=0.02)$. See Table 58 .

TABLE 58

SUPPORT FOR NATIONAL HEALTH INSURANCE (NHI), BY RESPONDENT PHYSICIANS WHO HAVE PATIENTS ON MEDICAID AND PHYSICIANS WITH NO PATIENTS ON MEDICAID, $\mathbf{N}=946$

\begin{tabular}{lccc}
\hline Support Level & $\begin{array}{c}\text { No Medicaid } \\
\text { Patients }\end{array}$ & $\begin{array}{c}\text { Has Medicaid } \\
\text { Patients }\end{array}$ & $N$ \\
& & & \\
Very Supportive & $22.40 \%$ & $20.10 \%$ & 193 \\
Supportive & 35.20 & 24.24 & 243 \\
Neutral & 17.60 & 16.32 & 156 \\
Not Supportive & 16.00 & 25.94 & 233 \\
Unalterably Opposed & 8.80 & 13.40 & 121 \\
Total & $100.0 \%$ & $100.0 \%$ & \\
$\mathrm{~N}$ & 125 & 821 & 946 \\
$\mathrm{X}^{2}=11.612$ & Model $\mathrm{p}=0.020$ & $\mathrm{Df}=4$ & \\
\hline
\end{tabular}

It appears contrary to conventional wisdom that physicians who accept Medicaid patients would not be supportive of national health insurance. With that in mind, this finding, too, was examined using bi-variate analysis, regressing the percentage of a physician's patients on Medicaid onto the physician's support measure for national health insurance. As a group, the greater the percentage of Medicaid patients that physicians have, the greater their support for national health insurance is 
likely to be. The finding was significant $(p<0.001)$. See Table 59 .

TABLE 59

SIMPLE REGRESSION ANALYSIS OF PHYSICIAN SUPPORT FOR N NATIONAL HEALTH INSURANCE (NHI), BY PERCENTAGE OF PHYSICIANS' PATIENTS ON MEDICAID, $\mathbf{N}=946$.

Y Variable: Support for National Health Insurance (Scale 1 to 5, where $1=$ very supportive and $5=$ unalterable opposition)

Independent Variable

Coefficient $\quad P(2$ Tail $)$

Constant

2.981

0.000

Percent of Patients on Medicaid

$-0.012$

0.000

$R^{2}=0.014 \quad F=13.579 \quad p<0.001$

However, on further examination of this relationship, the distribution of support was found not to be linear, but curve linear. As shown in Table 60, next page, a greater percentage of physicians who have no Medicaid patients were supportive of national health insurance $(\mathrm{NHI})$, with 57.6 percent $(n=125)$ of them indicating some measure of support. However, only 35.1 percent $(n=328)$ of physicians who had some, but less than 10 percent of their patients on Medicaid, were supportive of NHI. Support increased again among the physicians with 10 percent or more of their patients on Medicaid, with 50.5 percent $(n=493)$ of this group indicating support. These differences were significant $(p<0.001)$. See Table 60 for these findings. 
This trend remained significant $(p<0.001)$ and similar when rural and urban physicians were examined independently. Both groups reported significant drops in support for national health insurance among physicians who had some but less than 10 percent of their patients on Medicaid, with support increasing again among those physicians with 10 percent or greater of their patients on Medicaid.

TABLE 60

SUPPORT FOR NATIONAL HEALTH INSURANCE (NHI), BY RESPONDENT PHYSICIANS WHOSE PRACTICE HAS NO MEDICAID PATIENTS (NO-MCAID), WITH 10 PERCENT OR LESS OF PATIENTS ON MEDICAID (1-10\%), AND WITH MORE THAN 10 PERCENT OF PATIENTS ON MEDICAID $(>10 \%), \quad \mathrm{N}=946$

\begin{tabular}{lccc}
\hline \multirow{2}{*}{ Support Level } & \multicolumn{3}{c}{ Percentage of Patients on Medicaid } \\
\cline { 2 - 4 } & No Medicaid & $1-10 \%$ & $>10 \%$ \\
Very Supportive & $22.40 \%$ & $17.07 \%$ & $22.11 \%$ \\
Supportive & 35.20 & 17.99 & 28.40 \\
Neutral & 17.60 & 14.33 & 17.65 \\
Not Supportive & 16.00 & 32.32 & 21.70 \\
Unalterably Opposed & 8.80 & 18.29 & 10.14 \\
Total & $100.0 \%$ & $100.0 \%$ & $100.0 \%$ \\
$\mathrm{~N}$ & 125 & 328 & 493 \\
$\mathrm{X}^{2}=42.992$ & Model p $<0.001$ & Df $=8$ & \\
\hline
\end{tabular}


Mean Levels of Support for National Health Insurance

Overall, Oregon primary care physicians had a mean NHI support measure of 2.795. Of the primary care physicians surveyed for this study, pediatricians and the general other category of physicians had mean support measures for national health insurance that are most supportive (on a scale of $1=$ most supportive) with a support measure of 2.333 and 2.343 , respectively. Internal medicine physicians were next in their measure of support for $\mathrm{NHI}$, with a mean measure of 2.74 , followed by family practice (FP) physicians' mean measures of 2.905. OB/GYN physicians expressed the lowest measure of support for NHI, clearly in the range of opposition. These differences in mean support were significant. Table 61 displays these findings.

\section{TABLE 61}

$$
\begin{gathered}
\text { OREGON PRIMARY CARE PHYSICIAN } \\
\text { RESPONDENTS MEAN SUPPORT MEASURES } \\
\text { FOR NATIONAL HEALTH INSURANCE (NHI), BY } \\
\text { PRIMARY CARE SPECIALTY, } \mathrm{N}=1138 \\
\text { ( } 1=\text { VERY SUPPORTIVE TO } 5=\text { UNALTERABLE OPPOSITION) }
\end{gathered}
$$

\begin{tabular}{lcccr}
\hline Specialty & Rank & $\begin{array}{c}\text { Mean } \\
\text { Support Score }\end{array}$ & SD & $N$ \\
All Physicians & & 2.795 & 1.345 & 1138 \\
Other & 1 & 2.333 & 1.168 & 66 \\
Pediatrics & 2 & 2.343 & 1.134 & 137 \\
Internal Medicine & 3 & 2.745 & 1.373 & 329 \\
Family Practice & 4 & 2.905 & 1.371 & 473 \\
OB/GYN & 5 & 3.260 & 1.260 & 123 \\
ANOVA F $=10.759$ & \multicolumn{2}{c}{ Model p $<0.000$} \\
\hline
\end{tabular}


NHI Mean Support Measures: Rural and Urban Physicians

Except for the general Other category of physicians, mean support for national health insurance was greatest among urban physicians. Significant differences in NHI support were found between rural and urban internal medicine (IM), OB/GYN, and family practice (FP) physicians. The most significant $(p<0.001)$ difference in NHI support measures was found between rural and urban family practice (FP) physicians. Rural FP physicians had a mean support measure of 3.144 , clearly in the opposition range, yet urban FP physicians had a mean support measure of 2.649 , more in the range of support for NHI. As Table 62 shows, except for pediatricians (who expressed support regardless of their geographic location), and the general other categories of physicians, all other rural practice primary care physicians expressed mean opposition measures to the concept of NHI.

TABLE 62

OREGON PRIMARY CARE PHYSICIAN RESPONDENTS MEAN SUPPORT MEASURES FOR NATIONAL HEALTH INSURANCE (NHI), BY GEOGRAPHIC LOCATION OF PRACTICE, $\mathrm{N}=1106$

\begin{tabular}{lll}
\hline & \multicolumn{2}{c}{ Place of Practice } \\
\cline { 2 - 3 } Support Level & & Urban \\
& 3.036 & $2.634^{* * * * *}$ \\
All Physicians & 2.442 & 2.289 \\
Pediatricians & 3.041 & $2.621^{* * * *}$ \\
Internal Medicine & 3.550 & $3.120^{*}$ \\
OB/GYN & 3.144 & $2.649^{* * * * *}$ \\
Family Practice & 2.241 & 2.405 \\
Other & & \\
\hline$*_{p}<0.10 \quad *_{p}<0.05 \quad *^{* * *}<0.01$ & $* * * * p<0.001$ & \\
\end{tabular}

${ }^{*} \mathrm{p}<0.10 \quad * *_{\mathrm{p}}<0.05 \quad * * * \mathrm{p}<0.01 \quad * * * *_{\mathrm{p}}<0.001$ 
Mean Support for NHI: Type of Practice

Support for national health insurance (NHI) among primary care physicians who practice in solo or partnerships and those who practice in group practices was mixed. While pediatricians expressed support. for NHI regardless of their type of practice, pediatricians who practice in group practices were significantly $(p<0.001)$ more supportive of NHI than were their solo/partnership practice counterparts.

Internal medicine (IM) physicians and family practice (FP) physicians in group practices were significantly $(p<0.001)$ more supportive of NHI than were their colleagues in solo/partnership practices. Both group practice IM and FP physicians had mean support measures that fell in the support range, 2.439 and 2.649, respectively, while their solo/partnership practice counterparts had mean support measures that are considered opposition to NHI, at 3.156 and 3.144 respectively.

$\mathrm{OB} / \mathrm{GYN}$ physicans have mean support measures that fall clearly in the range of opposition to NHI, regardless of their place of practice. Solo/partnership OB/GYN physicians have a mean measure of 3.420 and group practice $O B / G Y N$ physicians have mean support measures of 3.056. OB/GYNs in solo/partnership practices reported the third lowest support measure -- the highest measure of opposition -- of any physician group found in this study (osteopathic OB/GYN physicians reported the lowest mean support for NHI, and rural OB/GYN physicians were found to have the second lowest mean support measure found in this study). Table 7.65 displays these findings. 
TABLE 63

\section{OREGON PRIMARY CARE PHYSICIAN RESPONDENTS \\ MEAN SUPPORT MEASURES FOR NATIONAL HEALTH \\ INSURANCE (NHI), TYPE OF CLINICAL PRACTICE, $\mathbf{N}=1106$}

\begin{tabular}{lll}
\hline & \multicolumn{2}{c}{ Type of Practice } \\
\cline { 2 - 3 } Support Level & Solo/Part & Group \\
All Physicians & 3.150 & $2.467^{* * * * *}$ \\
Pediatricians & 2.677 & $2.042^{* * * * *}$ \\
Internal Medicine & 3.156 & $2.439^{* * * * *}$ \\
OB/GYN & 3.420 & 3.056 \\
Family Practice & 3.144 & $2.649^{* * * * *}$ \\
Other & 2.737 & $2.196^{*}$ \\
Between Group Significance: ${ }^{*} \mathrm{p}<0.10^{* * \mathrm{p}<0.05}$ & ${ }^{* * *} \mathrm{p}<0.01 \quad{ }^{* * * *} \mathrm{p}<0.001$
\end{tabular}

NHI Mean Support: M.D. and D.O. Physicians

Osteopathic (D.O.) physicians were significantly $(p<0.05)$ more opposed to NHI than were their allopathic (M.D.) counterparts. D.O.s were found to have a mean support measure of 3.049 , which would be considered opposition to NHI, and M.D.s were found to have a mean support measure of 2.774 , somewhat in the range of support for $\mathrm{NHI}$.

The greatest support measure among the osteopathic primary care specialists was from the pediatric physicians and the general other category of physicians, with support measures of 2.750 each. The greatest support measure found among allopathic physicians was among the pediatricians, as well, with a support measure of 2.331 . 
$\mathrm{OB} / \mathrm{GYN}$ physicians posted the lowest measure of support of any physician group analyzed in this study. OB/GYN physicians reported a mean support measure of 3.750, well within the range of opposition to NHI. Their M.D. counterparts were also opposed to NHI, with a mean support measure of 3.244. The differences between measures was not significant, however. Table 64 displays these findings.

TABLE 64

\begin{tabular}{|c|c|c|}
\hline \multirow[b]{2}{*}{ Support Level } & \multicolumn{2}{|c|}{ Type of Degree } \\
\hline & M.D. & D.O. \\
\hline All Physicians & 2.774 & $3.049^{*}$ \\
\hline Pediatricians & 2.331 & 2.750 \\
\hline Internal Medicine & 2.726 & 3.333 \\
\hline $\mathrm{OB} / \mathrm{GYN}$ & 3.244 & 3.750 \\
\hline Family Practice & 2.878 & 3.052 . \\
\hline Other & 2.276 & 2.750 \\
\hline
\end{tabular}

NHI Mean Support: Managed Care Physicians

No significant differences in mean support scores for national health insurance (NHI) were found among physicians who had managed care affiliations (MCA) and those who were not affiliated with an MCA. Both physicians groups reported mean 
support measures that were just in the support range, with a measure of 2.909 and 2.829 , respectively.

$\therefore$..Like earlier findings, the lowest measure of support for NHI was found among the OB/GYN physicians who were not affiliated with an MCA. However, the second lowest level of support was found among the OB/GYN physicians who were affiliated with an MCA. The MCA OB/GYN physicians had mean support measures of 3.260 and the non-MCA OB/GYN physicians had mean support measures of 3.455 , both measures within the range of opposition to NHI. The differences between the other primary care physicians' support measures was not significant, ranging from a high support measure of 2.185 among the non-MCA pediatricians to a 2.940 among the MCA internal medicine physicians. These findings are displayed in Table 65 .

\section{TABLE 65}

OREGON PRIMARY CARE PHYSICIAN RESPONDENTS' MEAN SUPPORT MEASURES FOR NATIONAL HEALTH INSURANCE (NHI), BY PHYSICIANS WITH MANAGED CARE AFFILIATIONS (MCA) AND WITHOUT MCA, $\mathrm{N}=939$

\begin{tabular}{|c|c|c|}
\hline \multirow[b]{2}{*}{ Support Level } & \multicolumn{2}{|c|}{ Managed Care Affiliation } \\
\hline & Affiliated & Not Affiliated \\
\hline All Physicians & 2.909 & 2.829 \\
\hline Pediatricians & 2.573 & 2.185 \\
\hline Internal Medicine & 2.940 & 2.802 \\
\hline OB/GYN & 3.260 & 3.455 \\
\hline Family Practice & 2.912 & 2.979 \\
\hline Other & 2.475 & 2.500 \\
\hline
\end{tabular}


NHI Mean Support: Physicians with Uninsured Patients

Physicians who treat uninsured patients reported somewhat higher mean support scores for national health insurance than did their counterparts who have no uninsured patients. The former group of physicians were found to have mean support measures of 2.860 and the latter group had mean support measures of 2.650 . This difference in support measures was not significant, however.

While not significant, in all categories except internal medicine, physicians who have no uninsured patients were more supportive of NHI than were physicians who have some of their patients uninsured. Even OB/GYN physicians in this category, who have generally been found to be opposed to NHI when examined in other parts of this study, reported mean support measures that would fall within the support range for national health insurance (2.800). Their OB/GYN counterparts who treat uninsured patients, however, reported mean support measures that would fall within the opposition range to NHI (3.319). These findings are displayed in Table 66 , next page. 
TABLE 66

\begin{tabular}{lcc}
\multicolumn{3}{c}{ OREGON PRIMARY CARE PHYSICIAN RESPONDENT } \\
MEAN SUPPORT MEASURES FOR NATIONAL HEALTH INSURAN \\
BY PHYSICIANS WITH PATIENTS WHO HAVE NO HEALTH INS \\
AND PHYSICIANS WITH NO UNINSURED PATIENTS, N \\
\hline \\
\cline { 2 - 2 } Support Level & $\begin{array}{c}\text { Some Patient Insurance Status } \\
\text { Uninsured }\end{array}$ & $\begin{array}{c}\text { All Patients } \\
\text { Insured }\end{array}$ \\
All Physicians & & \\
Pediatricians & 2.860 & 2.650 \\
Internal Medicine & & \\
OB/GYN & 2.307 & 2.667 \\
Family Practice & 2.649 & 2.871 \\
Other & 3.319 & 2.800 \\
& 2.948 & 2.667 \\
\end{tabular}

$*_{\mathrm{p}}<0.10 \quad * * \mathrm{p}<0.05 \quad * * * \mathrm{p}<0.01 \quad * * * * \mathrm{p}<0.001$

NHI Mean Support: Physicians Who Treat Medicaid Patients

Primary care physicians who do not accept Medicaid patients were significantly $(p<0.01)$ more supportive of national health insurance than were their counterparts who do treat Medicaid patients. Physicians with no Medicaid patients reported mean support measures of 2.536 , and their non-Medicaid counterparts was found to have a mean support measure of 2.883. See Table 67, next page. 
When the various mean support measures of the primary care specialists groups were examined, only family practice (FP) physicians were found to have significantly $(p<0.05)$ different mean support measures. As a group, FP physicians who have no Medicaid patients were more supportive of NHI than were their colleagues who treat Medicaid patients. While both groups reported mean support measures that were within the support range, the FP physicians who had no Medicaid patients were found to have significantly $(p<0.05$ ) higher support mean support measures. This finding is displayed in Table 67.

TABLE 67

OREGON PRIMARY CARE PHYSICIAN RESPONDENTS' MEAN SUPPORT MEASURES FOR NATIONAL HEALTH INSURANCE (NHI), BY PHYSICIANS WITH MEDICAID AND NON-MEDICAID PATIENTS, $\mathrm{N}=946$

\begin{tabular}{lcc}
\hline & \multicolumn{2}{c}{ Physician Practice Status } \\
\cline { 2 - 3 } Support Level & $\begin{array}{c}\text { Some Medicaid } \\
\text { Patients }\end{array}$ & $\begin{array}{c}\text { No Medicaid } \\
\text { Patients }\end{array}$ \\
All Physicians & 2.883 & $2.536^{* * * *}$ \\
Pediatricians & 2.342 & \\
Internal Medicine & 2.890 & 2.421 \\
OB/GYN & 3.316 & 2.568 \\
Family Practice & 2.970 & 3.091 \\
Other & 2.429 & $2.462^{* * *}$ \\
\hline
\end{tabular}

${ }^{*} \mathrm{p}<0.10 \quad{ }^{* *} \mathrm{p}<0.05 \quad{ }^{* * *} \mathrm{p}<0.01 \quad{ }^{* * * *} \mathrm{p}<0.001$

NHI Mean Support: Among Newly Established Physicians 
NHI Mean Support: Amorg Newly Established Physicians

Newly established physicians (those in practice less than five years) were significantly $(\mathrm{p}<0.001)$ more supportive of national health insurance $(\mathrm{NHI})$ than were their established colleagues. Newly practicing physicians had mean support measures of 2.502 and established physicians had mean support measures of 2.877 . That trend held among all primary care specialty physicians.

Except for the OB/GYN group, physicians who had been in practice less than five years were found to have mean support measures that indicated support for NHI. Only newly practicing OB/GYN physicians were found to have mean support scores that approached support for NHI, as their score of 3.000 suggests that they are more supportive of NHI than their established colleagues. Following the trend found elsewhere, however, established OB/GYN physicans were clearly more nonsupportive of NHI than their newly practicing counterparts, with a mean support measure of 3.305 .

A significant difference was found between newly established family practice (FP) physicians and their established counterparts. While the newly practicing FP physicians reported mean support measures of 2.481 , indicating support for NHI, the established FP physicians were found to have mean support measures of 2.992, suggesting more opposition to the concept. This difference was significant $(p<$ 0.01). This finding is displayed in Table 68, next page. 
TABLE 68

\begin{tabular}{|c|c|c|}
\hline \multirow[b]{2}{*}{ Support Level } & \multicolumn{2}{|c|}{ Physician Practice Status } \\
\hline & Newly Est. & Established \\
\hline All Physicians & 2.502 & $2.877^{* * * * *}$ \\
\hline Pediatricians & 2.037 & $2.417^{*}$ \\
\hline Internal Medicine & 2.612 & 2.799 \\
\hline OB/GYN & 3.000 & 3.305 \\
\hline Family Practice & 2.481 & $2.992^{* * * *}$ \\
\hline Other & 2.222 & 2.383 \\
\hline
\end{tabular}

${ }^{*} \mathrm{p}<0.10 \quad * * \mathrm{p}<0.05 \quad * * * \mathrm{p}<0.01 \quad * * * * \mathrm{p}<0.001$

When this trend is examined further, mean support for NHI was found to be a function of the number of years a physician has been in practice. The longer the length of practice, the less support for national health insurance was found. This finding was significant. As Table 69 shows, mean support for NHI changes from clear support among physicians who have been in practice less than five years to clear non-support among physicians who have been in practice more than 20 years.

The trend of increasing non-support to NHI is not universal, however. Pediatricians in practice less than five years were most supportive of NHI, however, non-support for NHI increases among this group of physicians and then drops again among the group in practice the longest (over 20 years). That curve linear trend was also found among internal medicine and OB/GYN physicians. IM physicians who had 
been in practice from 5 to 10 years were most non-supportive of $\mathrm{NHI}$, but support increased, somewhat, among those in practice over 10 years. OB/GYN physicians, generally non-supportive of NHI regardless of the length of time they had been in practice, were also found to have curve linear support measures, decreasing with length of practice, and then increasing among those OB/GYN physicians who had been in practice over 20 years.

TABLE 69

OREGON PRIMARY CARE PHYSICIANS' MEAN SUPPORT MEASURE FOR NATIONAL HEALTH INSURANCE, BY LENGTH OF YEARS IN PRACTICE, $\mathrm{N}=1128$

Physicians Type

Physicians' Years in Practice

\begin{tabular}{llll}
\hline 5yrs $5-10 y r s \quad>10-20 y$ & $>$ yyrs
\end{tabular}

All Physicians

2.502

2.697

2.873

$3.023 * * * * *$

Pediatricians

2.037

2.167

2.558

2.423

Internal Medicine

2.612

2.906

2.753

2.765

OB/GYN

3.000

3.214

3.400

3.216

Family Practice

2.481

2.673

2.945

$3.248^{* * * * *}$

Other

2.222

2.000

2.579

2.500

Between Groups Significance: * $\mathrm{p}<0.10 \quad * * \mathrm{p}<0.10 \quad * * * \mathrm{p}<0.01 \quad * * * * \mathrm{p}<0.001$

Family practice physicians were found to have significantly $(\mathrm{p}<0.001)$ decreasing measures of support as a function of length of time in practice. The longer the FP physicians had been in practice, the less support for NHI was found. Table 69 shows these findings. 


\section{Analysis of All Independent Variables}

A regression analysis of all of the independent variables examined in this study found that seven of the variables significantly $(p<0.10)$ explained variation in physicians support measures for national health insurance (NHI). As Table 70, page 181, shows, 20.9 percent of the physicians' support measures can be explained by:

1) The physicians' attitude towards health care rationing policies;

2) Percentage of their patients without health insurance;

3) Physicians' geographic location of practice (rural or urban);

4) Type of clinical practice (solo/partnership or group practice);

5) Percentage of their patients seeking maternity care;

6) Percentage of their patients on Medicaid; and

7) The number of years a physician has been in practice.

None of the other variables in the model significantly explained variation in a physicians' support measure for national health insurance.

A physician's support measure for health care rationing policies significantly $(p<0.001)$ explained variation in a physician's support measure for national health insurance. The regression analysis reveals that physicians who expressed a higher level of support for health care rationing policies also tended to have higher levels of support for national health insurance ( $\mathrm{NHI}$ ), and visa versa, however, the measures were 0.328 points lower for NHI. This finding suggests that some physicians are supportive of change in the way health care is financed or delivered, regardless of the type of change. This finding also suggests that physicians who are non-supportive of health care rationing polices are also non-supportive of $\mathrm{NHI}$. 
Conversely, physicians who have high percentages of patients with health insurance were significantly $(p<0.001)$ more likely to have higher national health insurance support measures than physicians with lower percentages of their patients without health insurance. The regression coefficient shows that for every 10 percent of physicians' patients without health insurance, as a group, their support for NHI would be predicted to increase .15 points.

The regression confirms earlier findings that as the percentage of physicians' patients on Medicaid increases, so does their support for national health insurance. Physicians with half of their patient mix on Medicaid would be predicted to have mean support measures 0.40 points higher than physicians without any patients on Medicaid. That trend was reversed for physicians with high percentages of their patients on Medicare. As the percentage of patient mix on Medicare goes up, the support for NHI goes down in exactly the same fashion as the Medicaid variable. Holding the other variables constant, physicians with 50 percent of their patient mix insured by Medicare -- an insurance program that pays physicians relatively well in comparison to how Medicaid pays -- would be predicted to have a 0.40 lower support score for NHI than physicians who have no patients on Medicare.

As the percentage of a physicians' patients who seek care for preventative services increases, the physicians' support for national health insurance (NHI) decreases. This finding was significant $(p<0.05)$. This is the second practice variable that significantly explained variation in physicians' support for $\mathrm{NHI}$ measures, the other being the percentage of maternity care patients a physician sees. 
Supporting an earlier finding, geographic location is a significant variable in expiaining variance in physicians' support for national health insurance. Urban primary care physicians are more supportive of NHI than are rural primary care physicians. As shown in the model, with all other variables held constant, rural physicians would be predicted to have a 0.102 lower score of support for NHI than would their urban colleagues.

As found earlier, the number of years a physician has been in practice also explains variance in a physician's support for national health insurance (NHI). The more years in practice, the less support is found for NHI. This variable was significant $(p<0.010)$. Also, physicians in small solo/partnerships had significantly $(p<0.05)$ less support for NHI than did their group-practice counterparts. Solo/partnership physicians would be predicted to have a 0.280 lower mean support measure for NHI than would their group-practice colleagues.

As noted above, the type of patients a physician sees in practice significantly $(p<0.015)$ explains some variance in the support measures for national health insurance (NHI). Physicians who see a greater percentage of patients for maternity care were significantly less supportive of NHI than physicians who saw no patients for maternity care. This finding reflects the strong non-support for $\mathrm{NHI}$ found throughout this study among the OB/GYN physicians. A further analysis of finding reveals that $\mathrm{OB} / \mathrm{GYN}$ physicians see 34.5 percent of their patients for this maternity care, while family practice (FP) physicians see just over 4.4 percent of their patients for this purpose. Pediatricians see none of their patients for maternity care, and 
internal medicine physicians see less than one percent of their patients for maternity care. These differences were significant $(p<0.001)$. See Table 70 , below.

TABLE 70

MULTI-VARIATE REGRESSION ANALYSIS OF DEPENDENT VARIABLE: OREGON PRIMARY CARE PHYSICIANS' MEASURE OF SUPPORT FOR NATIONAL HEALTH INSURANCE $(1=$ VERY SUPPORTIVE TO $5=$ =UNALTERABLE -OPPOSITION), LISTED IN ORDER OF STRENGTH,${ }^{1} \cdot \mathrm{N}=587$

Y Variable: Measure of Support for National Health Insurance

$\mathrm{R}^{2}=0.209 \quad$ Adjusted Multiple $\mathrm{R}^{2}=0.185$

Independent Variables $(X)$

Constant

Support for Health Care Rationing Policies

Percent of Patients: Without Health Insurance

Percent of Patients: On Medicare

Percent of Patients: Charged Fee-for-Service

Geographic Location ( $0=$ Rural $1=$ Urban)

Type of Practice Setting ( $0=$ Group $1=$ Solo)

Percent of Practice: Maternity Care

Percent of Practice: Acute Care Nonfatal

Percent of Patients: On Medicaid

Years Practicing Medicine

Percent of Practice in Office

Percent of Practice: Preventative Care

Percent of Practice: Chronic Care-Fatal

Percent of Practice: Acute Care-Fatal

Percent of Practice: Chronic Care-Nonfatal

Percent of Practice Devoted to Specialty

MCA Affiliation $(1=$ Yes $0=$ No)
Coefficient $\quad P(2$ Tail)

$\begin{array}{rl}2.371 & 0.000^{*} \\ 0.313 & 0.000^{*} \\ -0.016 & 0.000^{*} \\ 0.006 & 0.148 \\ 0.005 & 0.179 \\ -0.273 & 0.019^{*} \\ 0.265 & 0.015^{*} \\ 0.009 & 0.088^{*} \\ -0.004 & 0.248 \\ -0.009 & 0.035^{*} \\ 0.082 & 0.094^{*} \\ -0.002 & 0.414 \\ 0.005 & 0.181 \\ -0.001 & 0.834 \\ -0.009 & 0.286 \\ 0.003 & 0.468 \\ -0.002 & 0.314 \\ 0.071 & 0.581\end{array}$

MODEL ANOVA

Model F Ratio 8.835 $\quad P<0.001 \quad$ Df 17

1 - Strength is determined by the variable's standardized coefficient * Statistically significant variable 


\section{Support for NHI by Pediatricians}

When the regression model was applied to pediatric physicians, only one variable significantly $(p<0.007)$ explained variation in this group's support for national health insurance. As can be seen in the model in Table 71 , next page, as a group, pediatricians' attitude toward health care rationing significantly $(p<0.007)$ explained variation in the pediatricians' support for national health insurance (NHI). However, as was found in the model for all physicians, pediatric support for NHI was not as great as their support for health care rationing policies. As can be seen in the model, pediatricians who support health care rationing policies also support NHI. Alternately, pediatricians who did not to support health care rationing policies also did not support NHI. As the model suggests, even pediatricians who have high mean support measures for health care rationing would be predicted to have lower mean support measures for national health insurance.

Rural and urban pediatricians were found to have the same measures of support for NHI. This finding separates pediatricians, as a group, from the larger group of all primary care physicians, with geographic location of practice as a significant variable in explaining variation in the larger group's measure of NHI support.

Interestingly, other variables significant in the general primary care physicians' model did not significantly explain pediatricians' support for NHI. The percentage of a pediatricians' patients without health insurance, for instance, did not significantly explain variation in the pediatricians' NHI support measure. Nor did the percentage 
of pediatricians' patients on Medicaid. None of the practice specific variables were

TABLE 71

REGRESSION ANALYSIS OF OREGON PEDIATRIC PHYSICIANS SUPPORT

FOR NATIONAL HEALTH INSURANCE (NHI), $\mathrm{N}=69$ SCALE: $1=$ VERY

SUPPORTIVE TO $5=$ UNALTERABLY OPPOSED

Dependent Variable $(Y)=$ Measure of Support for National Health Insurance by Pediatric Physicians in Oregon

Independent Variables $(X)$

Constant

Support for Health Care Rationing Policies

Percent of Patients: Without Health Insurance

Percent of Patients: On Medicare

Percent of Patients: Charged Fee-for-Service

Geographic Location $(0=$ Rural $1=$ Urban)

Type of Practice ( $0=$ Group $1=$ Solo/partnership)

Percent of Practice: Maternity Care

Percent of Practice: Acute Care Nonfatal

Percent of Patients: On Medicaid

Years Practicing Medicine

Percent of Practice in Office

Percent of Practice: Preventative Care

Percent of Practice: Chronic Care Fatal

Percent of Practice: Acute Care Fatal

Percent of Practice: Chronic Care Nonfatal

Percent of Practice: Devoted to Specialty

MCA Affiliation $(0=$ No $1=$ Yes $)$
Coefficient $\quad P(2$ Tail $)$

2.102

0.373

$-0.015$

$-0.007$

0.012

0.363

0.067

1.084

$-0.014$

0.002

0.096

$-0.002$

0.003

$-0.019$

$-0.030$

$-0.023$

0.000

0.109
0.382

$0.007^{*}$

0.356

0.757

0.271

0.323

0.819

0.384

0.278

0.864

0.566

0.905

0.825

0.612

0.365

0.118

0.920

0.770

$\mathrm{R}^{2}=0.430 \quad$ Adjusted Multiple $\mathrm{R}^{2}=0.205$

ANOVA F 2.029 Model P $=0.027$ Df 17

* Statistically significant variable 
significant in the model. While the model, itself, explained over 40 percent $\left(\mathrm{R}^{2}=\right.$ 0.403) of the variation in the pediatricians' support measure for NHI, none of the other variables in the model significantly explained variation in pediatricians' support for NHI, with the exception of the measure of support for health care rationing policies.

Support for NHI by Internal Medicine Physicians (IM)

The regression model as applied to internal medicine (IM) physicians significantly explained 22.6 percent $\left(R^{2}=0.226\right)$ of the variation in IM physicians' support measure for national health insurance (NHI). As was found with pediatric physicians, IM physicians' support for health care rationing policies significantly ( $p$ $<0.10$ ) explained the variation in the IM physicians' support for national health insurance (NHI). Again, as was found with pediatricians, the relationship was positive. The model suggests that IM physicians who are supportive of health care rationing are supportive of NHI. Alternately, IM physicians who are opposed to health care rationing are generally opposed to NHI. However, like with pediatricians, IM physicians were less supportive of NHI than they were of health care rationing policies.

The percentage of IM physicians' patients on Medicare also significantly $(\mathrm{p}<$ 0.01) explained the variation in the IM physicians' support for national health insurance (NHI). However, this relationship was found to be negative. This finding 
suggests that physicians with high percentages of patients insured by Medicare would be less supportive of NHI than would physicians with smail percentages of their patients insured by Medicare.

Urban internal medicine (IM) physicians were found to be significantly $(\mathrm{p}<$ $0.10)$ more supportive of NHI than were their rural colleagues. This finding is contrary to that found with urban and rural pediatricians, where support was the same between the two groups. According to the model in Table 72, next page, urban IM physicians have mean support measures almost half a point $(-0.485)$ greater than rural IM physicians (on a scale where 1 is the most supportive).

The percentage of IM physicians' patients on Medicaid significantly $(\mathrm{p}<$ 0.002) explained the variation in the IM physicians' support for NHI. Again, this relationship was negative. With a score of 1 being the most supportive of NHI, the model shows that the greater the percentage of an internal medicine (IM) physicians' patients on Medicaid, the more supportive of NHI the IM physicians were. This model suggests that for every 10 percent increase in Medicaid patients an IM physician experiences, a -0.36 point increase in support for $\mathrm{NHI}$ would be expected.

The IM physicians' case mix independent variable revealed an interesting finding. As shown in Table 71, the greater the percentage of an IM physician's patients being seen for maternity care, the lower the IM physician's support for national health insurance (NHI) was found to be. This variable was significant $(p<$ 0.05 ), and is similar to the finding for $\mathrm{OB} / \mathrm{GYN}$ physicians. The relationship held for both rural and urban IM physicians. 
TABLE 72

REGRESSION ANALYSIS OF OREGON INTERNAL MEDICINE (IM) PHYSICIANS' SUPPORT FOR NATIONAL HEALTH INSURANCE (NHI), $\mathbf{N}=69$ SCALE: $1=$ VERY SUPPORTIVE TO $5=$ UNALTERABLY OPPOSED

Dependent Variable $(Y)=$ Measure of Support for National Health Insurance by Internal Medicine Physicians in Oregon

\section{Independent Variables $(X)$}

Constant

Support for Health Care Rationing Policies

Percent of Patients: Without Health Insurance

Percent of Patients: On Medicare

Percent of Patients: Charged Fee-for-Service

Geographic Location $(0=$ Rural $1=$ Urban)

Type of Practice $(0=$ Group $1=$ Solo/partnership $)$

Percent of Practice: Maternity Care

Percent of Practice: Acute Care Nonfatal

Percent of Patients: On Medicaid

Years Practicing Medicine

Percent of Practice in Office

Percent of Practice: Preventative Care

Percent of Practice: Chronic Care Fatal

Percent of Practice: Acute Care Fatal

Percent of Practice: Chronic Care Nonfatal

Percent of Practice: Devoted to Specialty

MCA Affiliation ( $0=$ No $1=$ Yes)

$$
\text { Coefficient }
$$

$P(2$ Tail $)$

$$
2.676
$$

0.188

$-0.005$

0.014

0.010

$-0.485$

0.215

0.295

0.007

$-0.036$

$-0.063$

$-0.006$

0.007

0.002

$-0.020$

0.005

$-0.004$

0.177
$0.008 *$

$0.069 *$

0.548

$0.066^{*}$

0.247

$0.053 *$

0.374

$0.068^{*}$

0.380

$0.002 *$

0.533

0.199

0.356

0.768

0.280

0.521

0.375

0.517

$\mathrm{R}^{2}=0.226 \quad$ Adjusted Multiple $\mathrm{R}^{2}=0.132$

ANOVA $F=2.408 \quad$ Model $P=0.003 \quad$ Df 17

*Statistically significant variable

None of the other variables in the IM physician model were significant. While length of years practicing was significant for the entire physician sample, it did not 
significantly explain the variation in internal medicine (IM) physicians' support for NHI. None of the IM physicians' practice variables significantly explained NHI support measures, nor did the IM physicians' type of practice. Solo/partnership and group-practice IM physicians were found to have the same measures of support for NHI. The regression model for internal medicine physicians is shown in Table 72, previous page.

\section{Support for $N H I$ by $O B / G Y N$ Physicians}

The regression model for $\mathrm{OB} / \mathrm{GYN}$ physicians found that these physicians had the lowest measure of support for NHI than all other primary care physician groups analyzed for this study. Controlling for the effect of all other variables on OB/GYNs' NHI support measure, OB/GYN continued to have the least amount of support for NHI.

The regression model of OB/GYN physicians explained 35.2 percent $\left(\mathrm{R}^{2}=\right.$ 0.352) of the groups' measure of support for national health insurance (NHI). Only two variables were significant in the model, however. Unlike earlier findings with pediatricians and internal medicine physicians, an OB/GYN physicians' measure of support for health care rationing polices did not significantly explain the variation in the group's measure of support for NHI. However, like earlier findings, the percentage of an OB/GYN physicians' patients on Medicaid did significantly $(p<$ 0.01) explain the variation in the NHI support measure. According to the model, 
every 10 percent increase in Medicaid patients would predict an increase in support for NHI of almost half a point ( -0.490 points). This finding suggests that $O B / G Y N$ physicians with low or no Medicaid patients are the least supportive of NHI.

TABLE 73

REGRESSION ANALYSIS OF OREGON OB/GYN PHYSICIANS SUPPORT FOR NATIONAL HEALTH INSURANCE (NHI), $N=69$ SCALE: $1=$ VERY SUPPORTIVE TO 5=UNALTERABLY OPPOSED

Dependent Variable $(Y)=$ Measure of Support for National Health Insurance by OB/GYN Physicians in Oregon

Independent Variables $(X)$

Constant

Support for Health Care Rationing Policies

Percent of Patients: Without Health Insurance

Percent of Patients: On Medicare

Percent of Patients: Charged Fee-for-Service

Geographic Location ( $0=$ Rural $1=$ Urban)

Type of Practice ( $0=$ Group $1=$ Solo/partnership)

Percent of Practice: Maternity Care

Percent of Practice: Acute Care Nonfatal

Percent of Patients: On Medicaid

Years Practicing Medicine

Percent of Practice in Office

Percent of Practice: Preventative Care

Percent of Practice: Chronic Care Fatal

Percent of Practice: Acute Care Fatal

Percent of Practice: Chronic Care Nonfatal

Percent of Practice: Devoted to Specialty

HMO Affiliation $(0=$ No $1=$ Yes $)$
Coefficient

4.437

0.166

$-0.049$

0.029

$-0.007$

$-1.332$

$-0.003$

$-0.001$

$-0.022$

$-0.005$

0.150

$-0.011$

0.009

$-0.031$

0.034

0.005

0.001

0.718
P(2 Tail)

0.012

0.282

$0.080^{*}$

0.142

0.526

$0.005^{*}$

0.995

0.924

0.155

0.720

0.384

0.292

0.445

0.221

0.347

0.741

0.950

0.169

$\mathrm{R}^{2}=0.352 \quad$ Adjusted Multiple $\mathrm{R}^{2}=0.107$

ANOVA $F=1.439 \quad$ Model $P=0.164 \quad$ Df 17

*Statistically significant variable 
Like that found for internal medicine physicians, urban OB/GYN physicians were significantly $(p<0.005)$ more supportive of national health insurance $(\mathrm{NHI})$ than were their rural counterparts. However, this variable explained the greatest amount of support among OB/GYN physicians than any other variable in the model. This finding is reported in Table 73, previous page.

\section{Support for NHI by Family Practice Physicians}

Several variables in the model applied to family practice (FP) physicians significantly explained variation in their support for national health insurance (NHI). The most significant $(p<0.001)$ variable was the FP physicians' measure of support for health care rationing policies. Like that found for pediatricians and internal medicine physicians, support for health care rationing polices was positively correlated with the FP physicians' support for national health insurance. Family Practice (FP) physicians who were supportive of health care rationing policies would be predicted to be supportive of NHI. Conversely, the model suggests that FP physicians who were opposed to health care rationing would also be opposed to NHI. However, even among those FP physicians supportive of health care rationing, their support for NHI is just as great.

As the model in Table 74 shows, the percentage of family practice (FP) physicians' patients who are on Medicaid significantly $(p<0.05)$ explained variation 
in the FP physicians' support for NHI. The greater the percentage of their patients on Medicaid, the greater the FP physicians' support for NHI was found to be.

Family practice physicians who practice in a solo/partnership practice were found to be significantly $(p<0.10)$ less supportive of national health insurance than their group-practice counterparts. While this variable was not found significant in explaining the variation in the other primary care physicians' support for NHI, it was found to be significant in explaining family practice physicians' support. According to the model, group practice FP physicians would have -0.301 points more support for NHI than would solo/partnership FP physicians.

The other significant $(p<0.10)$ variable in the model is the number of years a family practice physician had been in practice. The longer a FP physician had practiced medicine, the less support for NHI was found. Interestingly, this variable was not a significant predictor for the other primary care physicians in the study. Table 74, next page, shows the regression model for family practice physicians. 
TABLE 74

\section{REGRESSION ANALYSIS OF FAMILY PRACTICE PHYSICIANS' SUPPORT FOR NATIONAL HEALTH INSURANCE (NHI), $N=69$ SCALE: $1=$ VERY SUPPORTIVE TO $5=$ =UNALTERABLY OPPOSED}

\begin{tabular}{ll}
\hline Dependent Variable $(\mathrm{Y})=$ & $\begin{array}{l}\text { Measure of Support for National Health Insurance by } \\
\text { Family Practice Physicians in Oregon }\end{array}$
\end{tabular}

Independent Variables $(X)$

Constant

Support for Health Care Rationing Policies

( $1=$ very supportive to $S=$ unalterable opposition)

Percent of Patients: Without Health Insurance

Percent of Patients: On Medicare

Percent of Patients: Charged Fee-for-Service

Geographic Location $(0=$ Rural $1=$ Urban)

Type of Practice $(0=$ Group $1=$ Solo/partnership)

Percent of Practice: Maternity Care

Percent of Practice: Acute Care Nonfatal

Percent of Patients: On Medicaid

Years Practicing Medicine

Percent of Practice in Office

Percent of Practice: Preventative Care

Percent of Practice: Chronic Care Fatal

Percent of Practice: Acute Care Fatal

Percent of Practice: Chronic Care Nonfatal

Percent of Practice: Devoted to Specialty

HMO Affiliation $(0=$ No $1=$ Yes $)$
Coefficient

$$
1.821
$$

0.387

$-0.013$

0.002

0.005

$-0.245$

0.130

$-0.012$

$-0.005$

$-0.006$

0.128

0.002

$-0.006$

0.005

$-0.015$

0.007

0.001

$-0.184$
$P(2$ Tail)

0.044

$0.000^{*}$

$0.035^{*}$

0.792

0.366

0.173

0.074 *

0.365

0.396

0.443

$0.100^{*}$

0.785

0.405

0.547

0.365

0.317

0.838

0.337

$\mathrm{R}^{2}=0.268 \quad$ Adjusted Multiple $\mathrm{R}^{2}=0.217$

ANOVA $F=5.308 \quad$ Model $P<0.001 \quad$ Df 17

* Statistically significant variable 


\section{NHI Support by Other Types of Primary Care Physicians}

As discussed in earlier chapters, the Other category of physicians represents primary care physicians who are not considered one of the four AMA recognized specialty groups of pediatrics, internal medicine, OB/GYN, and family practice. Most of these physicians practice in hospitals (emergency department physicians), urgent care centers, public health agencies, or in some form of general practice. When the regression model was applied to this group of physicians, 70.5 percent $\left(\mathrm{R}^{2}\right.$ $=0.705$ ) of the variation in their support for national health insurance (NHI) was explained, the most variance explained of any of the primary care physician groups examined in this study.

As was found among some of the other primary care groups, this group of physicians' support measures for health care rationing policies and their percentage of their patients with no health insurance, significantly $(p<0.05)$ explained most of the variation in their support measure for NHI. As with the other physician groups, physicians in this group who support health care rationing policies would be predicted to support NHI, but not to the same extent. Like the pattern found for family practice physicians, the greater the percentage of uninsured patients this physician group treats, the greater their support for national health insurance (NHI) was found to be.

Other physicians who maintained a managed care affiliation (MCA), either by belonging to an health maintenance organization (HMO), preferred provider 
organization (PPO), or independent practice association (IPA), were significantly ( $p$ $<0.05)$ more supportive of NHI than were other physicians who were not affiliated with an MCA. However, in this case, MCA affiliation among this group of physicians would predict to a -1.049 point increase in support for NHI, more than a full point increase. This is the second most significant variable that explains increase in support for NHI of any group of physicians studied. This regression table, with the probabilities of all independent variables is shown in Table 75, next page.

Figure 10, page 195, shows all of the probabilities associated with the independent variables outlined in the hypothesis matrix discussed in Chapter 9 (See page 83). These probabilities are from each of the respective regression analyses for each Oregon primary care specialty. 
TABLE 75

REGRESSION ANALYSIS OF OTHER PRIMARY CARE (OPC) PHYSICIANS' SUPPORT FOR NATIONAL HEALTH INSURANCE (NHI), $N=69$ SCALE: 1 =VERY SUPPORTIVE TO 5=UNALTERABLY OPPOSED

\section{Dependent Variable $(Y)=$ Measure of Support for National Health Insurance by Other Primary Care Physicians in Oregon}

Independent Variables $(X)$

Constant

Support for Health Care Rationing Policies

Percent of Patients: Without Health Insurance

Percent of Patients: On Medicare

Percent of Patients: Charged Fee-for-Service

Geographic Location ( $0=$ Rural $1=$ Urban)

Type of Practice ( $0=$ Group $1=$ Solo/partnership)

Percent of Practice: Maternity Care

Percent of Practice: Acute Care Nonfatal

Percent of Patients: On Medicaid

Years Practicing Medicine

Percent of Practice in Office

Percent of Practice: Preventative Care

Percent of Practice: Chronic Care Fatal

Percent of Practice: Acute Care Fatal

Percent of Practice: Chronic Care Nonfatal

Percent of Practice: Devoted to Specialty

MCA Affiliation $(0=$ No $1=$ Yes $)$
Coefficient

3.065

0.371

$-0.043$

$-0.014$

$-0.014$

0.336

$-0.107$

0.231

$-0.005$

0.001

0.021

0.005

0.010

0.028

0.014

$-0.004$

$-0.009$

$-0.049$
P(2 Tail)

0.080

$0.063^{*}$

$0.011 * *$

0.394

0.324

0.441

0.813

$0.039 *$

0.603

0.966

0.903

0.405

0.399

0.102

0.395

0.689

0.196

0.048 *

$\mathrm{R}^{2}=0.805 \quad$ Adjusted Multiple $\mathrm{R}^{2}=0.568$

ANOVA $F=3.393 \quad$ Model $P=0.013 \quad$ Df 17

*Statistically significant variable 


\begin{tabular}{|c|c|c|c|c|c|c|c|c|}
\hline SUPPORT FOR & & & & Indepe I & Variables & & & \\
\hline $\begin{array}{l}\text { NATIONAL. HEALTH } \\
\text { INSURANCE, by: }\end{array}$ & $\begin{array}{c}\text { Support For } \\
\text { HC Rationing }\end{array}$ & $\begin{array}{l}\text { Percent Pts } \\
\text { Uninsured. }\end{array}$ & $\begin{array}{l}\text { Percent Pts } \\
\text { Medicare }\end{array}$ & $\begin{array}{l}\text { Percent Pts } \\
\text { Fee For Svc. }\end{array}$ & $\begin{array}{l}\text { Geographic } \\
\text { Location }\end{array}$ & $\begin{array}{l}\text { Type of } \\
\text { Practice }\end{array}$ & $\begin{array}{l}\text { Pct. Practice } \\
\text { Maternity }\end{array}$ & $\begin{array}{l}\text { Pct. Practice } \\
\text { Acute, Nonfata }\end{array}$ \\
\hline All Physicians & $0.000^{*}$ & $0.000 *$ & 0.121 & 0.178 & $0.024^{*}$ & $0.015^{*}$ & $0.005 * *$ & $0.033 *$ \\
\hline Pediatricians & $0.007 *$ & 0.356 & 0.757 & 0.271 & 0.323 & 0.819 & 0.384 & 0.278 \\
\hline Internal Medicine & $0.069^{*}$ & 0.548 & $0.066^{*}$ & 0.247 & $0.053 *$ & 0.374 & $0.068^{*}$ & 0.380 \\
\hline OB/GYN & 0.282 & $0.080^{*}$ & 0.142 & 0.526 & $0.005^{*}$ & 0.995 & 0.924 & 0.155 \\
\hline Family Practice & $0.000^{*}$ & $0.035^{*}$ & 0.792 & 0.366 & 0.173 & $0.074 *$ & 0.365 & 0.396 \\
\hline Other & $0.063 *$ & $0.011^{*}$ & 0.394 & 0.324 & 0.441 & 0.813 & $0.039^{*}$ & 0.603 \\
\hline
\end{tabular}

\begin{tabular}{|c|c|c|c|c|c|c|c|c|}
\hline \multirow[b]{2}{*}{$\begin{array}{l}\text { Pct. Patients } \\
\text { Medicaid }\end{array}$} & \multirow[b]{2}{*}{$\begin{array}{l}\text { Years in } \\
\text { Practice }\end{array}$} & \multicolumn{6}{|c|}{ Independent Variables } & \multirow[b]{2}{*}{$\begin{array}{c}\text { Managed Care } \\
\text { Affiliation }\end{array}$} \\
\hline & & $\begin{array}{l}\text { Pct. Practice } \\
\text { in Office }\end{array}$ & $\begin{array}{l}\text { Pct. Practice } \\
\text { Prev. Care }\end{array}$ & $\begin{array}{l}\text { Pct. Practice } \\
\text { Chronic, fatal }\end{array}$ & $\begin{array}{l}\text { Pct. Practice } \\
\text { Acute, fatal }\end{array}$ & $\begin{array}{c}\text { Pct. Practice } \\
\text { Chronic, nonfatal }\end{array}$ & $\begin{array}{l}\text { Pct. Practice } \\
\text { Specialty }\end{array}$ & \\
\hline $0.033 *$ & $0.085^{*}$ & 0.446 & $0.048 *$ & 0.720 & 0.388 & 0.142 & 0.416 & 0.611 \\
\hline 0.864 & 0.566 & 0.905 & 0.825 & 0.612 & 0.365 & 0.118 & 0.920 & 0.770 \\
\hline $0.002 *$ & 0.533 & 0.199 & 0.356 & 0.768 & 0.280 & 0.521 & 0.375 & 0.517 \\
\hline 0.720 & 0.384 & 0.292 & 0.445 & 0.211 & 0.347 & 0.741 & 0.950 & 0.169 \\
\hline 0.443 & $0.100^{*}$ & 0.785 & 0.405 & 0.547 & 0.365 & 0.317 & 0.838 & 0.337 \\
\hline 0.903 & 0.405 & 0.399 & 0.102 & 0.395 & 0.689 & 0.196 & $0.048 *$ & $0.048 *$ \\
\hline
\end{tabular}

*Statistically significant variable

Figure 10. Matrix of Regression Probabilities (2 Tail) of Hypothesis 2, Oregon Primary Care Physician Support for National Health Insurance 


\section{CHAPTER IX DISCUSSION AND CONCLUSIONS}

Two significant health care reform issues were observed during the month this research effort concluded (February 1994). First, the Oregon Health Plan (OHP) became a partly-functional reality (Fox and Leichter 1993) after the first phase of the Medicaid portion of the OHP began to enroll eligible residents (O'Neill 1994). ${ }^{10}$ Second, on the national agenda, the Clinton Health Security Plan, announced in September 1993, was under attack from many special interest groups, including the American Medical Association (Morin 1994; Clinton 1994).

Since February 1, 1994, approximately 10,700 Oregonians have been provided health insurance coverage under the Oregon Health Plan (O'Neill 1994). While the State of Oregon has been able to make some progress toward health care reform, the federal government's attempt toward developing a national health insurance (NHI) plan appears to be fraught with difficulty and resistance (Clinton 1994; The Oregonian 1994). The hypotheses advanced by this dissertation would have predicted these two

10 The employer mandate portion of the Oregon Health Plan is scheduled to be phased in 1997. The second phase of the Medicaid program, specifically Senate Bill 44 (SB 44), is scheduled to implemented on January 1, 1995. Another federal waiver is required to phase in SB 44 , however, as it covers the blind, disabled, aged, and foster children, groups not included in the original federal Medicaid waiver (Julnes 1994). 
scenarios.

As a group, while health care rationing policies appear to be strongly supported by Oregon primary care physicians, national health insurance does not.

Generalizing the results of this dissertation's findings to the state as a whole, over 70 percent of Oregon primary care physicians support health care rationing policies such as the Oregon Health Plan. Alternately, just over 47 percent of the same physicians expressed support for national health insurance (NHI). See Figure 11, below.

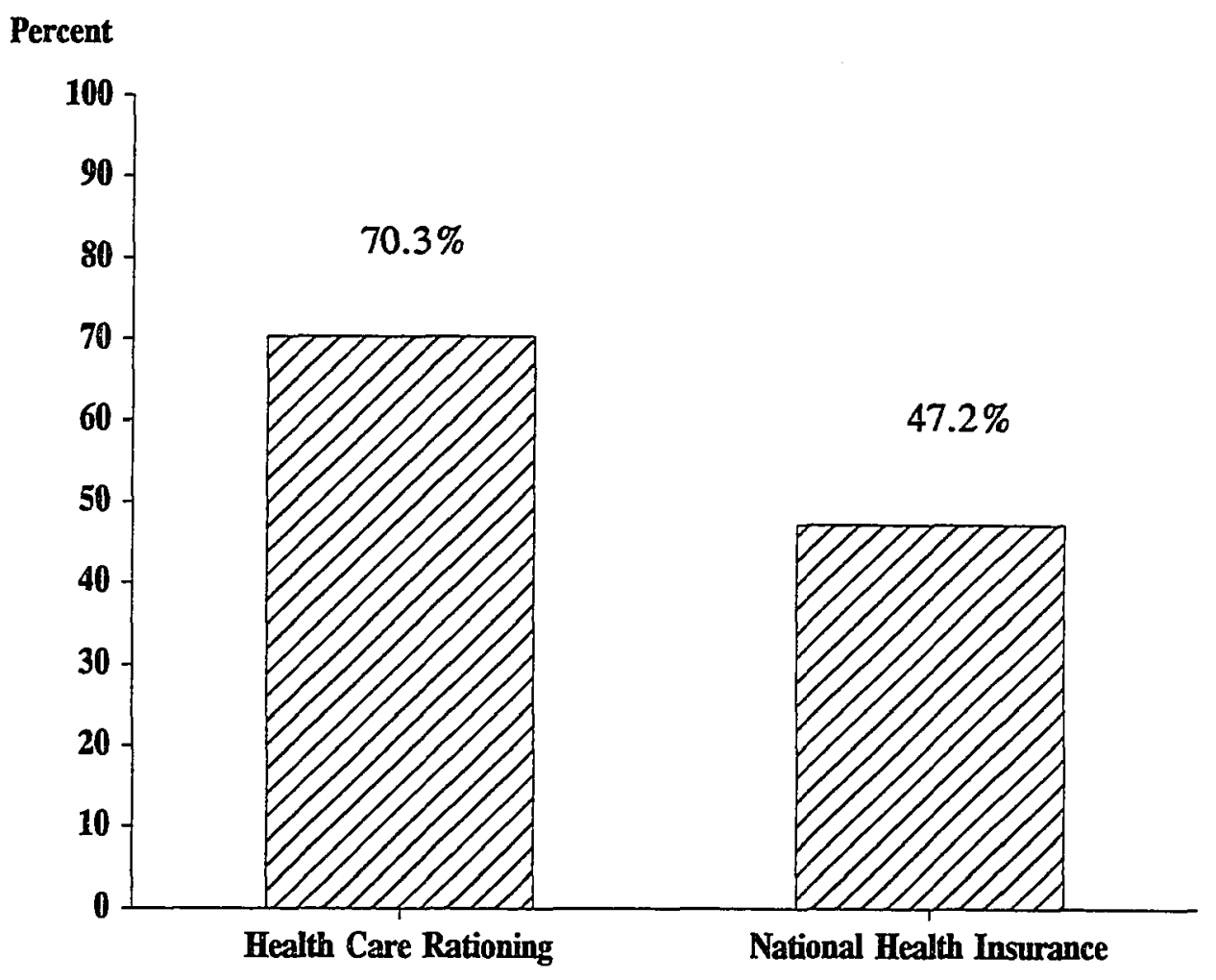

Figure 11. Percentage of Oregon Primary Care Physicians Expressing Support for Health Care Rationing and for National Health Insurance $(p<0.001)$. $N=$ 1128 
The measure of opposition to both types of health care reform is equally revealing. While 13.2 percent of the Oregon primary care physicians studied were non-supportive or unalterably opposed to health care rationing policies, more than a third, 36 percent, were non-supportive or unalterably opposed to NHI. These findings may partially explain why Oregon has been so successful in implementing its seemingly radical approach toward health care reform (despite the local and national criticism of its methodology (Julnes and Mason 1991)), while the Clinton Administration appears to be fighting to keep its own plan on the national agenda (Clinton 1994; Morin 1994; Matthews 1994b).

\section{Hypothesis One: Support for Health Care Rationing}

The first hypothesis advanced by this dissertation was that Oregon primary care physicians will not support health care rationing policies such as the Oregon Health Plan (OHP). This hypothesis was rejected in its null. Mean support measures show Oregon primary care physicians will support such health care rationing policies.

As groups, support for health care rationing policies such as the Oregon Health Plan was strongest among internal medicine physicians and weakest among pediatric physicians. However, all primary care physician specialty groups reported mean support measures that were clearly in the support range on the Lewin Force Field Model (See Figure 12, next page).

Urban primary care physicians tended to be more supportive of health care 
rationing policies than were their rural counterparts. However, both groups have mean support measures well within the support range on the same Force Field Model.

Among all of the various subcategories examined, only obstetricians and gynecologists $(\mathrm{OB} / \mathrm{GYN})$ located in rural areas were found to be opposed to health care rationing types of health care reform. Their mean support measure was clearly in the non-support range on the Force Field model. All other groups of primary care physicians, regardless of the city size of their practice were supportive of health care reform such as the OHP. Physicians who practice in medium sized urban cities were

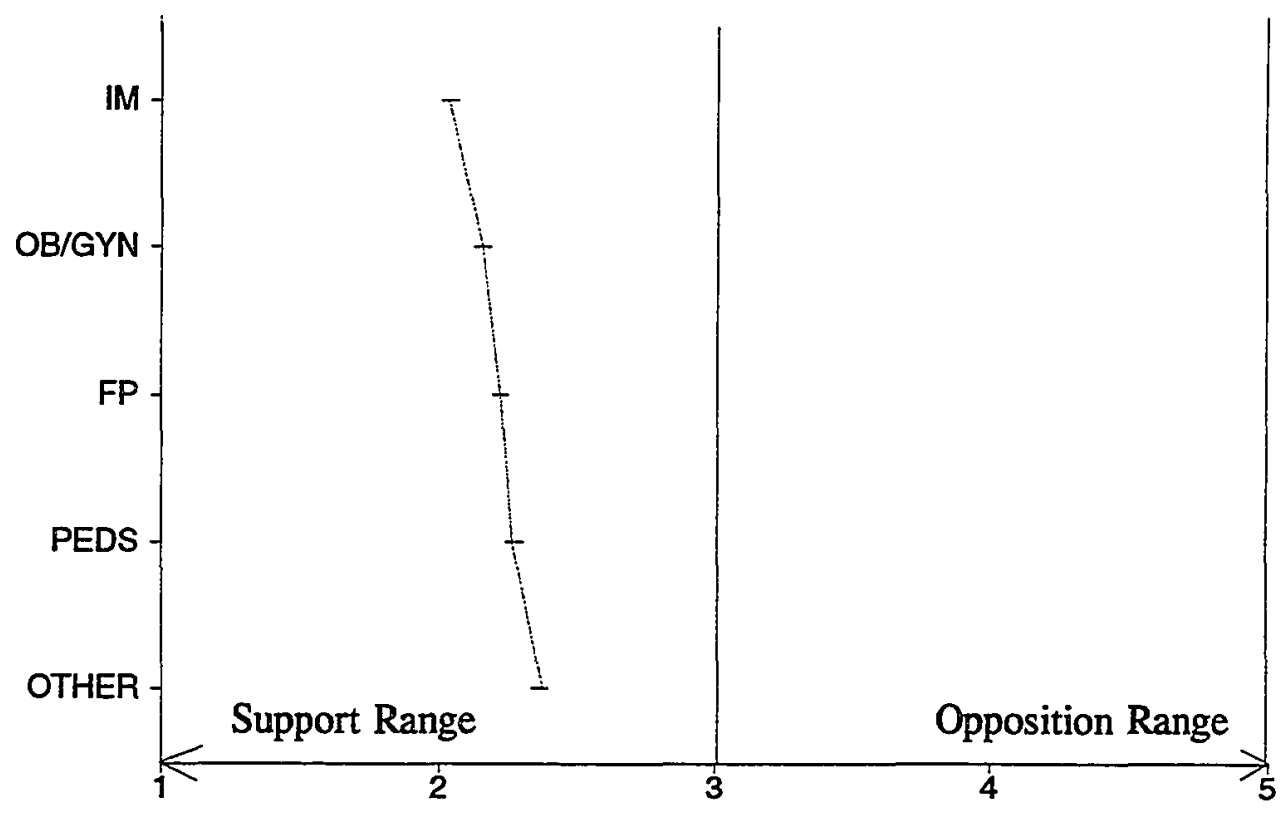

Figure 12. Lewin's Force Field Model of Oregon Primary Care Physicians' Support for Health Care Rationing. 
found to be most supportive of health care rationing policies, as determined by their mean support measure of 2.074. However, internal medicine (IM) physicians in medium sized urban cities had the greatest mean support score of any of primary care physician groups studied. Their mean score was 1.902 , well within the supportive to very supportive range on the Force Field Model.

In category after category, this research found primary care physicians supportive of health care rationing policies. Primary care physicians who practice in solo/partnerships arrangements were found to be equally supportive of health care rationing policies as were their colleagues who practiced in group practices (although group practice physicians reported somewhat more supportive mean scores). While statistically significant differences were found between these two group's mean support scores, both means were still well within the support range.

Allopathic (M.D.) and osteopathic (D.O.) primary care physicians were both supportive of health care rationing policies. None of the primary care specialties within these two types of medical practitioners were found to have mean support that were not within the support range on the Lewin Force Field Model.

Primary care physicians who had a managed care affiliation were supportive of OHP type health care reform, as were their colleagues who did not have such an affiliation. Likewise, physicians who saw uninsured patients were generally as supportive of health care rationing policies as were those primary care physicians who did not see patients who were uninsured. Both groups reported mean support scores within the support range. 
This research found that primary care physicians experience with Medicaid patients did not deter physicians from expressing support for the Oregon Health Plan. Whether the primary care physicians surveyed saw Medicaid patients or not, both groups were supportive of health rationing policies such as the OHP.

The amount of time a physician had been in practice did not seem to effect the physician's support for health care rationing. Physicians who had been in practice more than 20 years were not significantly more supportive of OHP type reform than were their colleagues who had been in practice less than five years. Support was generally the same with physicians who had been in practice 10 years to 20 years, or longer. See Table 76, next page.

\section{Hypothesis One: Explaining Why?}

While it was determined that Oregon primary care physicians would support health care rationing such as that proposed by Oregon Health Plan, few of their practice variables explained why they supported such reform. A physicians' attitude toward support for national health insurance was one of three variables that significantly explained variation in their support for health care rationing. It had the strongest explanatory power of all practice variables examined, as measured by its standardized coefficient.

According to a regression model used in this study, with all other variables held constant, as a group, primary care physicians who expressed non-support for 
TABLE 76

\section{LEWIN'S FORCE FIELD ANALYSIS APPLIED TO CATEGORIES OF OREGON PRIMARY CARE PHYSICIANS' SUPPORT FOR HEALTH CARE RATIONING POLICIES.}

\section{SUPPORT ${ }^{1}$}

\section{for HEALTH CARE RATIONING}

Pediatricians (all)

Internal Medicine Physicians (all)

OB/GYN Physicians (all)

Family Practice (all)

Other (all)

All City Sizes (except Rural OB/GYN)

Solo/Partnership (all)

Group Practice (all)

M.D. Physicians

D.O. Physicians

Managed Care Affiliated (MCA) Physicians

Non-MCA Affiliated Physicians

Physicians with uninsured patients (all)

Physicians without uninsured patients (all)

Physicians with Medicaid patients (all)

Physicians without Medicaid patients (all)

Newly Established Physicians (all)

Established Physicians (all)

\section{${ }^{1}$ OPPOSITION \\ to HEALTH CARE RATIONING}

Rural-OB/GYN Physicians

"All" refers to all primary care specialties in the specific category (OB/GYN, Internal Medicine, pediatricians, family practice, and other general primary care physicians).

1 - Support is a mean score of less than 3 on the Likert Scale; Opposition is a mean score of 3 or above on the same scale (See Figure 3, page 68, and Figure 6, page 117). 
national heaith insurance (a rating of 4 on the Likert Scale) would be predicted to have a health care rationing support score of 2.069 , well within the support range on the Force Field Model. Even physicians who reported unalterable opposition (a rating of 5 on the Likert Scale), would be predicted to have a 2.519 measure of their support for health care rationing. Again, this mean score would still be considered support for health care rationing policies. This finding suggests that physicians will support some form of health care reform, however, not specifically national health insurance (NHI).

Two other variables explained why physicians would support health care rationing. The percentage of a physicians' patients who are seen for maternity care predicted to a higher support for health care rationing score. This finding is most probably explained by the basic principle advanced by the Oregon Health Plan: to reduce costs associated with high-cost treatments and to distribute these costs towards primary care such as prenatal care and well-baby checkups. Physicians who had a high percentage of patients who needed such care, yet who were uninsured, would be expected to support health care reform such as the OHP.

The regression model also showed that physicians who practiced in solo/partnership arrangements were found to be less supportive of the OHP than were their group practice counterparts. This finding may be explained by the requirement that physicians accepting patients under the OHP must belong to a managed care type arrangement. Smaller, solo/partnership type practices tend not to be associated with such arrangements (Eastaugh 1987). 
The regression model suggests that more research is needed to explain the actual reasons behind the physicians' support for the OHP. Little of the actual variation in the primary care physicians' support for rationing could be explained (just under 12 percent) by this research. However, in the final analysis, except for rural $\mathrm{OB} / \mathrm{GYN}$ doctors (a total of 31 in all), one finding is clear: all primary care physician sub-groups - whether medically categorized or socio-economically categorized -- expressed support for health care rationing policies such as the Oregon Health Plan. The same was not true, however, for support for national health insurance (NHI).

\section{Support for National Health Insurance}

The second hypothesis advanced by this work was that Oregon primary care physicians would support national health insurance (NHI). This hypothesis could not be rejected in its stated form. As a group, a minority (47 percent) of Oregon primary care physicians were found to support NHI. However, as measured by their mean support scores for NHI, their support measure was within the support region of the Force Field Model. However, these support measures can not be considered strong support for NHI. See Figure 13, next page.

Mean support measures for NHI found some interesting patterns. While mean support measures among all primary care physicians was within the support range on the Lewin Force Field Model, the score approached the non-support region of the 
model, suggesting lukewarm support to the idea of NHI. Pediatricians and internal medicine physicians were both within the support range with almost identical scores of 2.333 and 2.343 , respectively. However, OB/GYN physicians were clearly within the non-support range with a mean score of 3.260 , with family practice physicians not too far behind at 2.905 .

An interesting division of support was found between primary care physicians who practiced in solo/partnership practices and their colleagues in group practices. The solo/partnership physicians were clearly less supportive of NHI than were the same primary care physicians who practiced in group clinics. Except for pediatricians, who reported mean support scores of 2.677 , internal medicine,

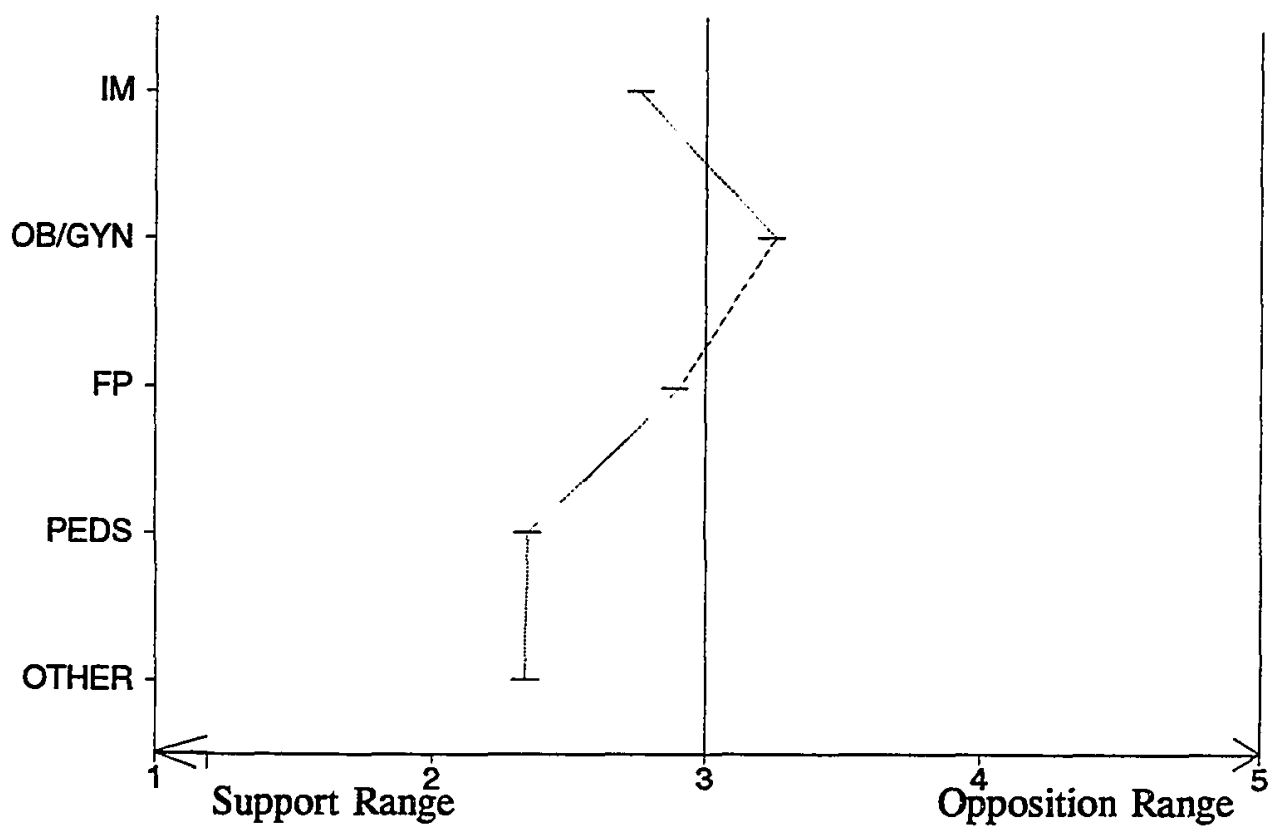

Figure 13. Lewin's Force Field Model of Oregon Primary Care Physicians' Support for National Health Insurance. 
OB/GYN, and family practice physicians who practiced in solo/partnership practices all expressed scores well within the non-support to opposition range. However, among their colleagues who practiced in group practices, only OB/GYN physicians expressed mean scores that would be considered non-supportive. All other primary care specialties had mean support scores within the support range on the Force Field Model. Interestingly, of all the primary care specialties, pediatricians had the highest support scores for NHI, however, they had the lowest support scores for health care rationing policies such as the Oregon Health Plan (although their scores were still within the support range on the Force Field Model).

Support for NHI was also found among both managed care affiliated (MCA) pediatricians and non-MCA pediatricians. Like earlier findings related to health care rationing, OB/GYN physicians from both MCA and non-MCA were not supportive of NHI. Both had scores approaching unalterable opposition to the idea of national health insurance (NHI).

One curious finding was mean support among primary care physicians who have patients with no health insurance. While their mean scores would be considered supportive of NHI, physicians with no uninsured patients actually showed more support than did their counterparts who accepted uninsured patients.

Another interesting and related finding was non-support among $\mathrm{OB} / \mathrm{GYN}$ physicians. Those obstetricians and gynecologists (OB/GYN) who had uninsured patients expressed mean scores considered non-supportive of NHI, while OB/GYN physicians with all of their patients with health insurance coverage expressed support 
scores that are within the support range on the Force Field Model.

This same trend was found among primary care physicians who accept Medicaid patients. Physicians with Medicaid patients had lower support measures than did physicians who did not accept Medicaid patients. Again, OB/GYN physicians in both categories expressed non-support to NHI, while pediatricians, internal medicine physicians, and family practice (FP) doctors with no Medicaid patients all reported scores that would be considered support for NHI. Family Practice (FP) physicians with some Medicaid patients had mean scores approaching the non-support range on the Force Field Model.

The number of years a physician had been in practice did determine whether he or she expressed support for NHI. Primary care physicians in practice less than five years had mean scores considered in the support range on the Force Field Model. However, as the number of years increased that the physician had been in practice, the lower the support score for NHI was found to be. Physicians in practice from 10 to 20 years approached non-support measures on the Force Field Model, while established physicians (in practice longer than 20 years) were clearly opposed to the concept of NHI.

It appears that strong support for $\mathrm{NHI}$ is far from assured. While some patterns of support could be seen from the data (such as with pediatricians and group practice physicians), other primary care physicians displayed resistance to the idea of NHI (primarily OB/GYN and solo/partnership physicians). See Table 77, next page. 


\section{LEWIN'S FORCE FIELD ANALYSIS APPLIED TO CATEGORIES OF OREGON PRIMARY CARE PHYSICIANS' SUPPORT FOR NATIONAL HEALTH INSURANCE}

\section{SUPPORT ${ }^{1}$}

\section{for NATIONAL HEALTH INSURANCE}

Pediatricians

Internal Medicine

Family Practice

Other

Rural Pediatricians

Rural Other Primary Care Physicians

Urban Pediatricians

Urban Internal Medicine Physicians

Urban family Practice

Urban Other Primary Care Physicians

Solo/Partnership Pediatricians

Solo/Partnership Other Physicians

Group Practice Pediatricians

Group Practice Internal Medicine

Group Practice Family Practice

Group Practice Other

M.D. and D.O Pediatricians

M.D. Internal Medicine

M.D. OB/GYN

M.D. Family Practice

M.D. Other

All Managed Care Affiliated Physicians except OB/GYN

Non-MCA Affiliated Physicians except $\mathrm{OB} / \mathrm{GYN}$

All Physicians with uninsured patients, except OB/GYN

Physicians without uninsured patients (ali)

All Physicians with Medicaid patients, except OB/GYN

Newly Established Physicians, except $\mathrm{OB} / \mathrm{GYN}$ and Family Practice
${ }^{1}$ OPPOSITION

to NATIONAL HEALTH INSURANCE

OB/GYN Physicians

Rural Physicians

Rural Internal Medicine

Rural OB/GYN

Rural Family Practice

Urban OB/GYN

Solo/Partnership Internal Medicine Solo/Partnership OB/GYN

Solo/partnership Family Practice

Group Practice OB/GYN

M.D. OB/GYN

D.O. Internal Medicine

D.O. OB/GYN

D.O. Family Practice

D.O. Other

MCA OB/GYN Physicians

Non-MCA OB/GYN Physicians

OB/GYN Physicians with uninsured patients

OB/GYN Physicians with Medicaid Patients

OB/GYN Physicians with No Medicaid Patients

Established OB/GYN Physicians

Established Family Practice Physicians

Newiy Established OB/GYN Physicians

Newly Established Family Practice

\footnotetext{
"All" refers to all primary care specialties in the specific category (OB/GYN, Internal Medicine, pediatricians, family practice, and other general primary care physicians).

1 - Support is a mean score of less than 3 on the Likert Scale; Opposition is a mean score of 3 or above on the same scale (See Figure 3, page 68, and Figure 6, page 117).
} 
Hypothesis Two: Explaining Why?

Just under 21 percent of variation in support for NHI was explained by seven practice variables (see page 181). Similar to the finding in the regression model on support for the OHP, physicians' attitude toward health care rationing policies explained the greatest variation in their support for NHI. However, as the model shows, when controlling for all other variables, a physician who reported an OHP support score of 2 (considered support for the OHP) would be predicted to have a overall lower mean NHI support score of 2.997, clearly approaching non-support for NHI. This shows that physicians in Oregon support the concept of health care rationing more than they do the concept of national health insurance.

Oregon primary care physicians who have a greater percentage of their patients with no health insurance showed more support for NHI. With every 10 percent of their patient mix that is uninsured, the model predicts an increase in support score of 0.16 points. This finding suggests that as more and more patients find themselves uninsured, the greater the support for NHI among the state's primary care physicians will become.

Like earlier findings on health care rationing, rural physicians expressed greater non-support for NHI than did their rural counterparts. However, unlike findings on health care rationing, physicians who had been in practice longer, showed an almost inverse, negative support score for national health insurance. Where no relationship was found between years in practice and support for the OHP, clearly, 
newer physicians are more supportive of NHI than are their more established colleagues.

In all, less than 21 percent of the explanation of a physicians' attitude toward support for national health insurance was found by this dissertation. Clearly, more research is needed to fully explain why some physicians resist the concept national health insurance (NHI) while others do not.

\section{Conclusions and Final Remarks}

Just two weeks before his election as President of the United States, Bill Clinton said:
Americans deserve a health-care plan that will bring costs down, that will get tough with the insurance companies and drug companies, that will cover every American, that will put a much greater emphasis on prevention and research (Clements 1993, 4).

Based upon those words, President Bill Clinton put forth his agenda for health care reform in 1993 (Clements 1993). In September of that year, President Clinton revealed his plan for national health insurance (NHI), the Health Security Plan.

Six months later, Hillary Rodham Clinton $(1994,7)$, First Lady and Chairperson of President Clinton's Task Force on Health Care Reform, writes of the Health Security Act of 1993, that the U.S. " ... stands at a unique moment in history." She believes that "In the coming months [the U.S. has] the opportunity to 
accomplish what our nation has never done before: provide health security to every American -- health care that can never be taken away" (Clinton 1997, 7).

However, John Kitzhaber, M.D., former Oregon Senate President and author of the Oregon Basic Health Services Act, suggests that Oregon may already have a solution to providing health security. In a summary of the Oregon Health Plan, he wrote "The [OHP] represents a comprehensive approach to the problem of health care access in the state of Oregon." He believes that, "... it guarantees universal access to a basic level of health care ... [yet] recognizes the fiscal limits which face Oregon and this nation" (Summary of the Oregon Basic Health Services Act 1989 1989, 3).

John Iglehart (1994), Founding Editor of Health Affairs and Uwe Reinhardt, Professor of Political Economy at Princeton University, believe that America needs only to look to its past failures at health care reform to recognize that the task of reforming the U.S. health care system is a complex undertaking. Inglehart and Reinhardt $(1994,5)$ write that "The challenge is daunting because it must attract broad political support in a nation that has never achieved consensus on an overriding social ethic (universal coverage) to which all other worthwhile goals in health care must take second place." Failure to affect such a change, the authors warn, would serve once again to relegate the U.S. as the "... major outlier among civilized nations, all of which provide their citizens with insurance protection against the unpredictable financial consequences of illness" (Inglehart and Reinhardt 1994, 6). Whether America takes the Clinton Health Security approach toward health care reform or the Oregon Health Plan strategy toward health care rationing, the task 
is indeed a daunting one. Clearly, in Oregon, primary care physicians support the concept of health care rationing. Perhaps, this support is so strong because the OHP represents a less threatening - economically, politically, and organizationally -- form of health care reform. Perhaps it is because John Kitzhaber is a fellow physician. Or perhaps it is because physicians understand that the elimination of certain services would not have a negative effect on the health status of their patients (Califano 1989; Kitzhaber 1991a). We already know that 55 percent of the 90 million emergency room vists in 1992 did not need emergency care (Connell 1994). The Rand Corporation has shown that over half of the coronary bypass surgeries done in this country are probably unnecessary (Califano 1989). Perhaps physicians know more about how they practice medicine and what services could be eliminated than they clearly admit. While more research is needed to find out why physicians actually support health care rationing, it appears clear that the critical mass exists among Oregon primary care doctors to ensure the successful implementation of health care reform that proposes to ration health care.

However, no clear critical mass supporting national health insurance (NHI) exists among the same primary care physicians. The support that does exist appears in pockets of primary care physicians throughout the state. However, one must keep in mind that when this study was undertaken, neither the Health Security Plan nor any other emerging NHI plans were available for the state's physicians to consider when answering the survey questions which generated the data used in this dissertation. Perhaps support is greater in 1994; perhaps not. Nonetheless, one reoccurring trend 
appears clear from this research: no majority support exists in Oregon for NHI among the same physicians who overwhelmingly support health care rationing policies such as the Oregon Health Plan.

This finding poses interesting policy questions regarding the success of any national health reform effort. If state and national policy makers are to make change in a mature and structured organization such as the U.S. health care system, restraining forces to such change cannot be ignored. While national leaders have shied away from health care rationing in their discussion of a universal health insurance strategy, this research suggests that the concept has a better chance of being implemented as a form of universal health insurance than does a NHI plan based upon such schemes as managed care and regional insurance alliances (Inglehart and Reinhardt 1994), as proposed by the Health Security Act.

Hillary Rodham Clinton (1994) urges experts in health policy to stay involved in the national debate and scrutinize the technical details of any health care reform proposed with which to expand access to those U.S. citizens without health insurance. She writes (Clinton 1994, 8), "The American people need the experts' help in understanding the complex and difficult issues that lie behind the design of any comprehensive reform effort." Yet, Blumenthal (1994) cautions that if health care reform is to succeed, it must include support from the nation's health care providers. If explicit health care rationing, developed by a public body in an open public process, would be accepted so strongly by Oregon's primary care physicians, perhaps it should be examined as a model necessary to ensure successful implementation of 
national health care reform. Perhaps the answer to this question was best stated by James Carville, President Bill Clinton's former campaign adviser, when he said "it's the ... doctors, stupid!" (Blumenthal 1994, 253).

\section{Areas for Future Research and Limitations to this Research}

While this research effort has examined an area of physicians' attitudes not previously studied, all research has its limitations, including this one. To guide future researchers and to put this work in perspective, several considerations about this dissertation should be recognized. First, Oregon primary care physicians are unique in that one of their own is considered the father of the Oregon Health Plan. John Kitzhaber, while a member of the Oregon Senate, also is an emergency department physician. Perhaps that is the reason behind the strong support for the Oregon Health Plan found among primary care physicians. More research would be needed to support this hypothesis.

This research examined Oregon primary care physicians' attitudes toward health care reform. No generalizations to specialist physicians should be made. The conclusions of this research can only be applied to the four categories of primary care physicians discussed in this dissertation. Likewise, conclusions reached here apply only to Oregon primary care physicians. Physicians in other states may have entirely different attitudes toward health care rationing policies and NHI. 
The data collection portion of this study was undertaken between January 1991 and June 1991. A lot has happened since that time. As mentioned previously, President Bill Clinton released his Health Security Act in 1993. In early 1994, several other federal models of universal health insurance have emerged (Morin 1994). On February 1, 1994, the first phase of the Oregon Health Plan became a reality. On March 3, 1994, an article appeared in The Oregonian (O'Neill 1994) newspaper reporting that physicians were struggling to put the Oregon Health Plan to work. Attitudes toward the OHP may change now that physicians have experienced the OHP in practice. Perhaps, this study should be replicated in the near future to see how physicians feel about health care rationing policies after they have had first hand experience with explicit health care rationing. Now that they have been able to see the OHP in action and have been able to read about the Clinton Health Security plan in concept, perhaps their attitudes will have changed. More research is needed in these areas, and may provide future areas of research in health care reform.

One last limitation to this research should be noted. Since the author of this dissertation used a secondary data source, including a pre-designed questionnaire, some of the phrasing and coding on the survey instrument were predetermined by the earlier research effort. As in all social science research on human subjects, the wording and phrasing of specific questions have been shown to bias the results of the survey. While it is felt that the results of this study are methodologically sound, the reader of this work should keep these limitations in mind when critically analyzing the results of this research. 


\section{REFERENCES CITED}

American College of Physicians. Access to Health Care, Annals of Internal Medicine, vol.112, no.641, 1990.

Anderson, Oden. "Health Services in the United States: A Review of Major Ideological Influences," chapter in Health Politics and Policy, T. Litman and L. Robins, editors, New York: Delmar Publishers, Inc., 1984, 67.

Associated Press. "Health: Critics point to unsolved problems," The Oregonian, February 6, 1992, A1,11.

Babbie, Earl R. Survey Research Methods, Belmont, California: Wadsworth Publishing Company, Inc., 1973.

Baker, Robert. "The Inevitability of Health Care Rationing: A Case Study of Rationing in the British National Service, "chapter in Rationing America's Medical Care: The Oregon Plan and Beyond, edited by Strosberg, M., Wiener, J, Baker, R., Fein, I., Washington, D.C.: The Brookings Institute, 1992.

Baker, Timothy. "Barriers to Health Care Access: An Analysis of Variables Predicting to Health Insurance Status," The Uninsured: A Research Report, unpublished paper, Portland, Oregon: Oregon Health Sciences University, May 28, 1991.

Baker, Timothy. A Report on the Uninsured in Oregon, Department of Health Sciences, Portland, Oregon: Linfield College Publications, 1994.

Beckhard, Richard and Reuben T. Harris. Organizational Transitions: Managing Complex Change, 2nd.ed., Reading, Massachusetts, 1987, 91.

Blendon, R., Edwards, J. "Caring for the Uninsured: Choices for Reform," Journal of the American Medical Association, Vol. 265:19, 1986, 1160-1163.

Blendon, R., Freeman, H., Kirkman-Liff, B., and Murphy, J. "Uncompensated care by hospitals or public insurance for the poor: does it make a difference?," Journal of the American Medical Association, 265:19, May 15, 1991.

Blumenthal, David. "The Vital Role of Professionalism in Health Care Reform," Health Affairs, Spring (I) 1994.

Borderline Medicine. a public television special, March 1991. 
Brown, Lawrence D., ed. Health Policy In Transition, Duram, North Carolina: Duke University Press, 1987.

Califano, Joseph. America's Health Care Revolution, New York: Simon \& Schuster, 1989.

Califano, Joseph A: "Health-care solution: Reason, don't ration," The Oregonian, May 15, 1991, C1.

Callahan, Daniel. Setting Limits: Medical Goals in an Aging Society, New York: Simon and Schuster, 1987.

Cerne, F. "Rate decreases unlikely despite health insurers health profits," American Hospital Association News, November 5, 1990, 26-28.

Clements, Mark. "The Growing Crisis in Health Care," Parade, February 28, 1993, 4.

Clinton, Hilary. "Meaningful Health Reform: The Time is Now, Health Affairs," Spring (I) 1994.

Coile, Russell C. The New Medicine: Reshaping Medical Practice and Health Care Management, Rockville, Maryland: Aspen Publications, 1990.

Cunningham P., Monheit A. "Insuring the children: a decade of change," Health Affairs, No.9, 1990, 76-90.

Darman, Richard G. U.S. Budget Director, Senate Finance Committee testimony, cited in Wright, John W., ed., The Universal Almanac, Kansas City, Missouri: Andrew and McMeel, 1991.

Davis, K. and D. Rowland. "Uninsured and underinsured: inequalities in health care in the United States, Milbank Quarterly, vol.61, 1983, 160-163.

Davis, K. "Expanding Medicare and Employer Plans to Achieve Universal Health Insurance," Journal of American Medical Associution, Vol. 265:19, May 15, 1991, 2525-2528. 
Davis, Keith and John W. Newstrom. Organizational Behavior: Readings and Exercises, 7th ed., New York: McGraw-Hill Series in Management, 1985.

Deming, W. Edwards. Out Of The Crisis, New York: MIT Press, 1986.

Derzon, Robert A. "Foreword," Introduction to Health Services, Williams and Torrens, eds., New York: John Wiley \& Sons, 1988.

Eastaugh, Steven R. Financing Health Care, Dover, MA: Auburn House Publishing Company, 1987.

Eddy, David M. "Clinical Decision Making: From Theory to Practice - the Individual vs Society: Resolving the Conflict," Journal of American Medical Association, vol.265, no.18, May 8, 1991, p.2399.

Employee Benefit Research Institute. Medical Benefits, November 30, 1989.

Fein, Rashi. Medical Care: Medical Costs, The Search For a Health Insurance Policy, Cambridge, Massachusetts: Harvard University Press, 1989.

Feldstein, Paul J. Health Care Economics, 3rd.ed., New York: John Wiley \& Sons, 1988.

Feldstein, Paul J. Health Care Economics, 4th.ed., New York: John Wiley \& Sons, 1992.

Ferguson, George and Yoshio Takane. Statistical Analysis in Psychology and Education, 6th ed., New York: McGraw-Hill Publishing Company, 1989.

Fox, Daniel M. and Howard M. Leichter. "The Ups and Downs of Oregon's Rationing Plan," Health Affairs, Summer 1993.

Frederick, Larry. "The Buck Stops With These Doctors -- And They Like It," Medical Economics, August 19, 1985.

Freeman, H., Blendon, R., Aiken, L., Sudman, S., Mullinex C., Corey, C. "Americans report on their access to health care," Health Affairs, Spring 1987, 13-14.

Friedman, E. "The Uninsured: From Dilemma to Crisis," The Journal of the American Medical Association," vol. 265:10, May 15, 1991, 2493. 
Friedman, E. "The Uninsured and underinsured: inequities in health care in the United States," Milbank Quarterly, vol.265:19, May 15, 1992.

Gibson, Mark, executive assistant to John Kitzhaber, personal interview with author, Portland, Oregon, September 1992.

Gortner, Harold, Mahler, Julianne, Nicholson, Jeanne. Organization Theory: A Public Perspective, Chicago: Doresy Press, 1987.

Hadley, J., Steinberg, E.P., Feder, J. "Comparison of uninsured and privately insured hospital patients: condition on admission, resource use, and outcome," Journal of the American Medical Association, vol. 265: 1991, 374-379.

Haglund, Keith and Peggy Peck. "MDs ponder Oregon plan," Medical Tribune, May $17,1990$.

Hayward, R., Bernard, A., Freeman, H., Corey, C. "Regular Source of Ambulatory Care and Access to Health Services," American Journal of Public Health, vol. 84:4, April 1991, 434-440.

Health Poll. "Physicians Thought Leaders Assess State of Nation's Health Care," Fall 1989.

Health Policy Forum 1994. "How Will Congress and the States Complete What Clinton Has Started?," conference brochure, Washington, D.C., June 20-21, 1994.

Health Services Commission. State of Oregon database survey of 1,001 Oregonians, conducted by Oregon State University, 1991.

Herman, M. "The poor: Their medical needs and the health services available to them, "Annals of the American Academy of Political and Social Science vol. $339,12-21,1972$.

Higgins, Linda C. "Care-Rationing Hits At Local Level," Medical World News, April 24, 1989.

Hughes, John S. "How Well Has Canada Contained the Costs of Doctoring?," Journal of American Medical Association, vol.265, no. 18, May 8, 1991, 2347.

Iglehart, John K. and Uwe E. Reinhardt. "From the Editor: A Policymakers' Dilemma," Health Affairs, Spring (I) 1994. 
InterStudy. "Installing Medical Outcomes System," medical conference monograph, Minneapolis, Minnesota, March 1990.

Jones, Charles O. An Introduction to the Study of Public Policy, 3rd. ed., Belmont: Duxbury Press, 1984.

Julnes, Theresa, personal conversation with author, Portland, Oregon, March 7 , 1994.

Julnes, Theresa and Thomas Mason. A Preliminary Report on Health Care Rationing in Oregon, Portland: Center for Urban Studies, Portland State University, 1989.

Julnes, Theresa and Timothy Baker. Family Practice: Optimizing the Delivery of Health Care, Portland, Oregon: Osteopathic Physicians and Surgeons of Oregon, 1991.

Kanter, Rosabeth M. The Change Makers, New York: Touchstone Books, 1983.

Karaim, Reed. "Demo contenders offer health plans," The Oregonian, February 6, 1992, A11.

Kertesz, Louise. "Doctors Sue Over Managed Care Program," Business Insurance, December 12, 1988.

Kitzhaber, John. from a transcription of a speech to the California Chapter of the American College of Emergency Physicians, Sacramento, CA, March 21, 1990.

Kitzhaber, John. author of OBHSA, personal conversation with Timothy Baker, Portland, Oregon, January 13, 1991a.

Kitzhaber, John. "The Need for a Clear Public Policy: Health vs Health Care," Oregon Basic Health Services Act: Summary, unpublished working paper, Salem, Oregon: State of Oregon, 1991b.

Kitzhaber, John, Baker, Timothy, and Hanville, Kay. Summary of the Oregon Basic Health Services Act, Portland, Oregon: OHSU Publication, May 1991.

Knudson, Harry, Woodworth, Robert, and Bell, Cecil. Management: an experiential approach, New York: McGraw-Hill Series in Management, 1979, 214.

Kotter, John P. Organizational Dynamics: Diagnosis and Intervention, Reading, MA: Addison-Wesley Publishing Company, 1978. 
Lamm, Richard C., cited in Hamilton, Joan, "High-Tech Health Care: Who Will Pay?,"Business Week, February 6, 1989.

Landsberg, Mitchell. "Nearly all state legisiatures to face budget shortages in 1990," The Oregonian, January 17, 1990.

Lindberg, G. "National Health Care Reform: An Aura of Inevitability is Upon Us," Journal of American Medical Association, 256:19, May 15, 1991, 2566-2567.

Litman, T. and Robins, L. Health Politics and Policy, New York: Delmar Publishers, Inc, 1984.

Longest, B. Management Practices for the Health Professionals, 3rd. ed., Reston, VA: Reston Publishing Company, 1984, 3.

MacKenzie, Bill. "Roberts maps health-care plan financing," The Oregonian, June 16, 1993, 1.

Matthews, Christopher. "Voters back away from 'unfair' plan," The Sunday Oregonian, March 6, 1994, E14.

Morgan, John. lecturer in social policy, University of Birmingham, England, personal interview with Timothy Baker, Portland, Oregon: Oregon Health Sciences University, 1990.

Morin, Richard. "Is there a health care crisis? Polls say yes -- and no, "The Oregonian, March 2, 1994, B7.

"Not enough for all: Oregon experiments with rationing health care," Newsweek, May $14,1990,53$.

O'Connell, Christopher. "Hospital visits often not urgent," The Oregonian, March 3, 1994, A13.

O'Neill, Patrick. "Medical costs soar in Portland," The Oregonian, November 10, 1992, C1.

O'Neill, Patrick. "Physicians struggle to put Oregon Health Plan to work, "The Oregonian, March 3, 1994, E4.

Oregon Basic Health Services Act 1989. Salem: Office of the Senate President, 1989. 
Oregon Health Services Commission. database survey of 1,001 Oregonians, conducted by Oregon State University, 1991.

The Oregonian. "Officials aim to defeat other plan," February 2, 1994, A11.

Page, Leigh. "New York's Universal Health Plan Faces Uphill Battle With Physicians, "American Medical News, September 22-29, 1989.

Pfeffer, Jeffrey. Power in Organizations, Marshfield, MA: Putman Publishers, 1981.

Relman, A.S. The New England Journal of Medicine, January 12, 1989, vi.

Robins, William. Medical Care Can Be Hazardous to your Healih, New York: Basic Books, 1982.

Robert W. Johnson Foundation. "Access To Health Care In the United States: Results of a 1986 Survey," Special Report Number 2, May 1987.

Raffel, R. and Raffel, M., The U.S. Health Care System, 3rd. ed., New York: Dalmar Publications, 1994.

Scholtes, Peter R. The Team Handbook, Wadison, WI: Joiner Associates, Inc., 1991.

Sharp, Ansel, Register, Charles, and Leftwich, Richard. "Health Issues: Is it Worth What It Costs," chapter 10 in Economics of Social Issues, 9th ed., Boston, MA: Irwin Publishers, 1990.

Short, Paul. Estimates of the Uninsured Population, Calendar Year 1987, Rockville, MD: Public Health Service, U.S. Department of Health and Human Services publication PHS 90-3469, National Medical Expenditure Survey Data Summary, May 2, 1990.

Singh, Susheela. Prenatal Care in The United States: A State and County Inventory, New York: The Alan Guttmacher Institute, November 1989.

Sipes-Mitzler, Page. Executive director of Health Services Commission, State of Oregon, personal conversation with author, Portland, Oregon, February 24, 1992.

Sipes-Mitzler, Page. Executive director of Health Services Commission, State of Oregon, personal conversation with author, Portland, Oregon, December 14, 1993. 
Starr, Paul. The Social Transformation of American Medicine, New York: Basic Books, 1982.

State of Oregon. Senate Bill 27, F-Engrossed, June 13, 1989.

State of Oregon. Senate Bill 534, B-Engrossed, June 21, 1989.

State of Oregon. Senate Bill 935, C-Engrossed, May 31, 1989.

Stokey, Edith and Richard Zeckhauser. A Primer for Policy Analysis, New York: W.W. Norton, 1978.

Strosberg, M., Wiener, J, Baker, R., Fein, I. Rationing America's Medical Care: The Oregon Plan and Beyond, Washington, D.C.: The Brookings Institute, 1992.

Summary of the Oregon Basic Health Services Act 1989, Salem: State of Oregon, 1991.

Taylor, Shelly E. Health Psychology, New York: Random House, 1986.

The New England Journal of Medicine, editorial by Arnold S. Relman, editor, cited in The Washington Post, January 12, 1989.

Triola, M. Elementry Statistics, 5th ed., Reading, MA: Addison-Wesley Publishing Company, 19923.

Trevifo, F., Moyer, M., Valdez, S., Stroup-Benham, C. "Health insurance coverage and utilizations of health services by Mexican Americans, mainland Puerto Ricans, and Cuban Americans, "Journal of the American Medical Association, vol. $265,1991,233-237$.

U.S. Department of Health and Human Services, National Center for Health Statistics, Health United States, 1990/91.

Walden D., Wilensky G., Kasper J. Changes in Health Insurance Status: Full Year and Part Year Coverage: Date Preview 21, Rockville, MD: National Center for Health Services Research, Department of Health and Human Services Publication PHS 85-3377, 1985.

Wilkinson, Leland. SYSTAT: The System for Statistics, Evanston, IL: SYSTAT, Inc., 1990. 
Williams and Torrens. Introduction to Health Services, 3rd.ed., New York: John Wiley \& Sons, 1988.

Williams and Torrens. Introduction to Health Services, 4th. ed., New York: John Wiley \& Sons, 1993.

Witkin, Gordon, Friedman, Dorian, and Guttman, Monika. "Health Care Fraud," U.S. News and World Report, February 24, 1992.

Wright, John W., ed. The Universal Almanac 1991, Kansas City, Missouri: Andrew and McMeel, 1990.

Wright, John W., ed. The Universal Almanac 1992, Kansas City, Missouri: Andrew and McMeel, 1991.

Wright, John W., ed. The Universal Almanac 1993, Kansas City, Missouri: Andrew and McMeel, 1992.

Wright, John W., ed. The Universal Almanac 1994, Kansas City, Missouri: Andrew and McMeel, 1993.

Zaldivar, R.A. "Study links lack of health insurance to early death," The Oregonian, August 12, 1993a, A10.

Zaldivar, R.A. "Finally, the nitty-gritty on health care," The Oregonian, September 22, 1993 b.

Zaldivar, R.A. "Debate clouds full health care story," The Oregonian, February 2, 1994, A11. 
APPENDIX A 
Theresa Julnes, Ph.D. Assistant Professor, PSU

Dear Primary Care Physician:

I am conducting a study on primary care providers in Oregon. This brief questionnaire will provide some data on the cost of health care delivery by primary care physicians. The results will only be reported in aggregate form. Therefore, individual responses will be kept confidential. Only the researcher will see these responses. I have numbered the questionnaires to keep track of each one as it is returned. This will help me work toward a full participation rate. Thank you for your help.

First, some general questions about your practice.

1. How would you describe your practice?

Solo or Partnership

Group Practice (HMO)

- Specialty Clinic (other than just primary care)

Primary Care Clinic

Private Hospital Appointment

- Public Hospital Appointment

Not currently practicing

2. If your practice is not group practice HMO, do you participate in a PPO, IPA, or a free-standing $\mathrm{HMO}$ ?

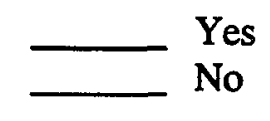

3. What type of area would you describe your practice is located in?

Urban - Large City (Over 200,000)

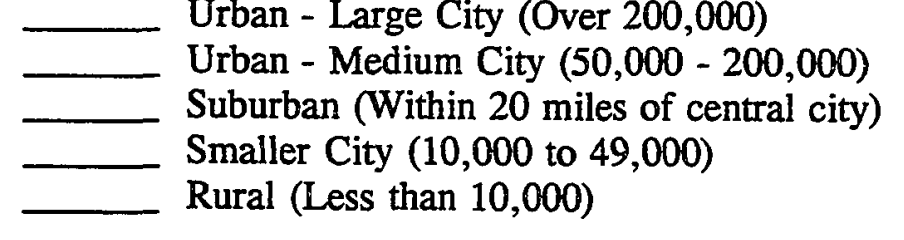

4. How many year have you been practicing?

Less than 5 years

5 years or more but less than 10 years

10 years to 20 years

More than 20 years 
5. What area of primary care do you practice in? (Check only one)

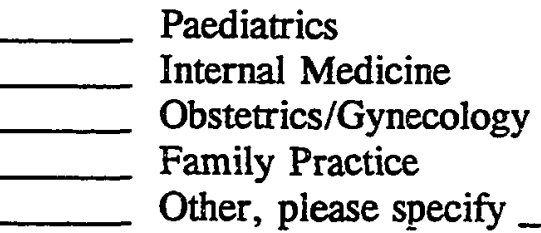

6. Do you hold a:

$$
\begin{aligned}
& \text { M.D. } \\
& \text { D.O. }
\end{aligned}
$$

Next, a question regarding your fees.

7. How much do you charge per visit?

Initial Office Visit:

90000 (Brief)

90010 (Limited)

90015 (Intermediate)

90017 (Extended)

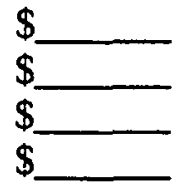

Established Visits:

90030 (Minimal)

90040 (Brief)

90050 (Limited)

90060 (Intermediate)

90070 (Extended)

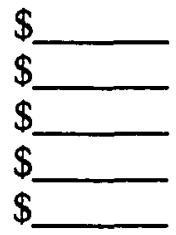

8. In your best estimate, what percent of your patients are covered by:

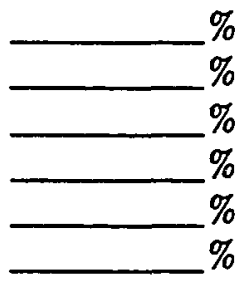

Medicaid

Medicare

Private Insurance - Fee-for-service

Private Insurance - HMO

Private Insurance - PPO

No Insurance 
Next, some questions about your referrals.

9. How often would you say you refer to other specialists? (For a specific need, not because you are not taking new patients).

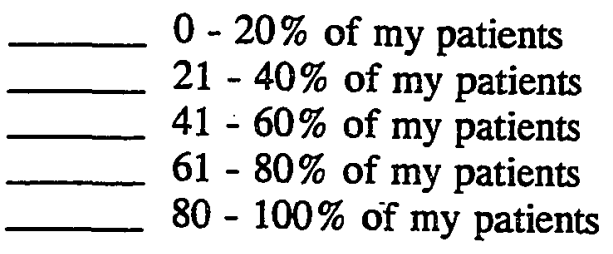
10. Of your referrals, what percent could reasonably be taken by a Family
Practitioner?

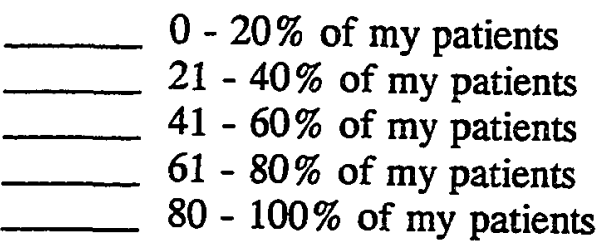

11. Of your practice, what percent could be attributed to:

Specialty

Family Practice

12. Of your patient encounters per week, how many were seen:

In the Office
In the Hospital

13. What percent of your patients were seen for:

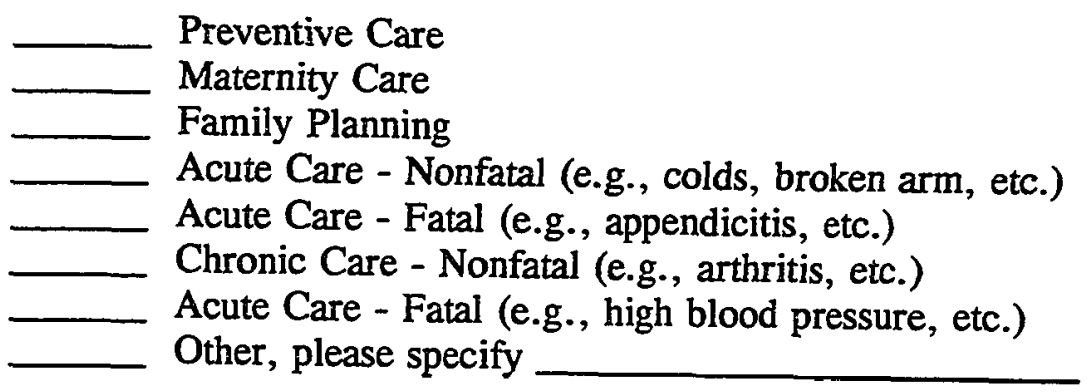


14. What percent of specialists in your community practice:

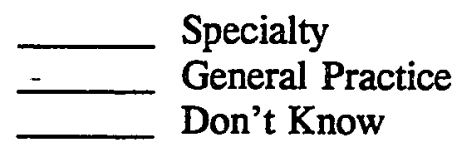

And finally, three questions regarding resource changes.

15. Please rate the following based on need for your community? Rate on a scale of 1 to 5 (with 1 - least important and 5 most important)

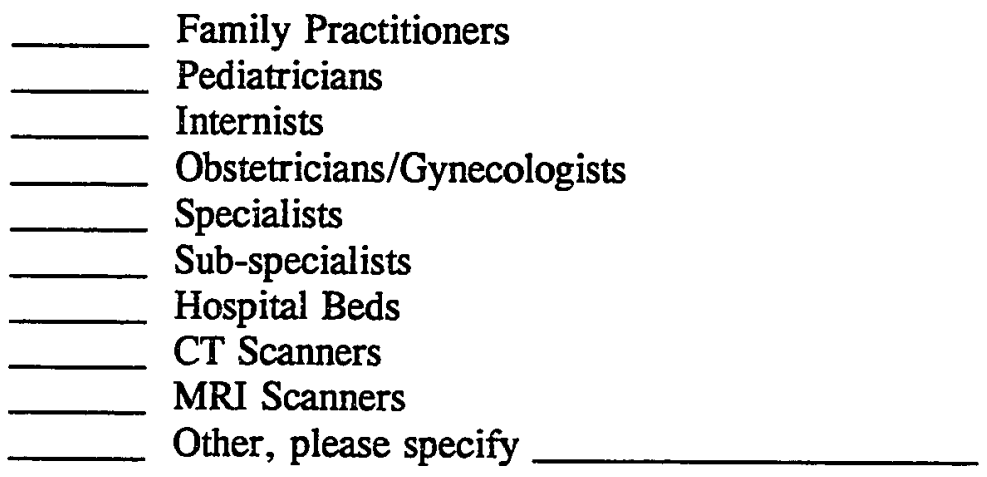

16. How do you think state dollars should be best spent by: Please rate on a scale of 1 to 5 (with 1 - least important and 5 - most important)

Upgrading Primary Care Training

Upgrading Specialist Training

Reducing the cost of Medical Education

Upgrading Hospital Beds

Other, please specify

17a. How supportive are you of: National Health Insurance?

Very supportive
Supportive
Neutral
Not supportive
Unalterably opposed 
17b. How supportive are you of: Health care rationing (such as that proposed by the Oregon Basic Health Services Act)?

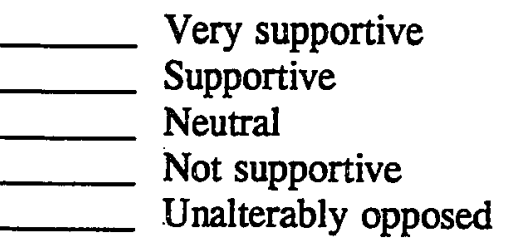

Thanks again for your time and consideration.

Please check here if you would like a copy of the report. 
APPENDIX B 
Timothy A. Baker

12008 N. Jantzen Beach Ave. Portland, Oregon 97217

Work: (206) 737-1888 Home: (503) 735-0371

\section{EDUCATION}

Ph.D. in Public Administration \& Policy, School of Urban and Public Affairs, Portland State University, Portiand, Oregon, June 1994.

M.P.A. in Health Administration, School of Urban and Public Affairs, Portland State University, Oregon, 1989.

B.S. (cum Laude) in Management, Linfield College, McMinnville, Oregon, May 1987.

Educational Honors: Phi Theta Kappa, International Honor Fraternity

Award for Professional Growth and Development, School of

Urban and Public Affairs, Portland State University, 1989 and 1990

Doctoral Representative to PAP Faculty Committee, 1990

\section{EMPLOYMENT}

Administrator, Southwest Washington Regional EMS \& Trauma Care System, Clark, Cowlitz, Klickitat, Skamania, Wahkiakum, \& Pacific Counties, Vancouver, Washington $10 / 90$ to present

Director, Health Sciences Program, Linfield College, Portland Campus Portland, Oregon $9 / 92$ to present

Senior Researcher, Oregon Health Sciences University, John Kitzhaber Grant - School of Medicine, Portland, Oregon 9/89 to 2/91

Deputy Director, International Airport Medical Services, Presidency of Aviation, Ministry of Health, Riyadh, Saudi Arabia 2/83 to 8/87

General Manager/Advertising Director, Pennington's Inc., Coos Bay, Oregon $12 / 76$ to $2 / 83$

Sales Representative, KCBY-TV, Inc., Coos Bay, Oregon $6 / 75$ to $12 / 76$

\section{ADJUNCT EMPLOYMENT \& INTERNSHIPS}

Consultant and Principal, InterMed - Research, Planning, and Consulting, Portland, Oregon. Clients include: Mid-Columbia Medical Center, The Dalles, Oregon, Al Maha Medical, Riyadh, Saudi Arabia, Department of Health, State of Washington; Linfield College, Division of Continuing Education; School of Nursing, Portland Campus. 9/1987 to Present

Adjunct Faculty, Economics and Business, Linfield College, McMinnville, Oregon 3/92 to present; teach courses in management, statistics, and health policy. Research Assistant, School of Urban and Public Affairs, Portland State University, 9/1991 to 6/1993. 


\section{ADJUNCT EMPLOYMENT \& INTERNSHIPS, Continued}

Administrative Intern - Kaiser Sunnyside Hospital, Portland, Oregon $5 / 1989$ to $9 / 1989$

Consultant, Royal Thai Ministry of Interior, Cholburi, Thailand 1986

\section{MEMBERSHIPS, HONORS}

Award for Community and Government Leadership, Washington Traffic Safety Commission, 1994

Administrator of the Year 1993 - State of Washington, Department of Health, EMS \& Trauma.

Listed in Who's Who in the World, Marquise Publications, 1993-94 edition

Listed in Who's Who in the West, Marquise Publications, 1992-93 edition

Listed in Who's Who in Science and Engineering, Marquise Publications, 1994-95 edition

Award for Professional Growth and Development, Portland State University, 1989/90

Award for Medical Excellence, Ministry of Health - Arabian Bechtel Hospital, Riyadh, Saudi Arabia, 1984

Award of Appreciation, Oregon Kidney Association, 1980

Public Service Award, American Radio \& Relay League, 1969

Associate Member - American Society of Healthcare Executives

Member - American Society of Public Administration

Member - American Public Health Association

Member - American Society for Quality Control

\section{SELECTED RESEARCH EFFORTS \& PUBLICATIONS}

Baker, T.A., and Julnes, T.E., Emergency Department Process Flow Study: Mid-Columbia Medical Center, Portland, OR: International Medical, November 1993.

Julnes, T.E. and Baker, T.A., "Family Practice and Internal Medicine Office Fees: An Analysis of Charge Differentials," Journal of Family Practice, July 1993.

Julnes, T.E., Baker, T.A., Family Practice: Optimizing the Delivery of Health Care, T.E. Julnes and T.A. Baker, Osteopathic Physicians \& Surgeons of Oregon, September 1991.

Baker, T.A., "Diagnosing and Curing Organizational IBS - Idiopathic Bureaucratic Syndrome, STAT, Portland, Oregon, July 1990.

Baker, T.A., Preliminary Trauma System Development Plan - Southwest Region, an InterMed Publication, June 30, 1991. 
Baker, T.A., Southwest Region Trauma System Development Plan, InterMed Publication, Portland, Oregon, 1992.

Baker, T.A., Southwest Region EMS \& Trauma System Development Plan, 3rd. ed., InterMed Publication, Portland, Oregon, 1993.

Julnes, T.E., Baker, T.A., "Prioritizing Health Care: Toward a Global Model of Health Care Financing," accepted for publication by the Journal of International Public Administration, $12 / 91$.

Kitzhaber, J., Baker, T., Fisher, E., Small Area Analysis of Oregon Hospital SMAs, J. Portland: Oregon Health Sciences University, February 1990.

Kitzhaber, J., Baker, T., Hanville, K., Medical Effectiveness in Health Care: Final Report, Meyer Memorial Trust, Portland, Oregon, February 1991.

Kitzhaber, J., Baker, T., Hanville, K., "Summary of Oregon Basic Health Services Act," Salem, Oregon: State of Oregon Publication, May 1991.

Baker, T., Variables Effecting Agency Nurse Usage at Kaiser Sunnyside Hospital, KaiserPortland State University Study, August 1989.

Baker, T. and Keliikoa, C. Emergency Medical Services Development Plan, Royal Thai Ministry of Interior, Cholburi, Thailand, 1986

Keliikoa, K., and Baker, T., Emergency Disaster Plan: King Khaled International Airport: Riyadh Saudi Arabia, 1985.

\section{SELECTED INVITED SPEAKING ENGAGEMENT; WORKSHOPS}

Guest Lecturer on Health Care in Developing Countries, Comparative Health Care Systems Class, Linfield College, Portland Campus, 1994.

Facilitator, Quality Improvement Planning Workshop, Frontier EMS System, The Dalles, Oregon, March 1994.

Guest Lecturer in Health Planning, School of Urban and Public Affairs, Portland State University, March 1994.

Presentation on EMS \& Trauma Systems Development, Governor's Steering Committee of EMS and Trauma, September 1993.

Strategic Planning Workshop Facilitator, Linfield College, Portland Campus, June 1993. 
Guest Lecturer in Health Planning, School of Urban and Public Affairs, Portland State University, May 1993.

Keynote Speaker, "Professionalism and the Paramedic: Where do you go from inere," Paramedic Training Program, Emanuel Hospital, Portland, Oregon, May 1993.

Guest Lecturer on Health Care Reform, School of Optometry, Pacific University, May 1993.

Guest Lecturer on the Oregon Health Plan, School of Nursing, Portland Campus, Linfield College, March 1993.

Guest Lecturer on the Oregon Health Plan, School of Medicine, Oregon Health Sciences University, Portland, Oregon, February 1993.

Guest Lecturer on Health Planning, School of Urban and Public Affairs, Portland State University, May 1992.

Guest Lecturer in Canadian Health Care System, School of Urban and Public Affairs, Portland State University, March 1992.

Lecturer, "The Demise of the Oregon Health Plan: Rationing or Irrational Public Policy," Faculty Lecture Series, Linfield College, Portland, Oregon, November 1992.

\section{ACADEMIC COMMITTEE MEMBERSHIP \& PUBLIC SERVICE}

Chair, Health Sciences Program Committee, Linfield College, Portland, Oregon 1993 to present

Member, Regional Advisory Committee on EMS \& Trauma, Washington Department of Health, 1990 to present

Member, Clark County EMS Training Subcommittee, 1991 to present

Task Force Member, Governors Steering Committee on Health Care reform, Washington Presidential Inauguration Committee, Linfield College, Portland Campus, 1992

Member, Campus Image Committee, Linfield College, Portland Campus, 1993 to present

Member, Division of Continuing Education, Program Evaluation Committee, Linfield College, McMinnville, OR

Member, Strategic Planning Subcommittee, Division of Continuing Education, Linfield College, Portland, OR.

Member, Trans-Cultural Nursing Task Force, School of Nursing, Linfield College, Portland, OR.

Board of Directors, Coos County Kiwanis Club, Coos Bay, Oregon. 